\title{
DEVELOPMENT OF AN ACTIVELY COMPLIANT \\ UNDERWATER MANIPULATOR
}

by

DAVID MARK DIPIETRO

B.S. Mechanical Engineering

Massachusetts Institute of Technology

(1986)

\author{
Submitted to the \\ Massachusetts Institute of Technology/ \\ Woods Hole Oceanographic Institution \\ Joint Program in Oceanography and Oceanographic Engineering \\ in Partial Fulfillment of the Requirements \\ of the Degree of \\ Master of Science \\ at the \\ Massachusetts Institute of Technology \\ and the \\ Woods Hole Oceanographic Institution
}

May 1988

- Massachusetts Institute of Technology and

Woods Hole Oceanographic Institution, 1988

Signature of Author

Joint Program in Oceanography and Oceanographic Engineering

Massachusetts Institute of Technology/

Woods Hole Oceanographic Institution

Certified by

Dr. Dana R. Yoerger

Associate Scientist, W.H.O.I.

Accepted by

Professor $w$. Kendall Melville, Chairman

Joint Committee for Oceanographic Engineering 
DEVELOPMENT OF AN ACTIVELY COMPLIANT

UNDERWATER MANIPULATOR

by

David Mark DiPietro

Submitted to the

Massachusetts Institute of Technology/

Woods Hole Oceanographic Institution

Joint Program in Oceanography and Oceanographic Engineering

on May 17,1988 in partial fulfillment

of the requirements of the Degree of

Master of Science

\section{ABSTRACT}

This thesis describes the design, construction, and evaluation of an actively compliant underwater manipulator for installation on the underwater remotely operated vehicle (ROV) JASON. The goal of this work has been to produce a high fidelity force-controllable manipulator exhibiting no backlash, low stiction/friction, high backdriveability, wide dynamic range, and possessing a large work envelope. By reducing the inherent dynamic nonlinearities, a wide range of joint compliances can realistically be achieved. This feature is important when implementing various force control schemes, particularly impedance control:. In addition, a mechanically "clean" transmission reduces the need for sensors and allows the user to rely on integral motor sensors to provide torque, position, and velocity information.

A three axis manipulator rated to full ocean depth was built. Each of the revolute joints is driven by a DC brushless sensorimotor working through a multi-stage cable/pulley transmission. The manipulator mechanism and wiring is fully enclosed by cast aluminum housings filled with mineral oil. Mineral oil functions to pressure compensate and lubricate the system. Exterior surfaces of the manipulator are smooth and continuous, and were designed to act as work surfaces. Joints one and two have a $240^{\circ}$ range of motion, while joint three can rotate $380^{\circ}$. The manipulator transmissions are modeled and predictions of manipulator stiffness, dynamic range, payload capacity, and hysteresis are compared with the results of tests conducted on the actual system. Operation of the cable/pulley transmissions are evaluated and suggestions for improvements are given.

Thesis Supervisor: Dr. Dana R. Yoerger

Title: Associate Scientist

Woods Hole Oceanographic Institution 

ACKNOWLEDGEMENTS

A very large number of people contributed to the success of this project, and made this the tremendous learning experience it has been for me. Although it may seem absurd to list so many people in a thesis, I cannot overstate my thanks for their assistance. Those who have had a large impact on the design and construction of the manipulator are listed here alphabetically, with the exception of the first four:

- Mom and Dad: This work is dedicated to my parents, who have made such a tremendous investment in my future. My graduations from MIT has in large part been due to their always supportive and motivating attitude--many thanks!

- Dr. Dana Yoerger: Allowed me to pursue this project, and gave me the flexibility and the responsibility to make it work. His door was always open and his attitude was always positive!

- Dr. Ken Salisbury: The man responsible for many of the conceptual ideas of this project. Like Dana, he was always there when I needed help or encouragement.

Few students have the opportunity to work for advisors as understanding as Dana and Ken--I am certainly appreciative of having had the opportunity!

- Mary Athanis: Helped me get in to the Joint Program, and made sure I had a fellowship!

- Dr. Robert Ballard: Provided the money, the place, and the energy!

- Richard Barabe: Dick introduced me to welding and showed me the subtle difference between a drawing and a weldment.

- Andy Bowen: Andy made JASON a reality. His design ability and vast knowledge of materials and methods helped me in ways to numerous to count.

- Martin Bowen: As pilot and technician of JASON, Martin was instrumental in influencing the size and layout of the manipulator, and answered a tremendous number of questions pertaining to the assembly of the manipulator.

- Charlie Corwin: Lended a big hand with the drawings just when I thought I was never going to finish them. 
- Carol Crosby: She was a terrific friend throughout the endeavor, and did much of the proof-reading of this document.

- Dave Delonga: Dave assisted in making several important control issues clearer to me, and was generally available for fielding difficult analytical queries.

- Larry Flick: Thanks go to Larry for making sure the money kept coming.

- Ralph Horber: Ralph, on behalf of Seiberco, did a tremendous job providing us with extremely high performance sensorimotors. He was always quick to respond to our requests, and invariably delivered what he promised.

- Anita Lavoie: Did the rest of the proof-reading and helped get this document in on time.

- Roger Maloof: An endless source of clever ideas and observations, Roger's design talent contributed a great deal to the project as well as my educational experience.

- Jim Newman: Thanks for getting the interface software together. Without him, my life would have been a complete nightmare!

- Ben Paul: To the best of my knowledge, Ben is the one who came up with the idea of cable/pulley reducers and transmissions as executed in this design.

- Charlie Peters: The fact that this project was ever completed is in large part due to Charlie's craftsmanship, ingenuity, patience, and persistence. Charlie did most of the machining, and assisted with the design. On a number of occasions he pulled me out of some tight spots!

- Pocasset Machine Corporation: Being the only CNC equipped shop in the area, I am very thankful that they were willing to take on the job of machining the pulleys.

- Hagen Schempt: Hagen went out of his way to give me assistance whenever he could, without expecting anything in return. His lucid explanations of control theory were particularly enlightening. He was also the first one to make the arm work under computer control.

- Bruce Schena: Long time friend, and consultant on this design. Had it not been for Bruce, getting through graduate school would have been much more difficult. 
- Tyler Shilling: Tyler, of Shilling Development, provided a great deal of advice during the early stages of development, and made available information pertaining to his own manipulator programs.

- Bill Townsend: Bill was the designer of the prototype one-link manipulator on which much of this design was predicated. The groundwork he laid made it possible for this project to advance rapidly. Bill's hard work and innovative solutions to problems were inspiring.

- Martin Woodward: "Woody", as he is known, has the well deserved reputation for being an extremely helpful machinist. Even though he never worked directly on the job, he was always willing to lend advice and encouragement, and was instrumental in the early design decisions.

- Chris von Alt: I never had any doubt that Chris, our chief engineer was behind me all the way. He was in large part responsible for helping me secure the funding necessary to actually build the manipulator.

Special thanks also go to Gretchen McManamin for making DSL a much brighter place to work!

In closing, I would like to thank God for being with me always and for giving me the strength to finish this project. 
TABLE OF CONTENTS

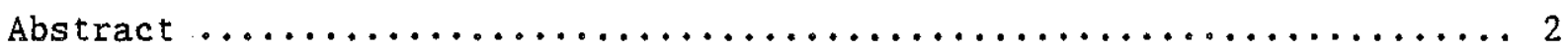

Acknowledgements $\ldots \ldots \ldots \ldots \ldots \ldots \ldots \ldots \ldots \ldots \ldots \ldots \ldots \ldots \ldots \ldots \ldots$

List of Figures $\ldots \ldots \ldots \ldots \ldots \ldots \ldots \ldots \ldots \ldots \ldots \ldots \ldots \ldots \ldots \ldots \ldots \ldots$

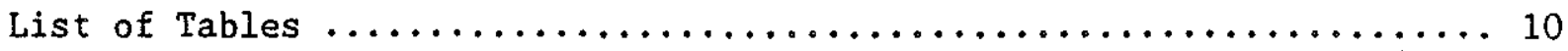

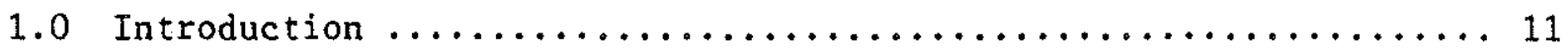

2.0 Requirements $\ldots \ldots \ldots \ldots \ldots \ldots \ldots \ldots \ldots \ldots \ldots \ldots \ldots \ldots \ldots \ldots \ldots \ldots$

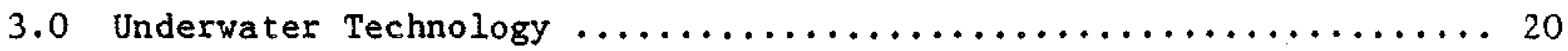

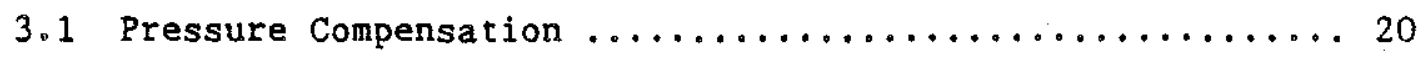

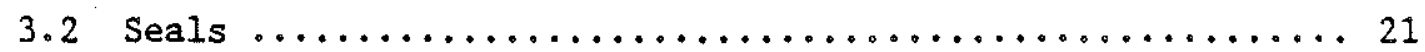

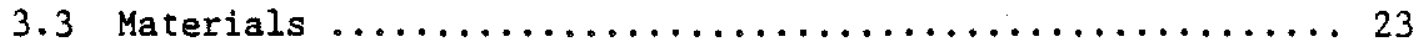

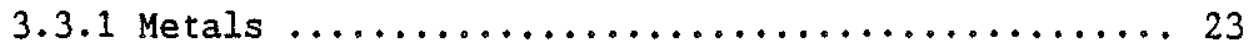

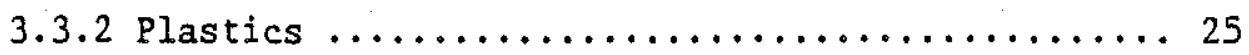

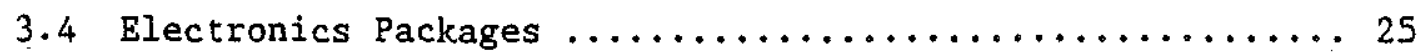

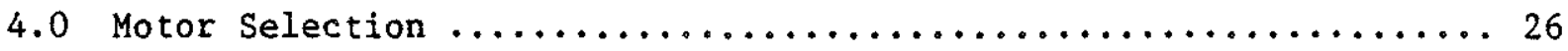

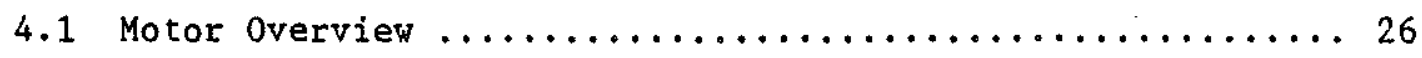

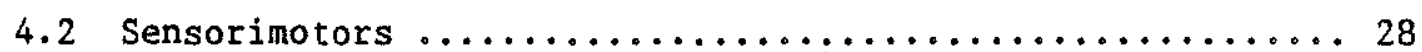

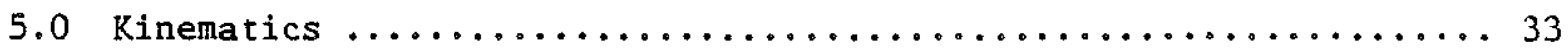

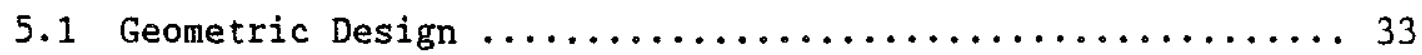

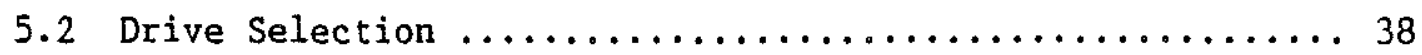

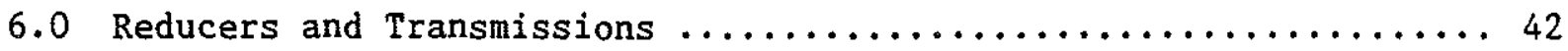

6.1 General Reduction and Transmission Issues .......... 42

6.2 Cable/Pulley Mechanisms ..................... 43

6.2 .1 Cable Circuit Pretensioning ............ 43

6.2 .2 Torque Ripple $\ldots \ldots \ldots \ldots \ldots \ldots \ldots \ldots \ldots \ldots, \ldots \ldots$

6.2 .3 Stiffness $\ldots \ldots \ldots \ldots \ldots \ldots \ldots \ldots \ldots \ldots \ldots \ldots \ldots \ldots$

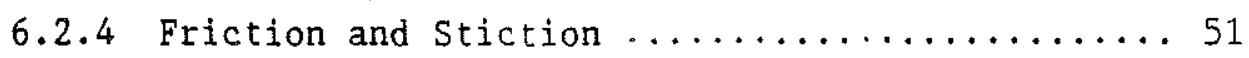

6.2 .5 Cable Properties ................... 51

6.3 Reducers .............................. 54 


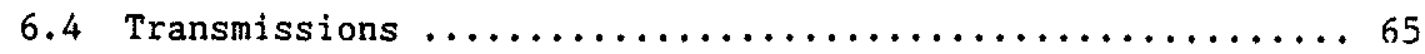

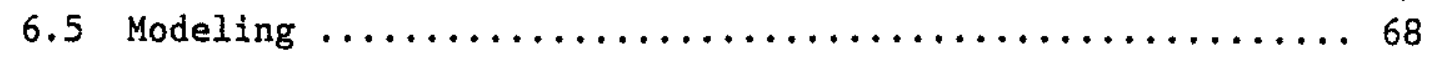

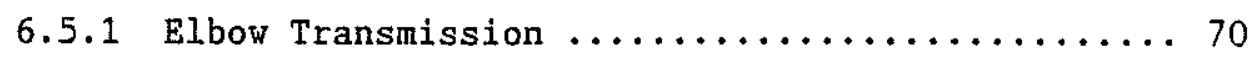

6.5 .2 Shoulder Transmissions .............. 71

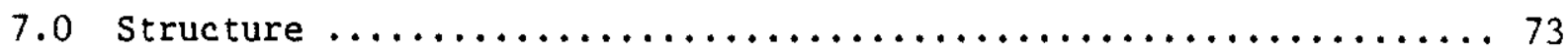

7.1 Housings and Associated Components $\ldots \ldots \ldots \ldots \ldots \ldots \ldots$

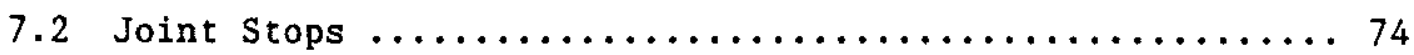

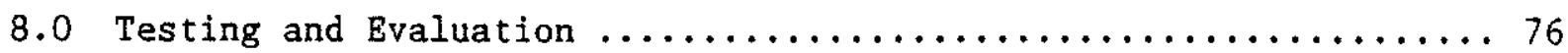

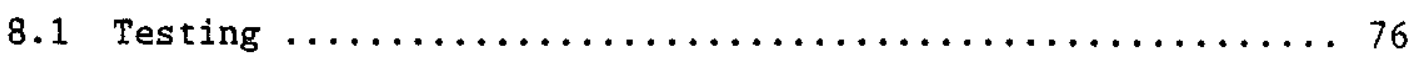

8.1 .1 General Observations ............... 76

8.1.2 Locking the Motors and Deflecting the output Links $\ldots \ldots \ldots \ldots \ldots \ldots \ldots \ldots \ldots \ldots$

8.1.3 Locking the Output Links and Rotating the Motors ................ 81

8.2 Stiffness Model $\ldots \ldots \ldots \ldots \ldots \ldots \ldots \ldots \ldots \ldots \ldots \ldots \ldots$

8.3 Design Evaluation $\ldots \ldots \ldots \ldots \ldots \ldots \ldots \ldots \ldots \ldots \ldots \ldots$

9.0 Recommendations for Future Work $\ldots \ldots \ldots \ldots \ldots \ldots \ldots \ldots \ldots \ldots$

9.1 Improvements to the Existing Design .............. 91

9.2 Long Term Conceptual Improvements ................ 92

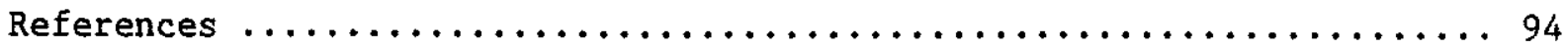

Appendix: Stretch of a Cable Wrapped Around a Pulley ........... 96 
LIST OF FTGURES

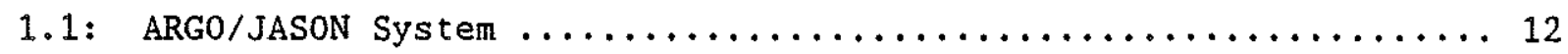

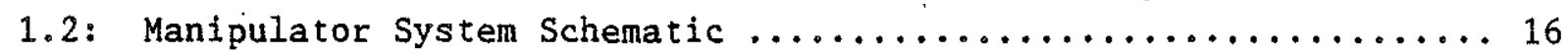

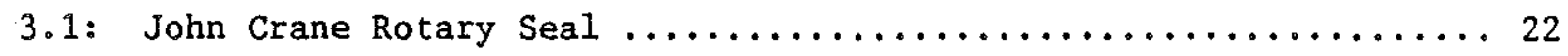

4.1: Seiberco Motor System .......................... 29

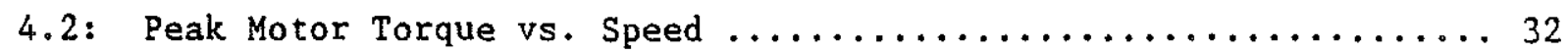

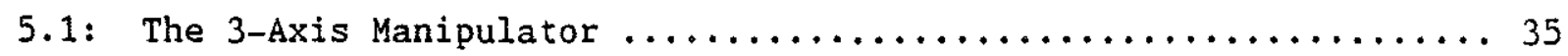

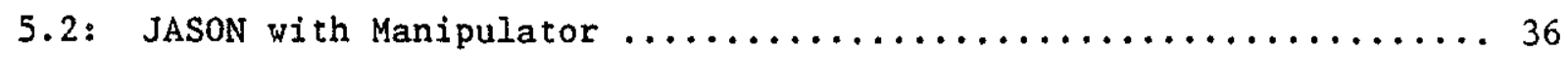

5.3: Kinematic Model of the Manipulator $\ldots \ldots \ldots \ldots \ldots \ldots \ldots \ldots \ldots \ldots$

5.4: Serial Drive Mechanism ......................... 39

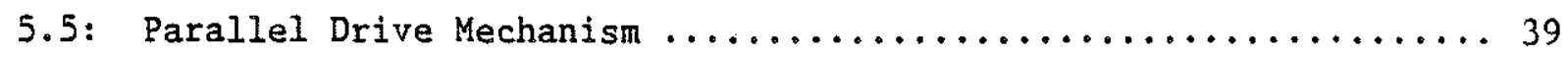

5.6: Serial Geometry, Parallel Drive .................. 40

6.1: One Circuit Consisting of Two Pulleys

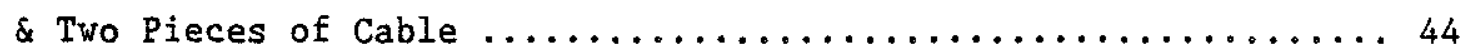

6.2: Split Pulley Pretensioning Technique ................. 46

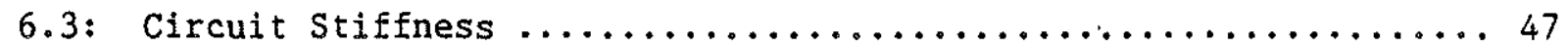

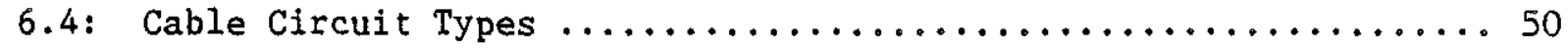

6.5: Cable Construction and Termination .................. 52

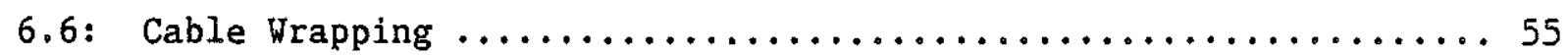

6.7: Cross-Section of Cables on a Pulley, Showing Cable Squash $\ldots \ldots \ldots \ldots \ldots \ldots \ldots \ldots \ldots \ldots \ldots \ldots \ldots$

6.8: Cable Wrapping (half the loop of a $3: 1$ Reducer is shown).

Pitch angle remains the same on both pulleys. ............ 58

6.9: The Basic Volume Occupied by a 3-Stage Reducer ............ 61

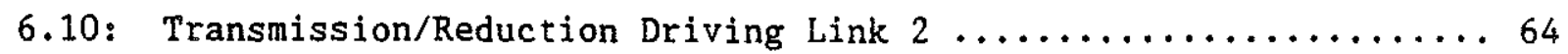

6.11: Typical Reducer Stage Having a Couple of Cables Acting Like a Set of Two Cables in Parallel .................66

6.12: Stiffness as a Function of Reducer Position ............6 67

6.13: Transmission Schematics \& Bond Graphs .................. 69

8.1: Manipulator, Test Stand, and operator .............. 77

8.2: Link 2 Endpoint Deflection vs. Applied Endpoint Load.

Test 1: Load applied in the negative direction ............ 79 
8.3: Link 2 Endpoint Deflection vs. Applied Endpoint Load

Test 2: Load applied in the positive direction ........... 80

8.4: Experimental Set-up for Dynamic Range Test $\ldots \ldots \ldots \ldots \ldots \ldots \ldots \ldots 8$

8.5: Endpoint Force vs. Motor Position.

Endpoint force on Link 2 was measured with JR3 Force Sensor, position data was measured with a rotary dial indicator ...... 84

8.6: Hypothetical Stiffness Curve for the Shoulder

Transmission/Reduction--based on empirical evidence ........ 85 
LIST OF TABLES

6.1 How Pulley Diameter Affects Cable Strength $\ldots \ldots \ldots \ldots \ldots \ldots \ldots \ldots$

8.1 Manipulator Specifications $\ldots \ldots \ldots \ldots \ldots \ldots \ldots \ldots \ldots \ldots \ldots \ldots$ 


\subsection{INTRODUCTION}

This thesis describes the development of a three degree-of-freedom manipulator intended for use in the deep ocean. The work has been part of a larger project, known as the ARGO/JASON program at the Deep Submergence Laboratory of the Woods Hole Oceanographic Institution. The aim of ARGO/JASON is to allow the deep reaches of the world's oceans to be explored effectively without the introduction of man into the aquatic environment. To accomplish useful tasks, a capable telerobotic system complete with a manipulator is necessary.

ARGO/JASON is a robotic system designed to operate for extended periods of time, with the support of scientists and technicians on board a surface ship. Figure 1.1 is unscaled representation of the ARGO/JASON system shown with a support ship. ARGO, a sled towed by the surface ship, has no thrusters and can only be positioned by moving its towing ship appropriately. Outfitted with various cameras and lights, the system is ideal for optically examining large regions of the ocean bottom. JASON, on the other hand, was conceived to serve as a complement to ARG0--being smaller, neutrally buoyant, and self-propelled, it is much more suited to close-up inspection of objects on the ocean bottom. ARGO and JASON are connected together by a tether, which is used to pass power and telemetry to JASON from the surface ship via ARGO.

Because effective scientific research in the ocean often entails direct interaction with objects, a manipulator was necessary for JASON. This manipulator was to be a multipurpose tool capable of delicate and well controlled contact with natural as well as man-made objects on the ocean floor. The decision to build a manipulator came when examination of existing underwater manipulators indicated that those which were appropriate in terms of size and weight invariably had poor force control properties.

A well designed manipulator intended for force control applications should have few dynamic nonlinearities. The few existing nonlinearities should be ones which have limited impact on performance. More specifically, behavior such as backlash or other hysteresis effects, stiction, and nonlinear stiffness are to be avoided in order to produce a manipulator which exhibits stability when in contact with the environment. 


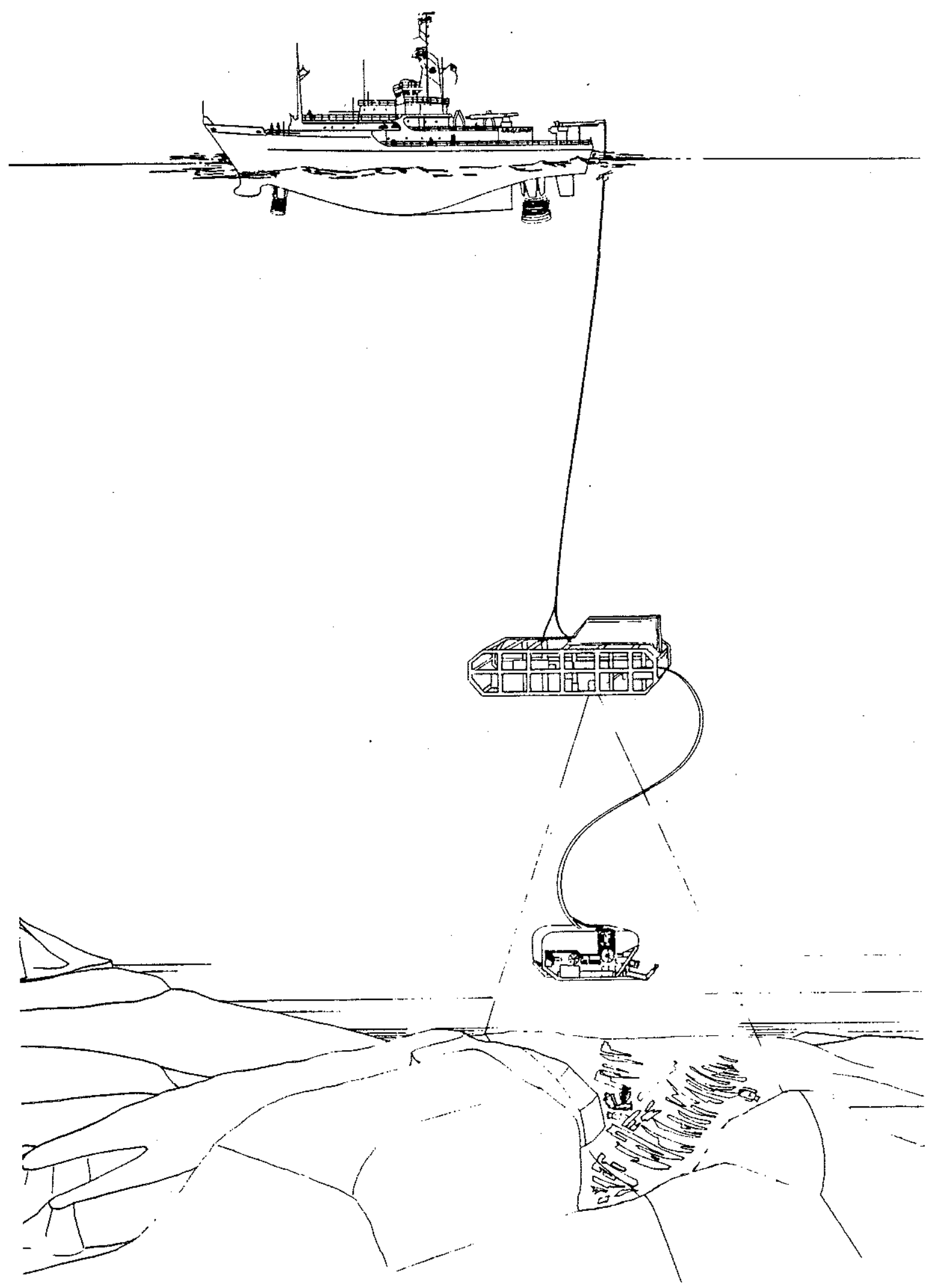

Figure 1.1: ARGO/JASON System 
Two of the major goals of this project were to build a manipulator with wide dynamic range and variably compliant joints. Advantageous qualities include backdriveability, high efficiency transmissions and reductions, low torque ripple output, and high stiffness. Possessing the ability to set impedance at each joint allows the manipulator to act appropriately in a wide variety of situations without the use of distal force sensors. For example, the joints could be set to feel "soft" when the manipulator is working close to an object and "stiff" when rapid motion through unrestricted space is necessary. Setting the joints to feel soft means commanding a low impedance, which means that if the manipulator contacts the environment, it will be compliant, and thus not damage itself or the object it has struck.

The manipulator described here possesses a serial linkage and is driven by brushless electric motors driving through cable/pulley transmissions and reductions. This system represents one possible approach to the issues enumerated above. Most of the development effort was directed at producing highly efficient cable/pulley transmissions and reductions. The development effort had dual goals: to produce a working manipulator for long term JASON applications, and also to create and try new robotic concepts. The two year program of research was composed of the following stages:

1. Study of existing technology: Existing designs were studied and evaluated. During this time, a preliminary decision was made to proceed with cables and pulleys as the transmission elements. This decision was based on the work of (Salisbury, Townsend, Eberman, DiPietro, '88). A prototype one degree-of-freedom manipulator was built at M.I.T. during this period.

2. Motor selection: Because an electric motor was needed for a number of applications in the ARGO/JASON program, and management felt a common motor for all applications would be most effective, motor selection was done before a general concept for the manipulator had been completed.

3. System layout: A serial kinematic linkage was chosen and general requirements were established through discussion with the 
engineering staff at D.S.L. The exact performance specifications for the motor were finalized in this phase as well.

4. Final design: The final design was established and drawings were produced to have the manipulator prototype developed. Mock-ups were built and tested in this period, and purchased parts were ordered.

5. Manufacturing : Shops within W.H.O.I. as well as outside vendors were recruited to build the manipulator. Several modifications were made to the original design during this time.

6. Control system design: Classical as well as modern impedance control schemes were written in C programming language for later use.

7. Test, debug, and rebuild: The manipulator's conformance with the design specifications was verified and modifications were made where appropriate.

While work on this manipulator closely paralleled, and was greatly aided by efforts to develop surface research manipulators at the Artificial Intelligence Laboratory at M.I.T., this manipulator was specifically designed for underwater use, and thus did not conform to many of the design trends seen in surface manipulators. For example, matching input and output impedances is often considered a key design objective for surface manipulators, in order to maximize power transfer and obtain high accelerations. While striving to obtain a good impedance match between the motor and the load remains a worthwhile objective, it was not given a high priority in light of the extremely high effective output inertia caused by added mass and entrained oil effects. To obtain an impedance match, very high reduction ratios would have been required. The choice of slectric motors takes advantage of the environment: instead of only being able to run the motors at "continuous rated torque" as one would be able to on the surface, the motors may be run continuously at "peak rated torque." This is attributable to the fact that the ocean acts as an unlimited heat sink which keeps the motors cool and thus allows a high current flow to be maintained continuously. In this way, fairly small motors could be used. These examples serve as a reminder that this 
manipulator should be evaluated in light of the setting it was designed for--the deep ocean.

A schematic of the manipulator system which was built is shown in Figure 1.2. A serial geometry as well as a serial drive mechanism were utilized. Each link is laterally offset from the one before it, providing a large range of motion, as well as easy stowage. The base and first link are virtually identical--both have electric motor driven 30:1 reductions fully enclosed in similar oil-filled housings. Link two possesses a 13:1 reduction at the output joint, driven by an electric motor mounted near the joint between links one and two. A cable/pulley transmission passes power from the motor to the reducer located at the joint. The manipulator housings enclose all wires, motors, and transmissions. Maximum extension of the manipulator was intended to be 30 inches, although the temporary link three does not reach this far. Load capacity in water at planned full extension is $25 \mathrm{lb}$, including the manipulator weight. Control electronics for the manipulator are housed in a separate cylindrical housing on board JASON.

Although the manipulator should be fully operational at full ocean depth, to effectively perform tasks, several other essential components are required. A wrist would certainly be a useful addition; an endeffector is practically a necessity. 


\section{Electronics Housing}

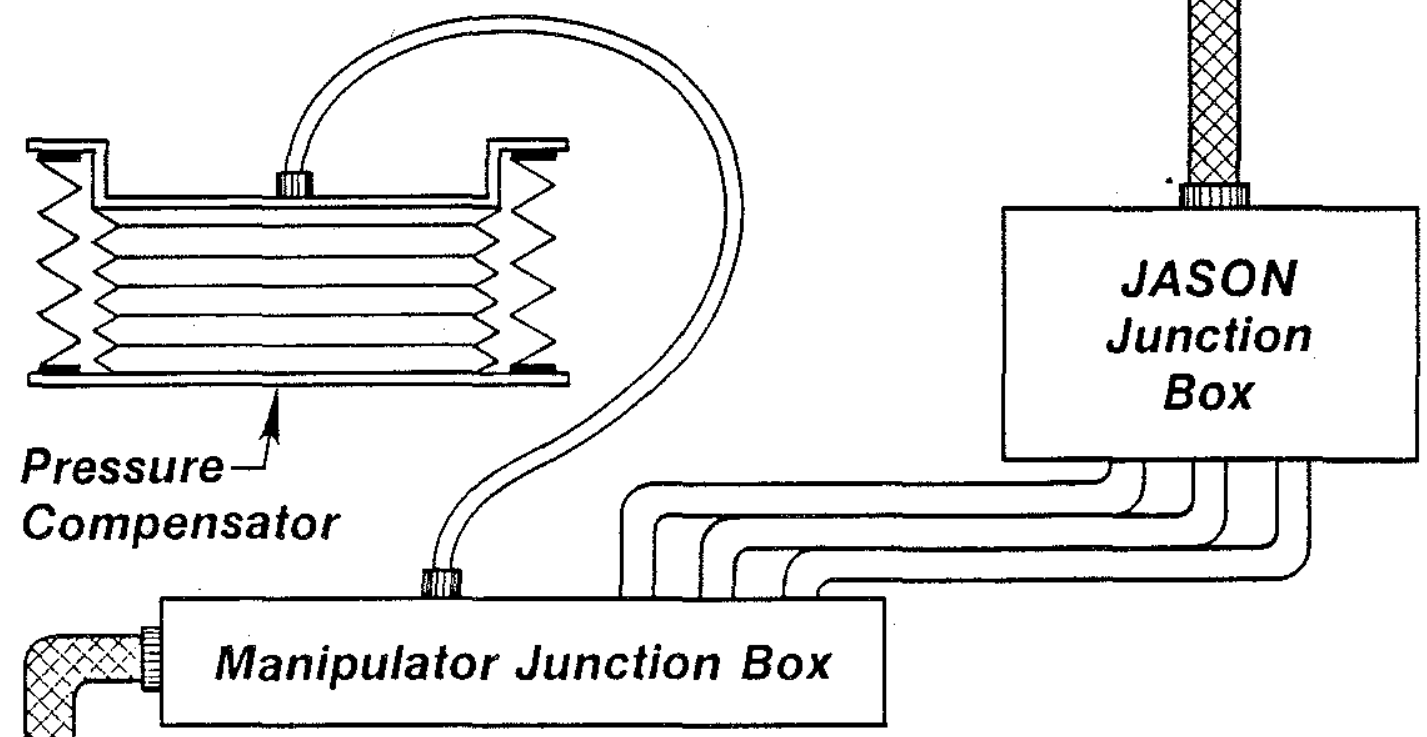

Hose carrying wires and pressure compensation oil

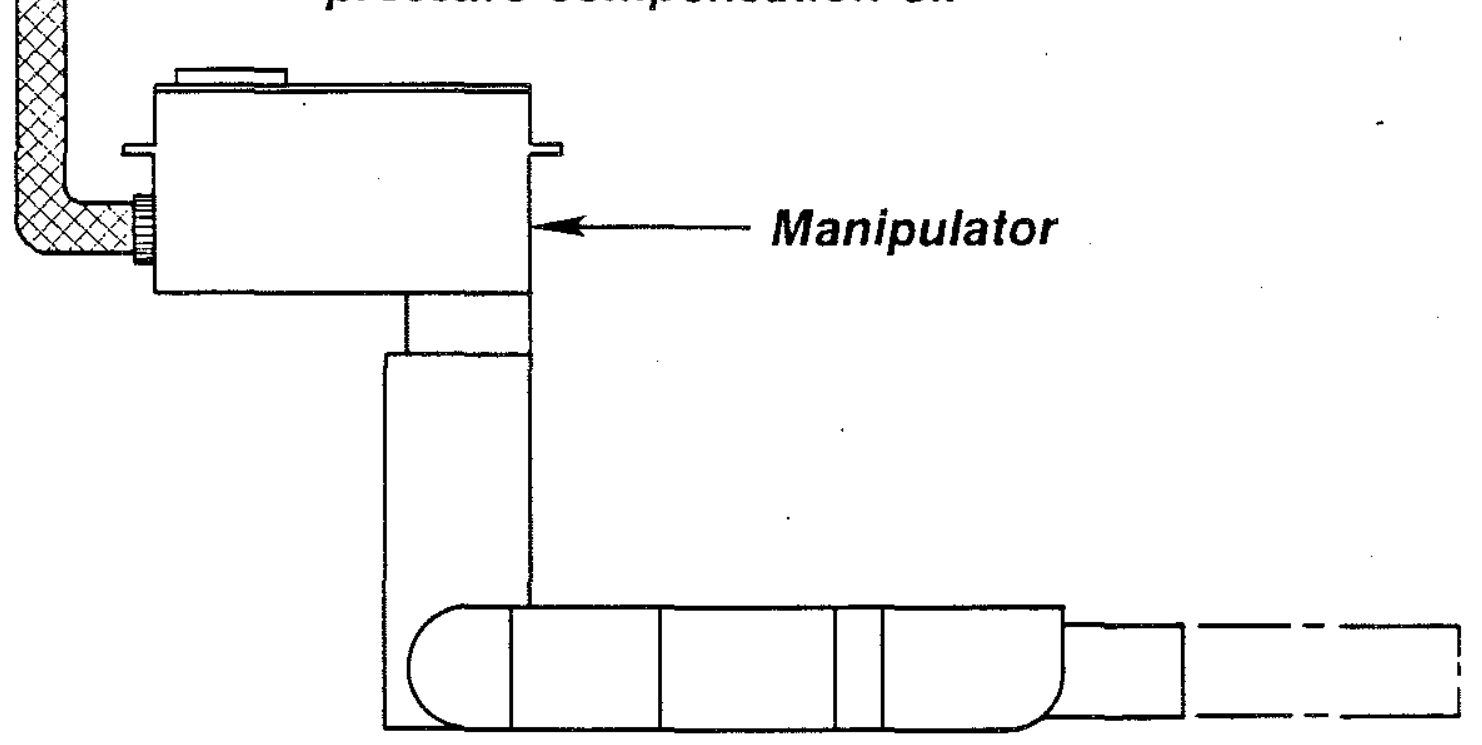

Figure 1.2: Manipulator System Schematic 


\subsection{REQUIREMENTS}

This project has been undertaken with a two-fold goal: 1) to implement and test new advances in actuator and transmission design, and 2) to provide a useful scientific tool for use in conjunction with the JASON vehicle. These objectives, by their nature, have led to a manipulator which is a compromise between a very bold design, and one that would perform reliably in the field. Because this project has focussed on producing a prototype of this system, it tended to utilize new actuator and transmission technology wherever possible. Advancing the state of the art in seal design, materials, finite element analysis, or any number of other fields has not been an objective of this research. Efforts have been made, however, to use the highest performance components and methods.

The topics listed below represent those which I deemed worthy of close attention during the design. In sum, this project has been undertaken with the conviction that an electric manipulator possessing excellent force control, force sensing resolution, positioning accuracy, and a wide dynamic range could be built. Below is a list of the specifics driving this design synthesis.

1. Force/Torque Control: The ability to sense and apply very fine torques and/or forces without the risk of limit cycling. In order to accomplish this, a manipulator with very low stiction is desired.

2. Backdriveability: To help avoid damage due to unanticipated interaction with the environment and to facilitate high resolution force control without the use of non-colocated sensors, backdriveability is a highly desireable feature. Allowing all joints to be backdriven was an objective.

3. Position Resolution: The need for high resolution position information is necessitated by the desire to execute precise torque/force control. Minimizing backlash and other forms of behavior which are nonlinear and difficult to characterize was thus important. 
4. Working Envelope: A large, continuous working envelope is a key design goal because with this feature, the relatively high bandwidth manipulator can move to a wide array of points and orientations without requiring large motions of the low bandwidth vehicle.

5. Dynamic Range: While the ability to exert very light forces and torques accurately certainly important, the manipulator's usefulness as a general purpose tool would be significantly reduced if fairly heavy loads could not be accommodated.

6. Environmental Compatibility: While this almost goes without stating, the manipulator must be able to interact with the sea water for extended periods without requiring significant refurbishing. In this catagory was also the goal of keeping sensitive components away from the corrosive ocean.

7. Sensors: Due to frequent sensor failures on other underwater equipment, keeping the number of sensors on the manipulator to a minimum was a goal intended to increase the maintainability as well as the operational effectiveness of the unit.

8. Modularity: On board research ships at sea, space is a valuable commodity, and thus minimizing the number of spare parts which must be taken along for a given system is of importance. In order to facilitate a small parts inventory, efforts have been made to use common components wherever possible. This approach provides the added benefit of making it easier for those servicing the manipulator to locate proper parts.

9. Efficiency: All power for JASON and its systems must travel through a cable which is several miles long. A high efficiency manipulator will allow a large proportion of the available pover to be used for ather purposes such as vehicle positioning (important if the vehicle/manipulator system were viewed as one large manipulator) and scientific operations.

10. Obstacle Avoidance: Being able to reach around objects in the workspace is an important quality in an unstructured, underwater 
environment. Less repositioning of the vehicle is necessary when the manipulator has good obstacle avoidance capabilities.

11. Size and Weight: Efforts have been made to keep the manipulator as compact and light as possible. A heavy manipulator would upset the weight and balance of the vehicle, and it would also reduce the amount of payload the manipulator could handle. Maintaining a small volume allows more space on JASON to be allotted to other pieces of equipment. 


\subsection{UNDERWATER TECHNOLOGY}

Before continuing with this document, a few words on general deep underwater technology trends are necessary. The deep ocean presents a special set of challenges--in many ways as different from the planet's surface as is outer space. At $6000 \mathrm{~m}(20,000 \mathrm{ft})$, the planned maximum operating depth of ARGO/JASON, pressure reaches 59 million Pascals (8600 psi), and temperature away from volcanic sites hovers in the neighborhood of 0 degrees $C$ ( 32 degrees $F$ ). The salt water speeds the rate of galvanic corrosion, and often carries sediment and other suspended particles.

Man has developed a number of specific products and techniques for dealing with the conditions mentioned above. Some of the ones used on the ARGO/JASON project are listed below.

\subsection{Pressure Compensation}

Components which can not be exposed to sea water are protected by being placed in housings. The equipment in these housings generally must interact with the environment in one of two ways: 1 . through a dynamic interface, as in the case of moving shaft protruding through a seal, or 2 . through a static interface, for example with an electrical penetrator passing wires from the inside to the outside of the housing. In both cases, assuming the housing has been sealed at the surface at atmospheric pressure, the pressure differential across the housing interfaces when the housing reaches operating depth will be very great. Static housing penetrators can be produced which can readily tolerate high pressure, but dynamic seals which are able to handle high pressure gradients are uncommon, expensive, and introduce high friction.

To circumvent these problems, housings on ARGO/JASON which have dynamic seals are pressure compensated to 4 psi above the ambient water pressure. On JASON this is accomplished through the use of a passive central compensation system consisting of a large spring-loaded bladder connected to all the individual housing on JASON by plastic hoses. The JASON compensator uses Carnation Lite Mineral 0il, which also serves as a lubricant for many of the mechanisms on JASON. 


\subsection{Seals}

As mentioned above, seals are available in two basic varieties: static and dynamic. Static seals used on ARGO/JASON are of the following kinds:

- Gaskets: these are generally used where flat surfaces come in contact. They are cheap and easy to custom make in virtually any pattern.

- Rings: 0-rings, quad-rings, and others are examples of these very flexible seals. Rings of this kind rely on smooth groove seats to be cut in one or both of the mating parts and thus are more expensive than gaskets and are more susceptible to damage. 0-rings do have the advantage, however of allowing direct contact between mating parts. We have found Buna-N to be the best material for both gaskets and rings.

- Liquid Sealants: A number of sealants. which can be applied in the liquid form and then harden are available. Although these sealants can supposedly be used without one of the other types of seals as back-up, they have only been used in this project in conjunction with other seal types. They have been used mostly to fill cracks and small holes.

Dynamic seals are available in a myriad of varieties and are far too numerous to list here. On JASON, the only type of dynamic seal utilized is the John Crane Type 21 rotary cartridge seal depicted in Figure 3.1 . The Alvin Group at W.H.O.I. has had excellent experience with these seals. They have very low friction compared to other commercially available rotary seals. The sealing surfaces consist of a carbon wiper running on a ceramic ring. Seals of this kind are used in the manipulator, camera pan and tilt, and the thrusters. Improved John Crane seals, having a siliconcarbide wiper running on a silicon-carbide ring, have even lower friction levels, but were made available after the manipulator design had been completed. 


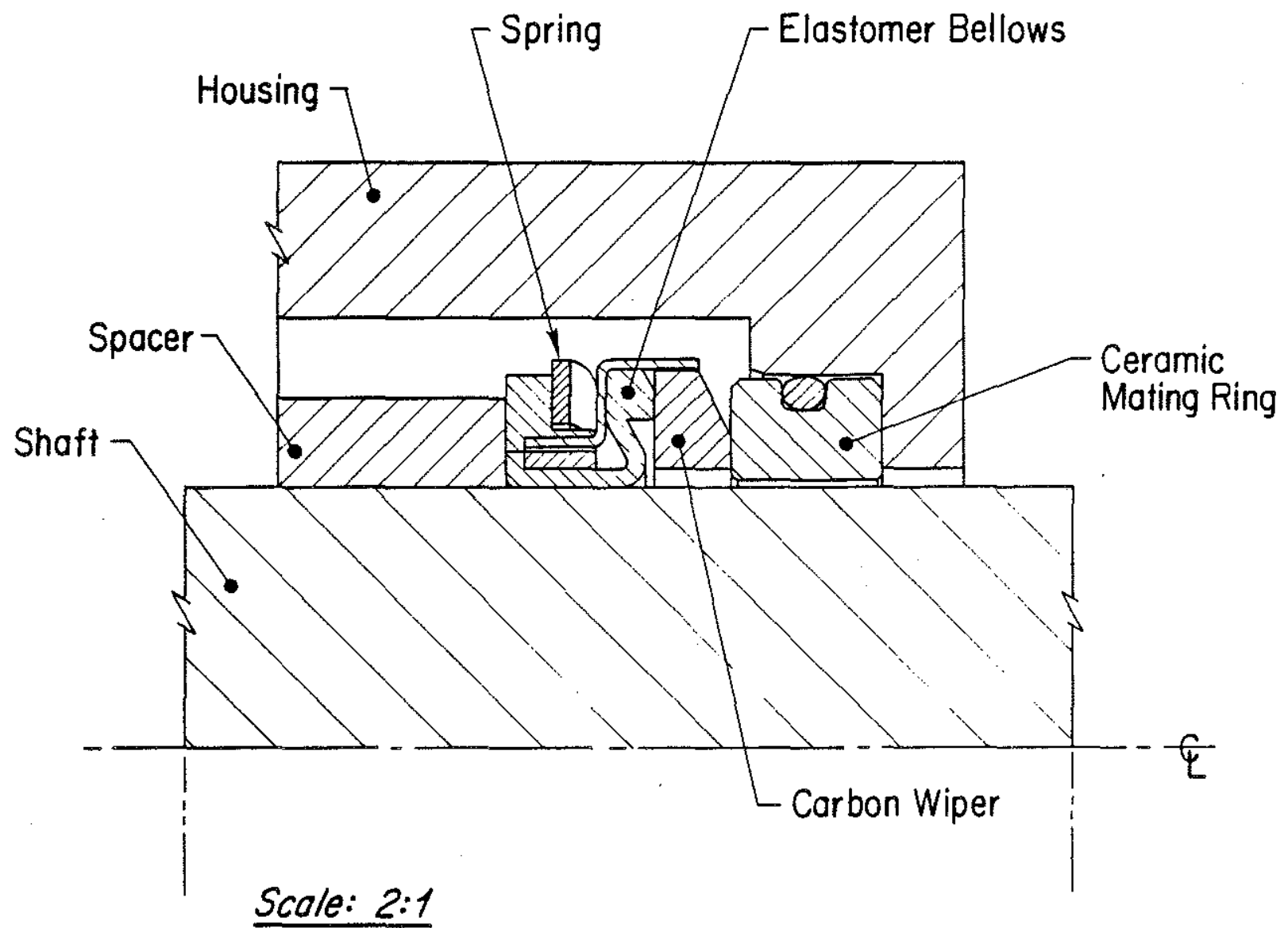

Figure 3.1: John Crane Rotary Seal 


\subsection{Materials}

Proper selection of materials for the underwater environment can not be overemphasized. Corrosion, swelling, and attack by organisms are all areas which should be considered when selecting materials. A number of excellent books exist which discuss materials suitable for the underwater environment (S. C. Dexter, '79; Materials Selector, '88; F. L. Laque, (75). Only materials actually used in this project will be discussed here.

\subsubsection{Metals}

Factors which influenced the choice of metals were availability, corrosion resistance, machinability, stiffness, strength, surface hardness, thermal expansion, weight density, and weldability. These factors played varying degrees of importance, depending on the application. Corrosion resistance bears special mention because failure to recognize its importance has often meant the catastrophic end to the lives of other underwater devices. Both general sea water corrosion and galvanic corrosion will play a part in the corrosion of the manipulator. Galvanic corrosion occurs when dissimilar metals are placed in electrical contact and immersed in sea water (Dexter, 179). The more corrosion resistant metal will corrode slower and the less resistant metal faster than either would alone. The galvanic series provided information on which materials will experience accelerated corrosion. The rate of attack on the less resistant metal (known as the anode) depends on the potential difference between the anode and the more resistive metal (the cathode), and the cathode to anode ratio of area exposed to sea water. In this design, cathode to anode area ratios were minimized and plans exist for mounting sacrificial zinc anodes to the manipulator.

The following is a list of the metals used, where in the design they were used, and why. In those cases where no specific numerical designation is given, the manufacturer was given the flexibility to use any metal which fit the general category.

- 6061-T6 Aluminum: covers, link three, JASON mounts. Attractive because of their high strength-to-weight ratios, low cost, excellent 
availability, and good machinability, aluminums of three kinds were used in this design. Compared to other aluminums, 6061 has reasonable corrosion resistance.

- A356 Aluminum: cast housings for links one, two, and the base. A cast aluminum possessing fairly good corrosion resistance compared to many other aluminums.

- 7075-T6 Aluminum: pulleys, joint torque tubes. 7075 is a very high strength aluminum and possesses many of the other general advantages of aluminum. It has poor corrosion resistance, however, and its only contact points with sea water were anodized.

- 302 and 303 Stainless Steel: cables, threaded fasteners. These materials are standard for threaded inserts, which have widespread use on the manipulator housings. The 303 stainless is particularly poor when immersed in sea water, but since it is only exposed to sea water when connected to aluminum, the aluminum will act as the anode and the corrosion rate of the cathodic 302 and 303 will be reduced.

- 316 Stainless Steel: motor drive shafts, cable terminations, snap rings, wavy washers. of the readily available stainless steels, 316 has been among the best for corrosion resistance.

- 420 Stainless steel: ball bearings (purchased parts). This is standard bearing material. 400 Series stainless steel does not have good sea water corrosion resistance, but the bearings should never be exposed.

- 17-4 PH Stainless Steel: Joint stops and shafts. 17-4 PH was selected because of its high strength, its capacity to be hardened, and decent corrosion resistance.

- Cold-rolled steel: motor rotors, pins, drive shaft collars. Steel of this kind was only used inside the housings and in parts which can easily be replaced, should sea water enter the housings and cause corrosion.

- Brass: joint taper retaining nuts. Selected as a dissimilar metal to aluminum to avoid galling with the A356 housings or the 7075 threaded torque tube ends. 


\subsubsection{Plastics}

Very few plastics are present in this design. In most cases they have been avoided because stronger and stiffer materials were required. In a few cases plastics could have been used for covers. With one exception, this has been avoided because of fear of getting stock plastic with voids in it. When plastic with voids is machined, the voids may become holes, which will in turn cause leakage. Voids may also implode when under high pressure, again causing leakage paths. The one exception is a white Delrin disk used as a cover on link three. The fact that it is white is important because plastics containing carbon have been found to cause severe galvanic corrosion in active metals such as aluminum. Black plastics are given their black color by the presence of carbon, which often also serves the dual purpose of protecting the plastic from ultraviolet radiation damage.

\subsection{Electronics Packages}

The supervisory control system planned for JASON necessitates having advanced electronic hardware onboard the vehicle. In JASON's case, virtually all the electronics are packaged in six (6) inch inside diameter titanium housings. Three of these housings are currently in use on the prototype vehicle: one for the supervisory controller, one for telemetry, and one interchangeable housing for either the manipulator control electronics or a science package. The inside volumes of these housings are filled with air at atmospheric pressure. 


\subsection{MOTOR SELECTION}

\subsection{Motor Overview}

The importance of effective motor selection can not be overstated. In this section, the important attributes of the motor used to drive the manipulator are presented. The context of the discussion is the products of some of the major servomotor manufacturers, namely Inland, Moog, Pittman, and Superior Electric, and one rather unique small firm-Seiberco.

Although a vast variety of electric motors are commercially available today, many of these prime movers are rendered inappropriate by the fact that the motors must operate in an oil bath for pressure compensation. Motors which rely on brushes for commutation have been found to experience arcing between the brushes and the commutator when immersed in an oil bath at high pressure. This is due to hydroplaning between the brushes and the commutator. As the brushes hydroplane away from the commutator, a gap opens over which arcing occurs. This arcing causes carbon particles to form and "weld" to the commutator. Rapid deterioration of the commutator and brushes then follows. Behavior of this kind has led engineers at W.H.O.I. to avoid using brushed direct current (DC) motors. Generally speaking, this leaves $A C$ motors and $D C$ brushless motors.

$\mathrm{AC}$ motors, defined here as motors running on three-phase line voltage, were considered impractical due to their constant running speed. This left only DC brushless motors from which to choose. At least three different types of brushless motors exist, and all have been used for robotic applications: the DC brushless torque motor, the variable reluctance motor, and the sensorimotor. The last motor is one of the most recent entrants to the servomotor market, and is produced by only one company that this author is aware of--Seiberco, Inc. All these brushless motors have a number of advantages:

- Highly efficient operation, common to DC motors in general

- Linear torque-speed characteristics

- High starting torque 
- Long life, due to the fact that the brushes and commutator to not. wear

- Simple mechanical construction

In choosing a motor, the characteristics of greatest importance are listed below in order of preference:

1. Electronics package: AlI the motor drivers and controllers were required to fit into a six inch diameter housing. Few, if any, of the stock commercial products fit this bill, making a redesign or modification of an existing electronics package imperative. Any company unwilling to embark upon a controller/driver redesign was deleted from the list.

2. High torque-to-weight ratio at low speed: By the time the motor selection had begun, the decision had been made to use a fairly small reduction between the motor and the load. Because of the underwater speed constraints described previously, high speed and high acceleration were not characteristics deemed important. For these reasons torque-to-weight was considered more important than power-to-weight-we wanted high torque at low speed (less than 1000 rpm).

3. Tight torque control: The manipulator is intended to be controlled by commanding joint torques. Being able to accurately command motor torque is thus of great importance. Torque ripple also falls into this category. (Torque ripple is defined here as any variation in the linear relationship between commanded torque and actual delivered torque,) Torque ripple, when unaccounted for, will tend to cause inaccuracies in manipulator movement or interaction force. Good torque control will permit good control of motions with or without contact forces with a minimum of sensors.

4. High positional accuracy: A positional accuracy of at least 8 bits per revolution desirable. With a reduction ratios of roughly 4 bits, this provides an overall position resolution of 12 bits. 12 bit resolution is generally considered the practical limit of most input devices such as masters or joysticks. 
5. Reasonable efficiency: Vehicle power consumption limits provide the manipulator with a certain maximum amount of power. The more efficient the motor system, the greater the amount of power delivered to the load.

6. Simplicity: As is the case in most design projects, the fewer the parts the better. This is particularly true in the oceanographic community. Space on a ship is limited, and thus the fewer spare parts which must be brought, the better!

\subsection{Sensorimotors}

Sensorimotors were ultimately choosen to power the manipulator (and also JASON's cameral pan and tilt mechanism). These motors have an extremely simple and compact design. Unlike conventional DC brushless motors, the sensorimotor provides rotor position and velocity feedback without the use of hall effect devices, encoders, or resolvers. According to Seiberco, the inherent position feedback information is derived from the permeance variation within the permanent magnet rotor and wound stator air gap. This position information is identical to that of a brushless resolver that outputs two sinusoidal signals phase shifted 90 degrees from each other.

Once the motor type had been determined, the actual motor size and performance had to be decided. In the interest of commonality, the decision was made to drive all three positional axes of the manipulator with the same model motor. While this approach does not lend itself to joint by joint optimization, it does make sense from an oceanographic systems perspective. This decision had a direct impact on the motor size decision. It practically ruled out large, direct drive motors because they are too heavy to mount on the elbow of a serial link manipulator. At the other extreme, small, high speed motors requiring large reductions seemed impractical because of the high viscous drag losses they would incur operating in an oil bath. Other issues which influenced motor size selection will be discussed in the transmission section.

An example of the motor system purchased, as well as an Instrument Bus Computer (IBC), is shown in Figure 4.1. In the foreground, from left to right, are a controller board, a power stage, a stator, and a rotor. 


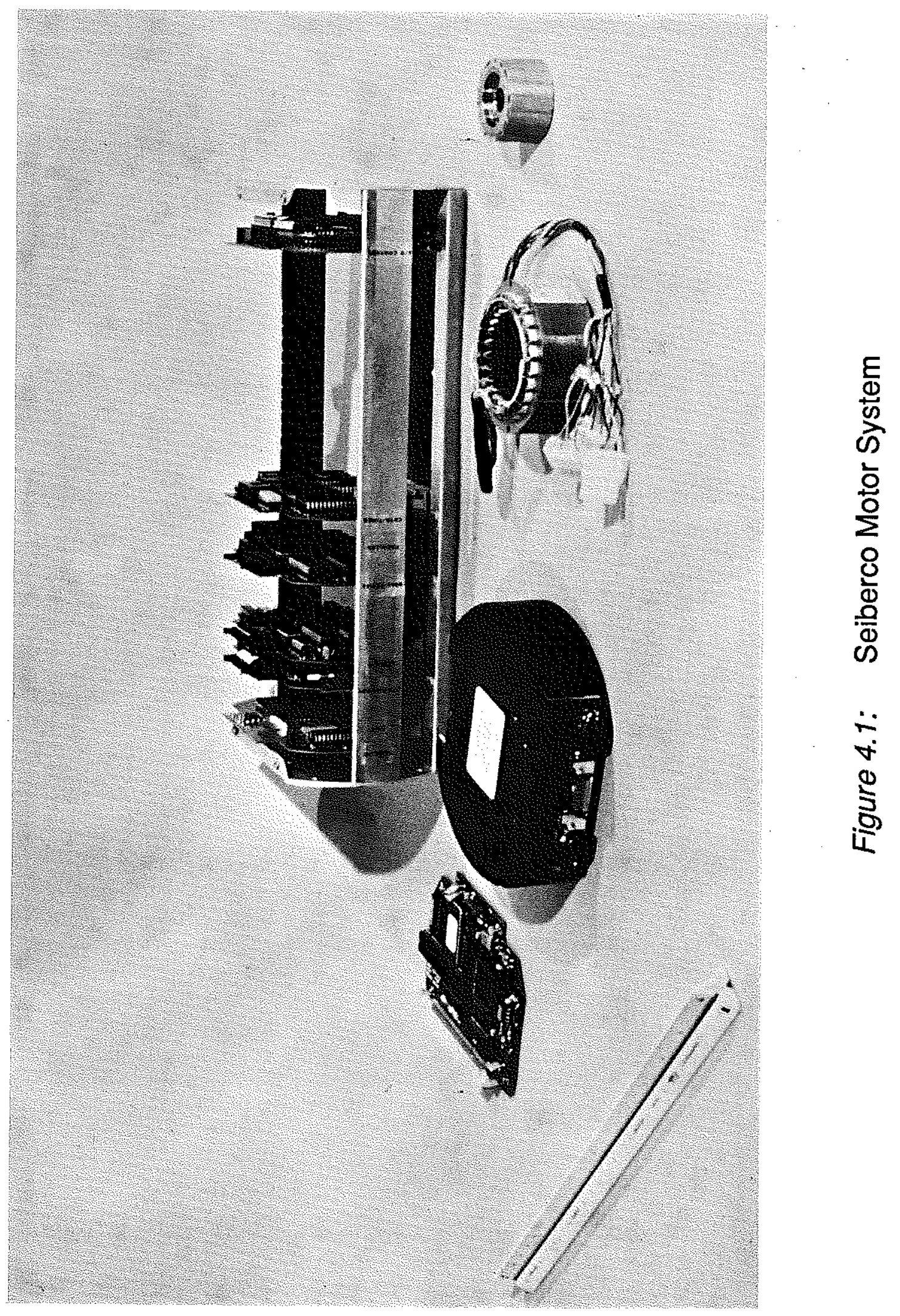


The IBC is shown in the background. Each of the controller boards plug into this bus. Scale is indicated by the 12 inch ruler on the left.

The motors are frameless, i.e. the stator and rotor are provided without bearings or housings. They represent a compromise between direct drive, and small, high speed motors. The stator diameter is 3.15 inches and the length is 1.20 inches. The laminated stator has 24 windings, of which 4 are used for sensing and the others for power. The rotor is composed of 18 samarium-cobalt magnets epoxied to a cold-rolled steel core. The magnets are skewed to reduce torque ripple. The skewing does reduce torque output by roughly $10 \%$ when compared to a motor without a skewed rotor, but nonetheless, the high energy rare earth magnets give the motor a very high torque-to-weight ratio.

Each motor is controlled by a single axis digital controller also manufactured by seiberco. Controllers are each mounted on a separate board which fits into an instrument bus chassis in the manipulator control housing. The controller is based on a 16 bit microprocessor running a proportional-integral-derivative (PID) control scheme with optional feedforward torque command (an 8 bit signed value). The controller possesses a host of useful features, including a variable current limit, variable PID gains, 16 bit velocity feedback, 32 bit position feedback, time at current limit, and a status indicator.

The controller sends signals to a power driver module operating off a nominal $120 \mathrm{~V}$ DC supply which is available onboard the vehicle. This module is also located in the manipulator control housing. The two phase motor is driven by a pair of H-bridge drivers, one per phase. Current sensing, used for torque control, is accomplished using a current sensing resistive element in each leg of the H-bridge. A pulse width modulator (PWM) operating at $70 \mathrm{kHz}$ determines the power to be sent to the motor by the MOSFET's (power transistors). The PWM approach provides very efficient operation and the MOSFET devices have the advantage of having fast response, high bandwidth, excellent stability over a wide range of motor speeds, and good noise immunity. The high efficiency operation of the drive electronics are particularly important because they are housed in a housing which is crowded with other electronics, and is difficult to effectively cool. Even so, special heat sinks were developed which connect the MOSFET's to the inside of the titanium housing. 
Motors used for the manipulator are configured with either one or two power stages driving them. Torque-speed curves for the single drive and dual drive systems are shown in Figure 4.2. A single drive motor is used to power joint one, while dual drives are used on joints two and three. Any given motor can be driven by either dual or single drive. Motors driven by dual drives have one drive powering each set of windings. Single drive motors have windings in parallel.

The choice of Seiberco as the motor manufacturer was a decision based largely on the fact that their motors have very high torque-toweight ratios. In addition, they allowed us to set the motor specifications, and ultimately designed a low speed motor optimized for our operating points. Seiberco also made all the necessary modifications to their existing controllers and drivers, so that they could conveniently fit inside our electronics housings. Physically, the motor was constructed in a frameless, modular way, with a tapered hole in the rotor for easy installation and backlash-free operation. We actually did much of the rotor design at W.H.O.I., suiting it specifically to the several applications we had for the motor (it was ultimately used in two camera pan and tilt projects, and the manipulator). Even the controller and interface software were customized to our requirements. The motor was also pressure and temperature tested by Seiberco at our site. Overall, Seiberco has been very helpful and flexible throughout the project, and ultimately provided a very high performance product. 


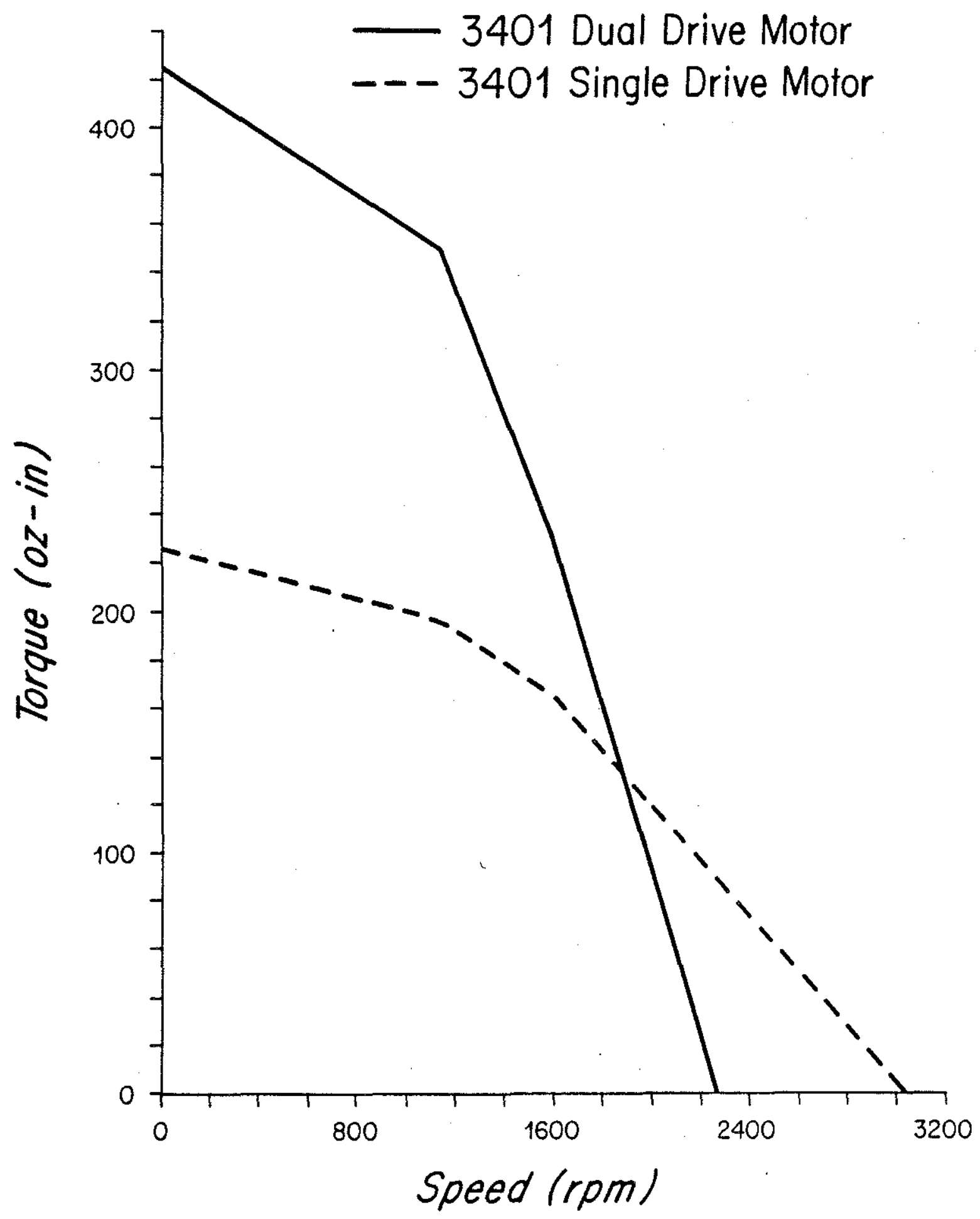

Figure 4.2: Peak Motor Torque vs. Speed 


\subsection{KINEMATICS}

The issues impacting kinematics may be divided into two major subheadings: geometry and drive mechanisms. While the two often influence each other in the design of surface robots, for this application, the selection of the proper geometric properties has been largely separated from the type of drive-train employed.

\subsection{Geometric Design}

There are at least two general possible linkage geometries: closed chains and serial chains. Parallel and serial drive mechanisms are possible for both of these classifications. The geometry of the manipulator has been driven by several important factors:

1. Obstacle Avoidance: As is the case with most robotic telerobots operating in an unstructured environment, straightline motion is often impeded by obstacles in the workspace. To reach a target, the manipulator should have the ability to reach around objects without the risk of entanglement.

2. Swept Volume: When moving to reach a goal, the manipulator may have to pass through narrow spaces. Limiting the amount of volume swept out by any given motion allows the manipulator to enter confined spaces and also has an impact on the amount of storage space required for the manipulator on board JASON.

3. Human Operator Needs: The manipulator will often be operated in a master-slave control mode. Because it is our intent to use all surfaces of the manipulator to execute tasks, having a close spatial correspondence between the human operator's arm and the manipulator means use of the manipulator will be more intuitive than if the manipulator had a non-anthropomorphic form.

Examination of the above issues led to the decision to construct a serial manipulator. 
The manipulator configuration chosen, as well as its range of motion relative to JASON, is shown in Figures 5.1 and 5.2. This configuration has been chosen because it allows a manipulator with revolute joints to enclose the largest possible volume. The manipulator has been designed such that when complete, link two would be the same length as link three, and joint three would have $360^{\circ}$ rotation capability. All points within the spherical volume enclosed can thus be reached. Having axes two and three parallel means that there is a decoupling between movements in the plane containing axis one, and movements normal to the plane. This is important from the standpoint of coordination and actuation energetics (Waldron, '88). Decoupling does not occur in the case where axes two and three are normal. In addition, having joint two parallel to joint three avoids the introduction of torsional loads which may be present in the configuration having axes two and three orthogonal.

The kinematic equations for the manipulator were developed based on the coordinate representation shown in Figure 5.3. Position of the manipulator endpoint relative to the base coordinate frame is given by

$$
\begin{aligned}
& x=c_{1}\left(I_{2} c_{2}+I_{3} c_{23}\right) \\
& y=s_{1}\left(I_{2} c_{2}+I_{3} c_{23}\right) \\
& z=-l_{1}+I_{2} s_{2}+I_{3} s_{23}
\end{aligned}
$$

where

$$
\begin{aligned}
& c_{1}=\cos \left(\theta_{1}\right) \\
& c_{2}=\cos \left(\theta_{2}\right) \\
& c_{23}=\cos \left(\theta_{2}+\theta_{3}\right) \\
& s_{23}=\sin \left(\theta_{2}+\theta_{3}\right)
\end{aligned}
$$$$
s_{1}=\sin \left(\theta_{1}\right)
$$$$
s_{2}=\sin \left(\theta_{2}\right)
$$

The Jacobian shown below was determined by differentiating each of the position coordinates with respect to each of the three joint angles.

$$
J=\left[\begin{array}{ccc}
\left(-s_{1} c_{2} 1_{2}-s_{1} c_{23} 1_{3}\right) & \left(-c_{1} s_{2} I_{2}-s_{23} c_{1} 1_{3}\right) & \left(-s_{23} c_{1} 1_{3}\right) \\
\left(c_{1} c_{2} I_{2}+c_{1} c_{23} I_{3}\right) & \left(-s_{1} s_{2} 1_{2}-s_{23} s_{1} 1_{3}\right) & \left(-s_{23} s_{1} 1_{3}\right) \\
0 & \left(c_{2} 1_{2}+c_{23} 1_{3}\right) & \left(c_{23} 1_{3}\right)
\end{array}\right]
$$

If JASON is viewed as the base coordinate frame, singularities exist at the outside and the inside of the workspace, and along the $z_{0}$ 


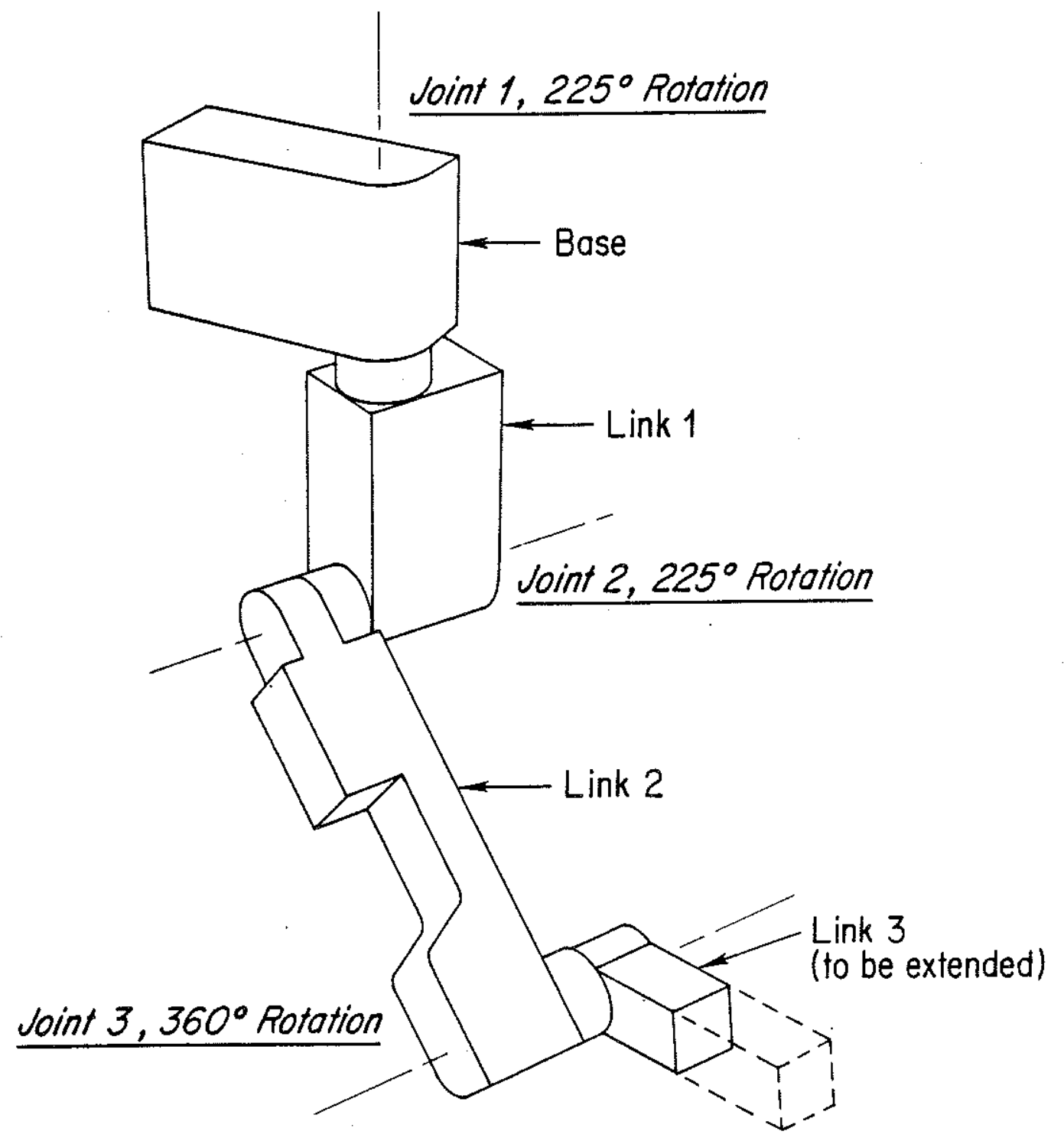

Figure 5.1: The 3-Axis Manipulator 


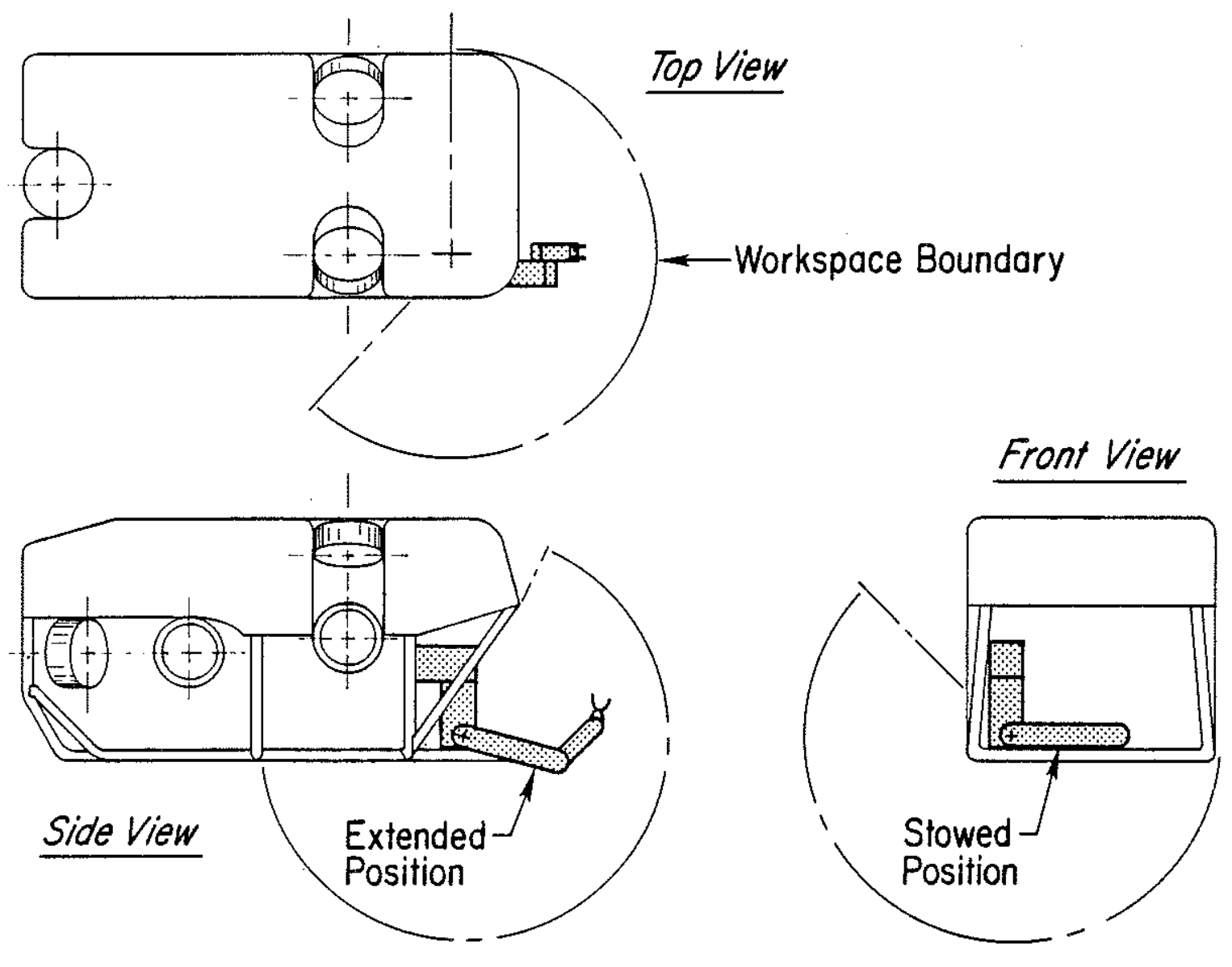

Figure 5.2: JASON with Manipulator 


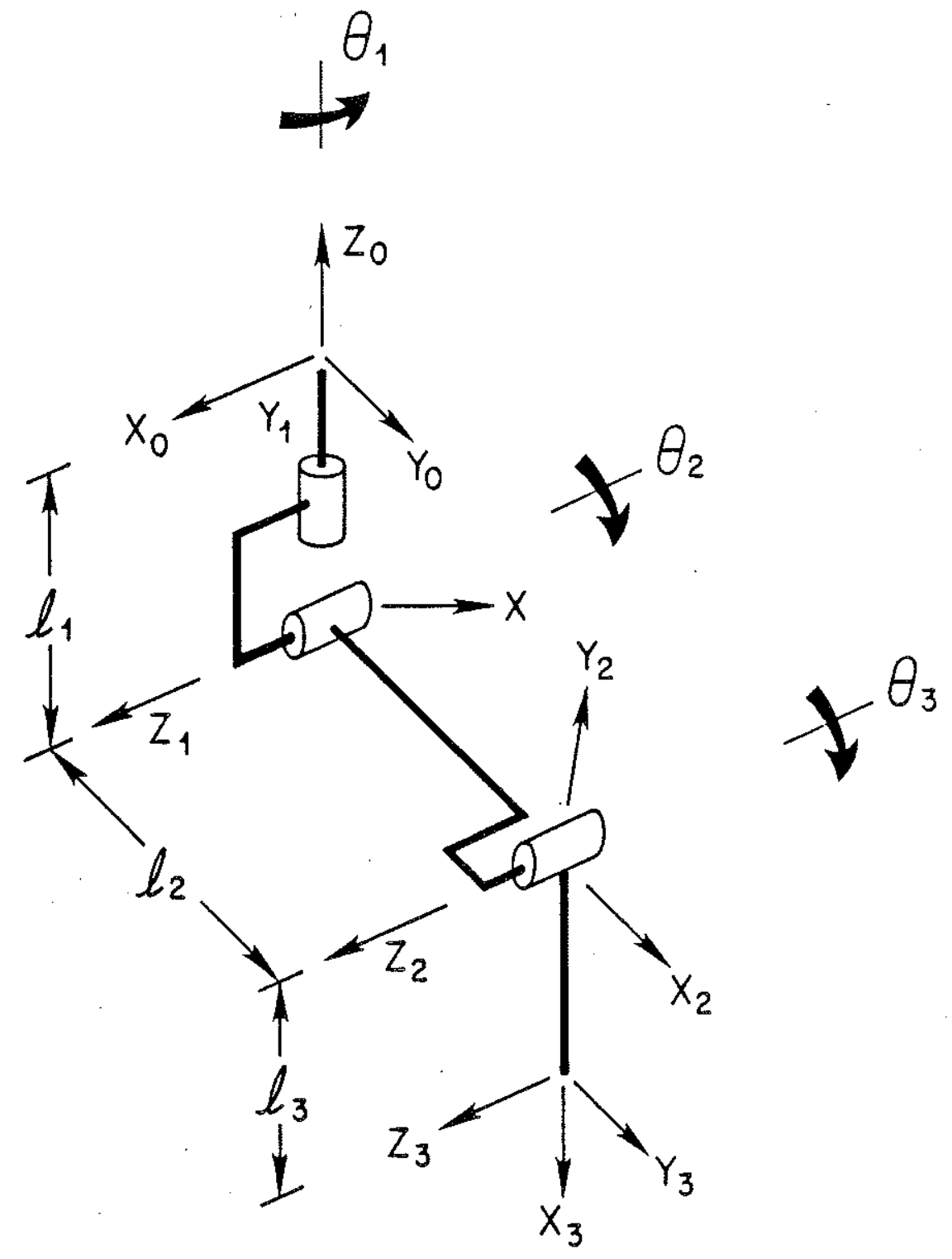

Denavit-Hartenberg Parameters:

\begin{tabular}{|c|c|c|c|}
\hline Link No. & $\underline{\alpha_{i}}$ & $a_{i}$ & $\delta_{i}$ \\
\hline 1 & $90^{\circ}$ & 0 & $l_{1}$ \\
\hline 2 & 0 & $\ell_{2}$ & 0 \\
\hline 3 & 0 & $l_{3}$ & 0 \\
\hline
\end{tabular}

Figure 5.3: Kinematic Model of the Manipulator 
axis. This last line of singularities could be tilted ont of the workspace by changing the mounting of the manipulator relative to JASON. If JASON is considered as part of the manipulator, redundant degrees of freedom exist, and the singularities disappear. While the workspace of the manipulator is very large, only the portion directly in front of JASON will probably be used in practice. The camera used by the human operator to track the manipulator will not be able to follow the manipulator outside this region. The manipulator has the extended workspace to allow for more advanced forms of supervisory control in which the human operator does not directly control or monitor the position of the manipulator optically, and also to ensure that the manipulator can "comply" should the environment suddenly be struck.

\subsection{Drive Selection}

Knowing the geometric configuration, the appropriate drive mechanism was selected next. Both serial and parallel drive mechanisms have been studied. Figure 5.4 shows a two degree-of-freedom serial manipulator, in which the motor at the base drives the first link and the motor on the first link drives the second link. In this case, the weight of the second motor and the torque it produces are both loads to the first motor. In the case of the parallel drive manipulator (Figure 5.5), shown in the form of a two degree-of-freedom five-bar linkage, neither the weight nor the reaction torque of one motor influences the other. Motor size generally must increase from the endpoint link to the base in serial manipulators because each motor must carry the weight and torque of all motors which lie between it and the endpoint. The motors of parallel drive manipulators, on the other hand, are not affected by the torques and weights of other motors.

The five bar linkage shown in Figure 5.6 actually has a serial chain geometry, demonstrating why drives have been distinguished from geometries. Parallel drive mechanisms can be packaged in such a way that the geometric shape of the manipulator remains serial. A cable/pulley drive is one way of accomplishing this. Although parallel drives are appealing for the reasons stated above, they have not been used in this design. Instead a serial drive mechanism has been developed that located the motors in such a way as to reduce their weight affects. The 


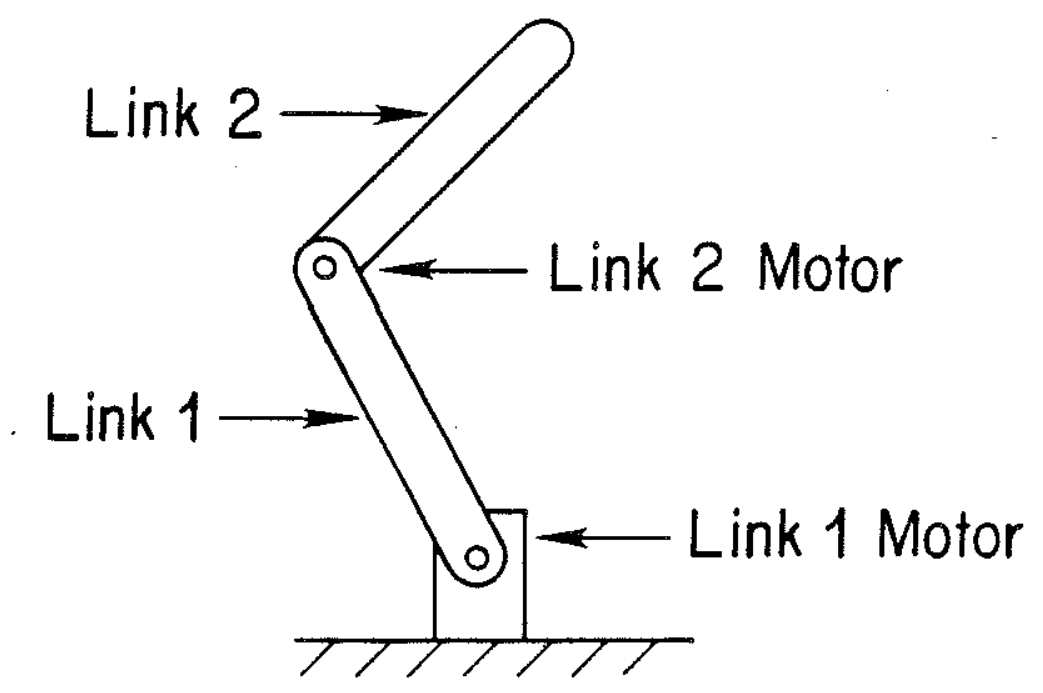

Figure 15.4: Serial Drive Mechanism

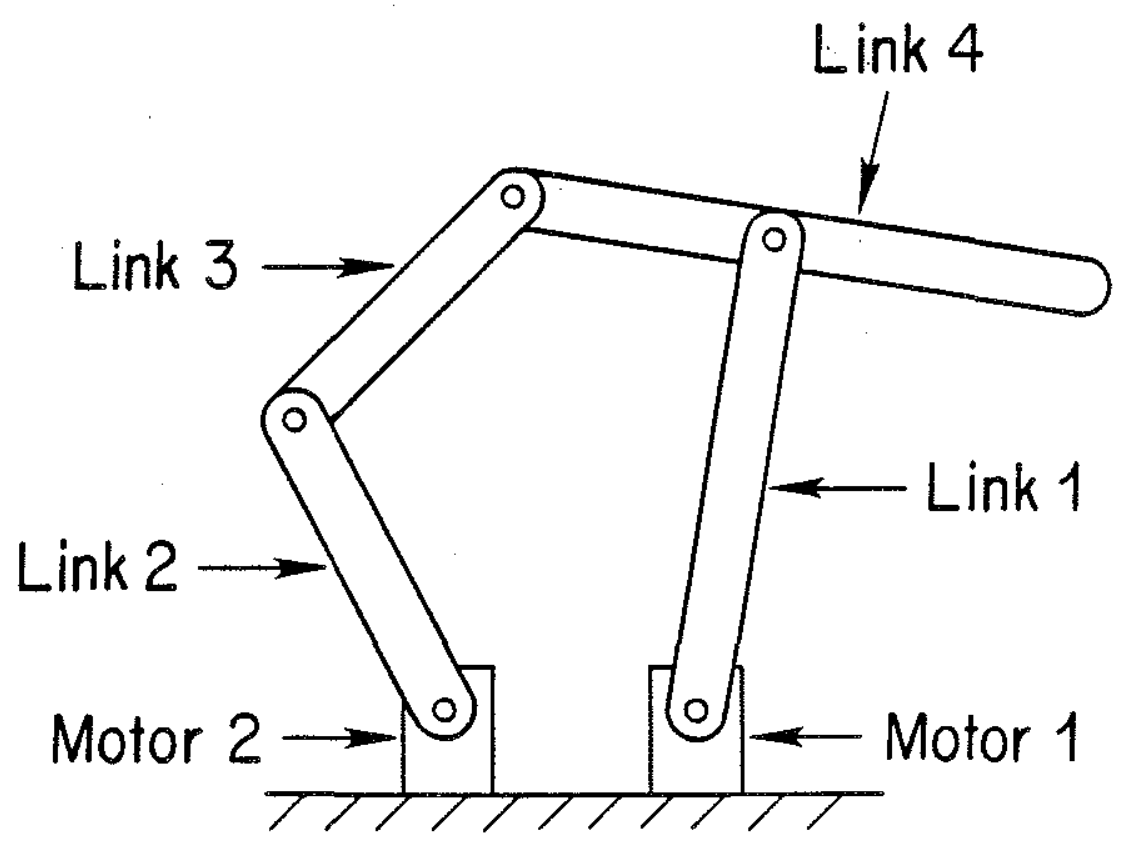

Figure 5.5: Parallel Drive Mechanism 


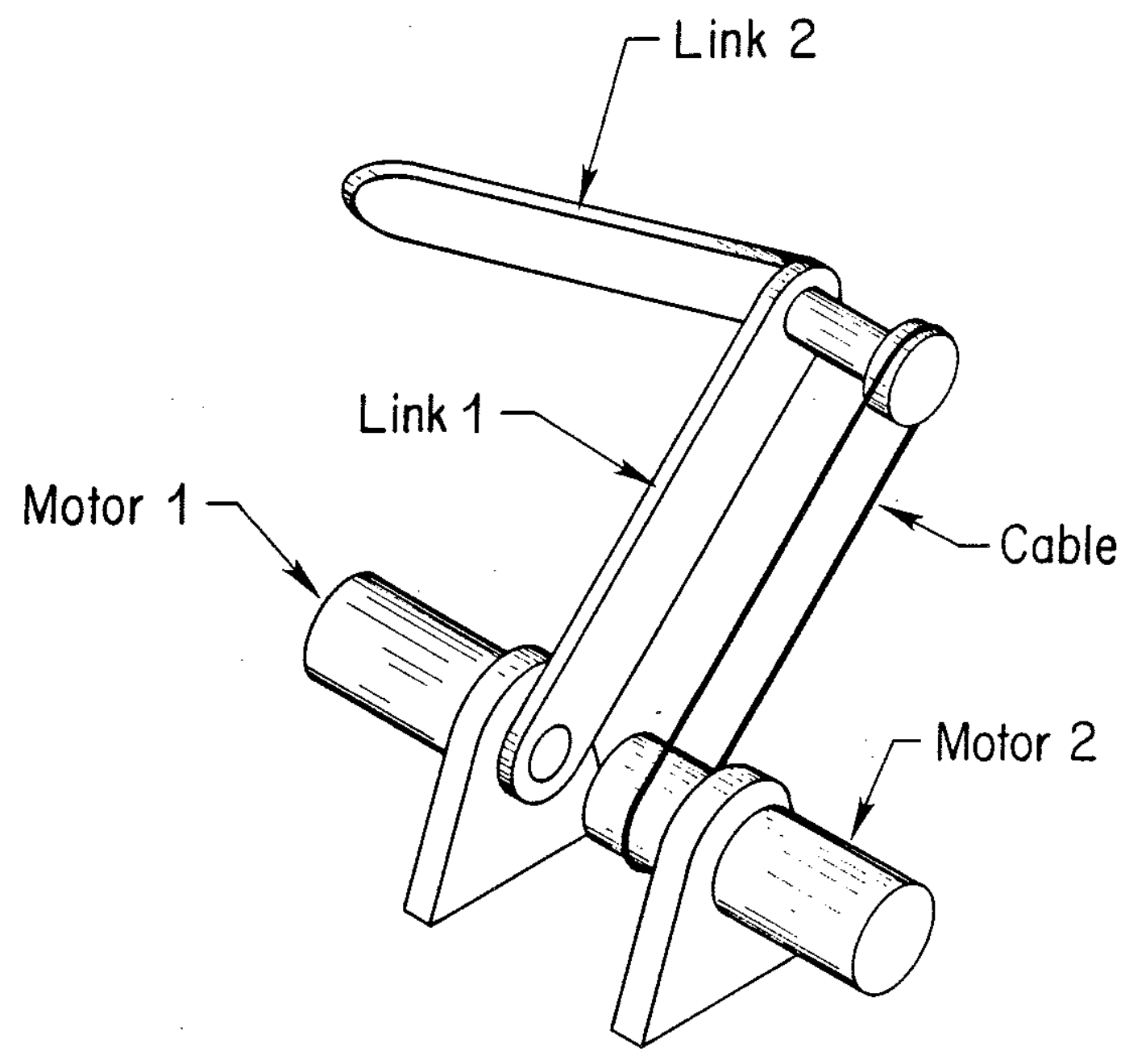

Figure 5.6: Serial Geometry, Parallel Drive 
transmission scheme which has been devised wi]l he discussed in the following section.

To further increase obstacle avoidance capability and reduce added mass affects when accelerating, underwater manipulator links should have a high aspect ratio (long and slender links). This in turn requires that reducers and transmissions be able to fit into a small package with a proper form factor. 


\subsection{REDUCTIONS AND TRANSMISSIONS}

\subsection{General Reduction and Transmission Issues}

Transmissions and reducers are defined as mechanisms which transmit power from one location to another, and mechanisms which alter the ratio of torque to speed, respectively. Often, as in the case of this design, transmissions and reducers may be coincident in the same mechanism. The approach to both transmissions and reducer design has been to produce the most ideal mechanisms possible, in the sense that effects of friction/stiction, backlash, hysteresis, and torque/speed variations of any kind should be minimal. In addition, every effort has been made to make the mechanisms as stiff as possible to ensure accurate positioning and adequate bandwidth. An ideal transmission or reducer provides a direct algebraic correspondance between motor dynamics and joint dynamics (and therefore end-effector dynamics as well), which has several important design implications:

- Motor torque translates directly into forces and moments which the manipulator is able to apply on the environment. As a result, interaction forces and moments can be controlled and monitored at the joint level without the loss of dynamic range often associated with the nonlinearities mentioned above.

- The need for endpoint force/torque sensors is reduced or eliminated by the fact that with an ideal transmission/reduction, the joint torque is a linear proportion of the motor torque/speed. Endpoint forces and torques may therefore be calculated by knowing link lengths and motor inputs.

- The intrinsic backdriveability of the system (which does not lock and has low friction, assuming the reflected inertia is reasonable) provides natural protection against unexpected impact loads at all times. The range of motion of each link was purposedly made large to accomodate this, as mentioned in the kinematics section. This permits stable, graceful reaction even to disturbances which exceed the controllable bandwidth of the system. 
Carefully designed systems composed of flexural memhers riding on pulleys can perform extremely well by the criteria described earlier. The flexural members used in this design are stainless steel cables, although high strength polyethylene fiber braided rope was also experimented with. The remainder of this section discusses the common issues concerning transmissions and reducers, and then discusses the subtleties of both independently.

\subsection{Cable/Pulley Mechanisms}

The idea of using flexural members and pulleys is not a new one. Several methods of using pulleys and flexural members exist. Belt drives rely on a continuous band of material wrapping around at least two pulleys, one the driven and one the drive. With this method, the belt can either rely on friction or teeth to engage the pulley. In the case of cables, which is our interest, continuous circuits are not practical because it is difficult to construct continuous loops of cable. In addition, if continuous loops were possible, they would rely on friction to engage the pulley. This would also be unacceptable, because with the design goal of having no distal output sensors, if the cable slips relative to the pulley, the position of the manipulator will no longer be known. In order to circumvent this difficulty, circuits are constructed using two separate pieces of cable, as shown in Figure 6.1. Each end of each of the two cables is attached to one of the two pulleys.

\subsubsection{Cable Circuit Pretensioning}

Anchoring the cables to the pulleys solves the problem of cable slip, but it does not deal with the problem of taking slack out of the circuit. This can be accomplished in one of at least four ways:

1. Idler pulleys can be used to load one side of the circuit. This method is easy to implement, but requires several added parts and it makes determination of output position relative to input position difficult. 

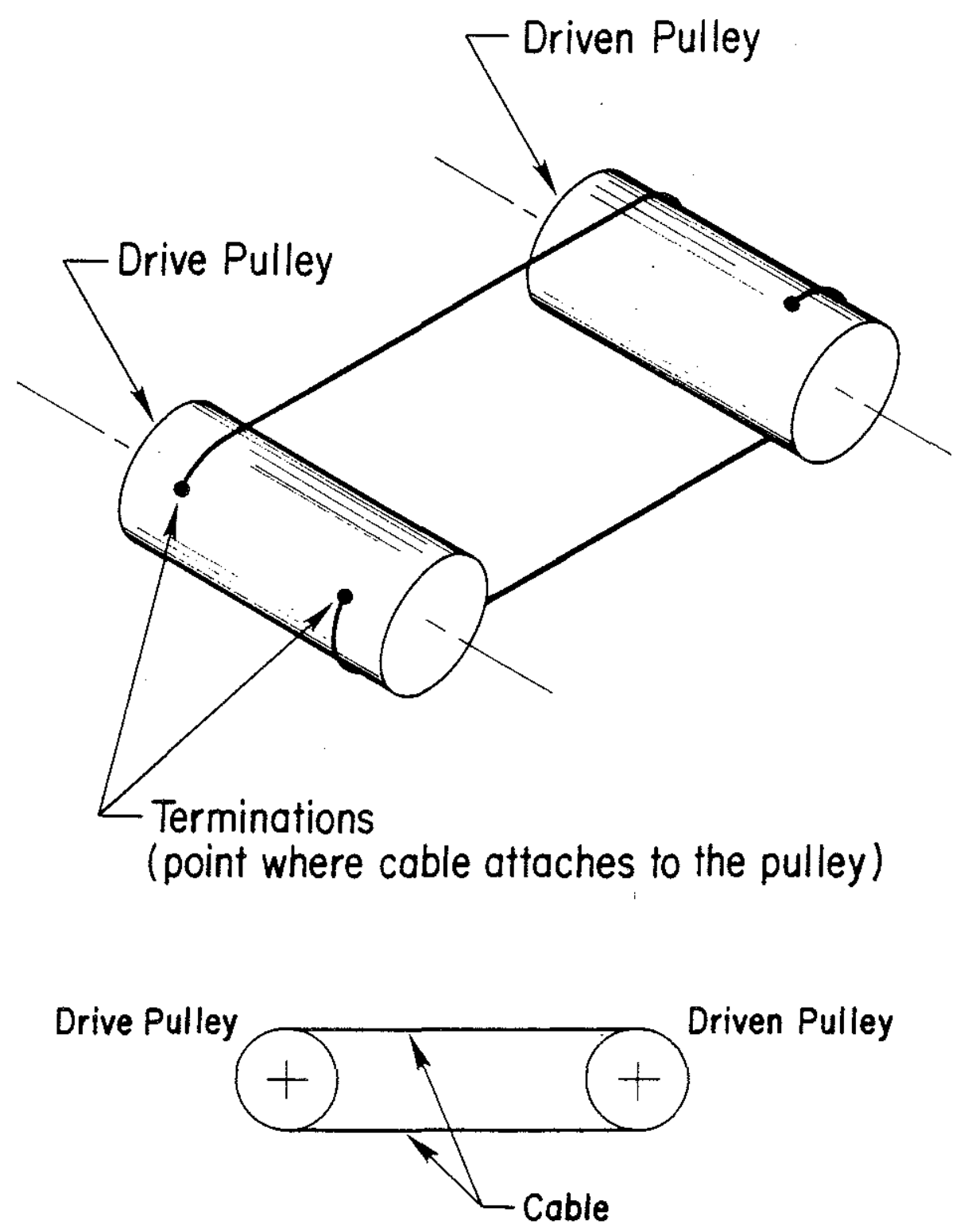

Side View

Figure 6.1: One Circuit Consisting of Two Pulleys \& Two Pieces of Cable 
2. Moveable pulley centers allow one or both of the pulleys to be moved perpendicular to its axis. This method is challenging to implement successfully because both axes must remain parallel after movement.

3. Turnbuckles on the cables or at the termination points could also be used. Turnbuckles on the cables tend to add inertia, are very difficult to wrap around pulleys, and can be difficult to set. Turnbuckles at the point where the cable terminates on the pulley surface are more practical, but tend to occupy in inordinate amount of space.

4. One of the two pulleys can be split as shown in Figure 6.2 , and the two halves turned in opposite directions. If the other pulley is one piece, this will remove slack and allow the cables to be pretensioned.

The last technique listed above was the one employed for this design. By using this design, the slack is removed and a pretension is set in the cable circuit.

Pretensioning the cable circuit effectively doubles the stiffness of the transmission/reduction. This can most easily shown by example. In Figure 6:3, the cables are initially pretensioned to $5 \mathrm{lb}$. each. Assuming the drive pulley is held stationary, when a $10 \mathrm{ft.-1b}$. torque is applied to the driven pulley having a radius of one (1) $\mathrm{ft.}$, the tension in the top cable increases to $10 \mathrm{lb}$. and the tension in the bottom cable decreases to 0 lb. Thus the pretensioned cables act like springs in parallel. The load is effectively shared by the two identical cables, the tension in one being reduced and the tension in the other being increased. The key is that the tension in both cables only changes by half the effective load. If, on the other hand, the circuit were not pretensioned, when the $10 \mathrm{ft} .-1 \mathrm{~b}$. torque was applied, the load in the top cable would go to ten pounds as before, and the bottom cable would remain at $01 \mathrm{~b}$. Ioad (the bottom cable would actually go slack). In this case, however, the change in load experienced by the top cable would be $10 \mathrm{Ib}$. Assuming that the cable can be modeled as a linear spring, we know that for a given cable, a $10 \mathrm{lb}$. change in load will cause twice as much strain change in the cable as a $5 \mathrm{lb}$. change in load. Therefore, for the example given, 


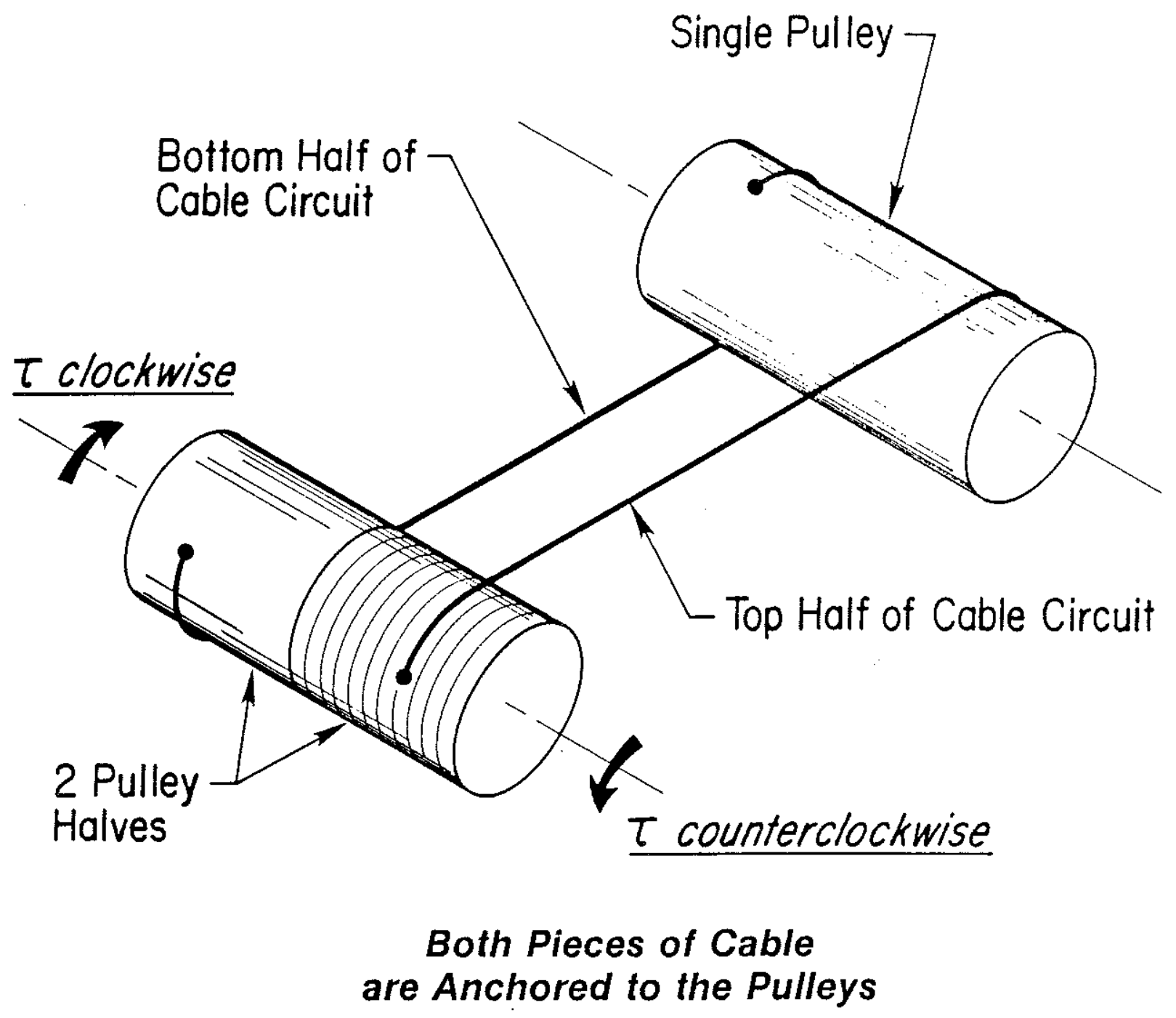

Figure 6.2: Split Pulley Pretensioning Technique 
Stationary
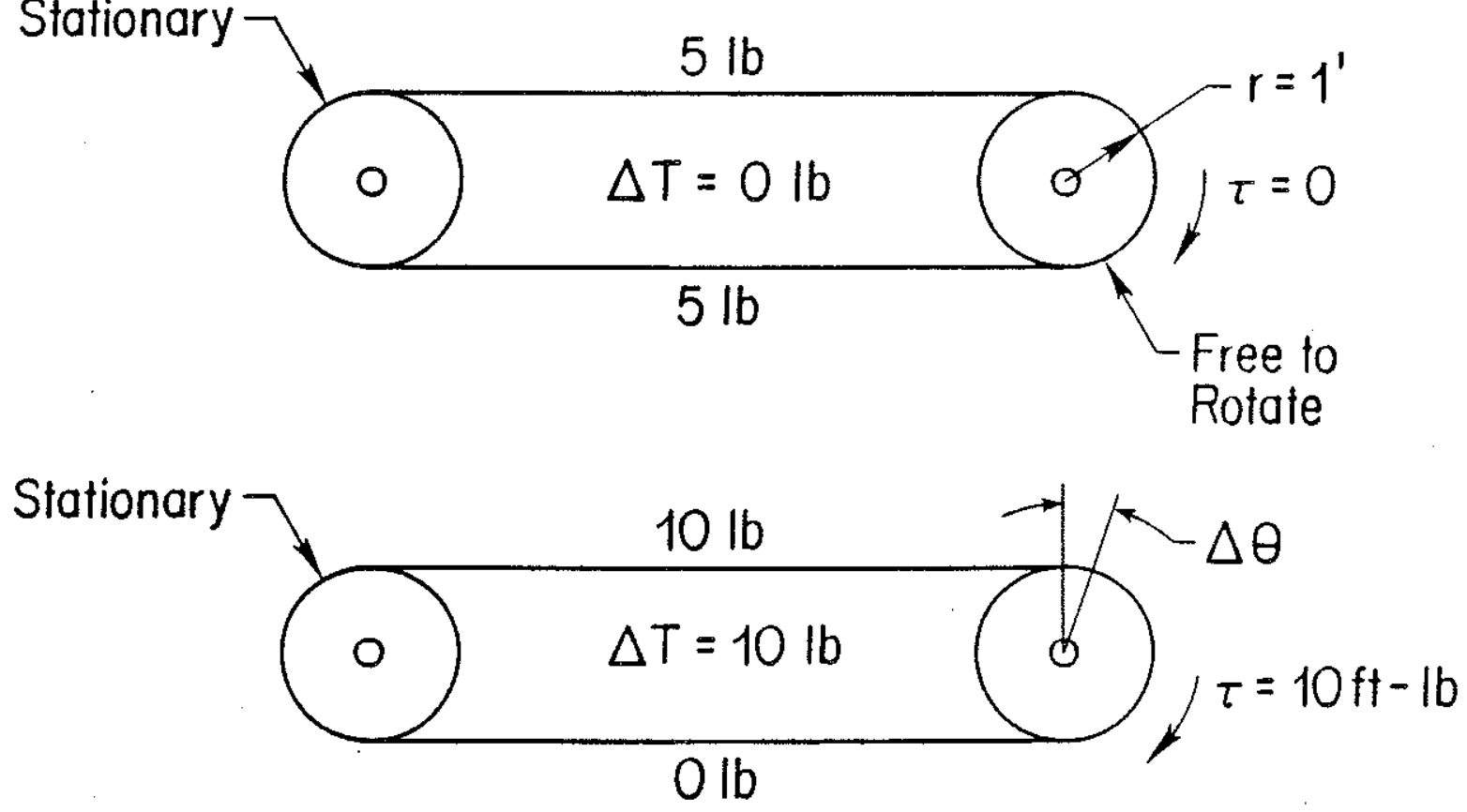

Pretensioned Cable Circuit
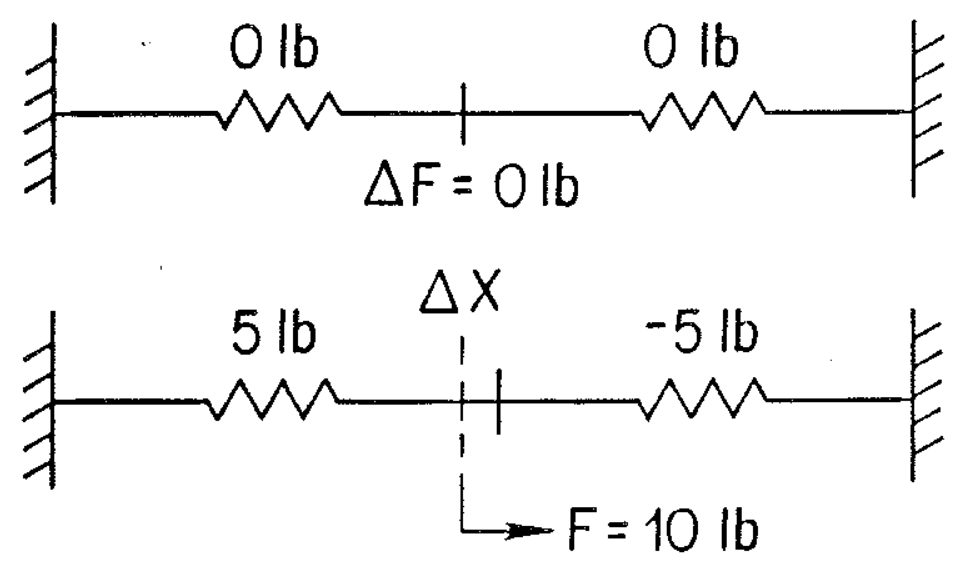

Analogous Springs in Parallel

Figure 6.3: Circuit Stiffness 
the pulley will rotate twice as much when the circuit is not pretensinned as compared to when it is.

To ensure that pretension always exists, the cable should be pretensioned initially to at least half the maximum torque divided by the radius of the pulley to which the torque is applied. In a split pulley design as described above, a torque equivalent to the magnitude of the tension in each cable added together and then multiplied by the radius of the split pulley must be applied to one half of the pulley while the other is held stationary. Another way to look at this is to hold the output pulley stationary and apply torques in opposite directions to each of the pulley halves. Examined from this perspective, the torque which must be applied to each half is equal to the necessary pretension in each cable times the radius of the pulley half.

\subsubsection{Torque Ripple}

When power transmission without torque/velocity ripple is important, as it is in this design, the pulley diameters that carry the cables must be concentric with the axis of rotation of the pulley. If they are not, ripple will be introduced. Ripple is directly proportional to the pretension in the cable, as long as the ripple does not cause one of the cables to become slack. This can be seen by considering a cable circuit consisting of two equal diameter pulleys, with the surface of the drive pulley concentric with its axis and the surface of the driven pulley having a concentricity error defined by $\varepsilon$. In this case, no torque load is applied to the driven pulley, but the cables are pretensioned according to the rules above. The torque ripple magnitude is given by

$$
\tau_{\text {ripple }}=2 \varepsilon \mathrm{T}_{\mathrm{p}} \sin (\theta)
$$

where $\theta$ is the pulley angular position, and $T_{p}$ is the cable pretension (Salisbury, Townsend, Eberman, DiPietro; '88).

\section{2 .3 Stiffness}

For a given cable diameter, axial stiffness is proportional to cable length. The stiffness of a cable/pulley circuit can be 
approximately calculated by dividing the cable into two types of sections: the free length of cable running from pulley to pulley, and the length of cable wrapped on the pulleys. Stretch in a free length of cable is fairly easy to calculate, and is given by

$$
\Delta \mathrm{x}=\mathrm{Tl} / \mathrm{E}_{\mathrm{ce}} \mathrm{A}
$$

where $\Delta x$ is defined as the cable stretch, $T$ is the tension in the cable, and $A$ is the cross-sectional area of the cable. The symbol 1 represents the length of the free section of cable. $E_{c e}$ is the effective Young's modulus of the cable, provided by the manufacturer.

The approximate stretch of the cable as it wraps around the pulley was slighty more difficult to derive. The derivation was done by (Delonga, '88). The resultant equation, showing the elongation of the wrapped cable $\Delta l$, is

$$
\Delta l=[\mathrm{rT} / \mathrm{EAf}]\left[1-e^{-f \theta}\right]
$$

where $r$ is the radius of the pulley the cable is being wrapped around, $f$ is the coefficient of sliding friction, $\theta$ is the angle measured in radians between the point of tangency of the cable and the pulley, and the point where the cable terminates on the pulley. In the case of multiple wraps, $\theta$ may be greater than $2 \pi$.

Stiffness is also affected by the type of cable circuit used. At least two possibilities exist: the standard loop and the "figure eight," both shown in Figure 6.4. When two pulleys are close together, the "figure eight" circuit can significantly reduce the amount of free cable length. Decreasing this length improves transmission/reducer stiffness. The figure eight pattern has the disadvantage of introducing what is known as reverse bending. Reverse bending occurs when a cable is wrapped in different directions on each pulley. This may reduce fatigue life. but since no empirical data has been found to support this, many of the cable circuits used in the manipulator design are of the figure eight type (Wire Rope Users' Manual, '81). Standard loop circuits were also used, primarily on lower stages where stiffness was less important. 

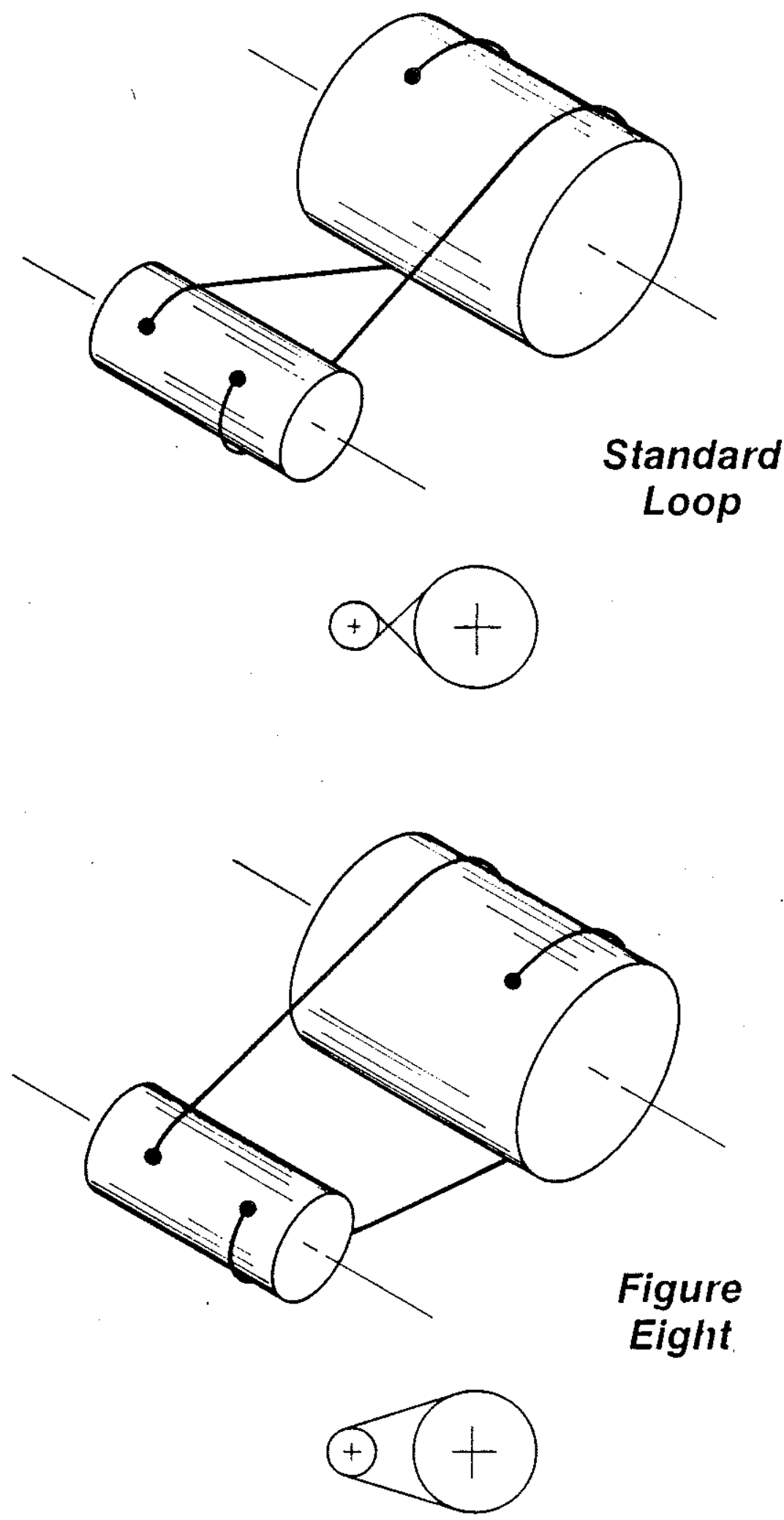

Figure 6.4: Cable Circuit Types 


\subsubsection{Friction and stiction}

(Townsend and Salisbury, '87) have identified three types of friction in cable/pulley mechanisms--cable-stretch friction, pulley/cable interface friction, and bearing friction. The first, identified as a Coulomb-type friction, produces the following power loss:

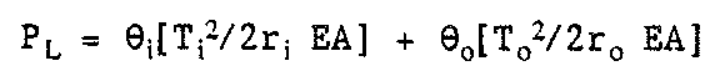

Subscript o represents the output pulley and the subscript $i$ represents the input pinion. $T$ represents torque at each pulley, $\theta$ symbolizes angular velocity, $r$ represents pulley radius, $E$ is the symbol for Young's modulus of the cable, and A reflects the cable area. The effects of these losses on efficiency are discussed in Section 6.3. (Salisbury, Townsend, Eberman, and DiPietro, '88) state that recent experiments at NASA/JPL on cable/pulley friction caused by lateral cable compliance show this friction to be stiction-like and proportional to cable tension.

Every effort has been made to reduce the friction and stiction in the bearings. Only roller-element bearings were used. Bearings of this kind have stiction and friction properties which are proportional to bearing load. Empirical data on bearing friction/stiction is readily available from bearing manufacturers.

\subsubsection{Cable Properties}

Before discussing the specifics of reducers and transmissions, a few of the specifics of cable construction and behavior must be mentioned. Load carrying cables are very complex mechanical elements that are not yet fully understood. The intent of this discussion is only to mention those issues which have a direct impact on this design. (The Wire Rope Users Manual should be consulted for a complete explanation of these issues.) Modern steel cables (also known as wire ropes) are constructed as shown in Figure 6.5. The three basic components of a cable are the individual extruded wires, the strands, and the core; both of the latter being composed of wires. The wires are all wrapped together in a similar helical pattern (known as the "lay") to form the strands, and the strands are then also wrapped in similar helical patterns to form the outer part 


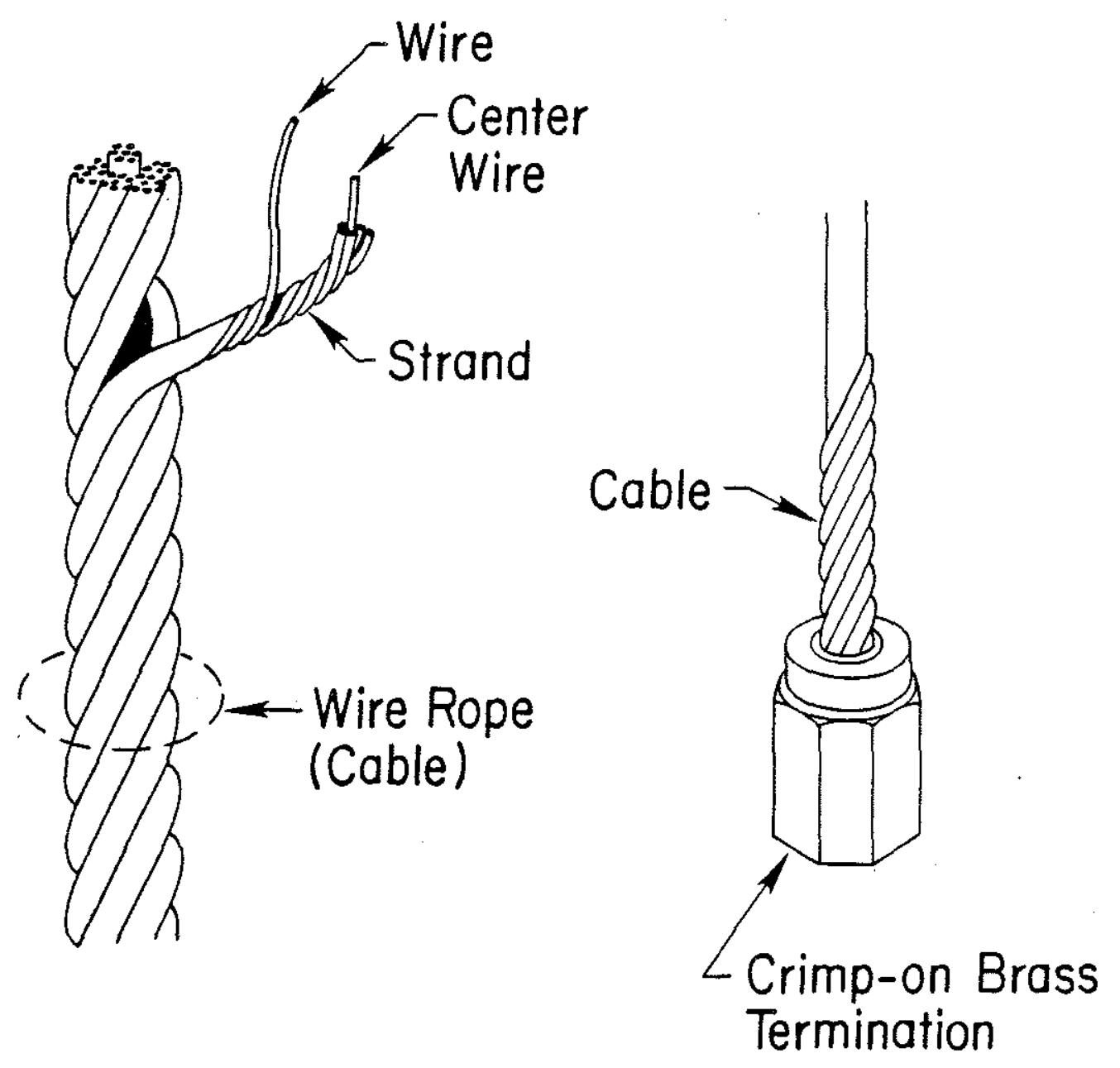

Figure 6.5: Cable Construction and Termination 
of the rope. The type of strand lay gives the cable its name, i.e. left lay cable has the outer strands wrapped with a left-hand lay. In order to torque balance the cable, the inner core is wound with a lay pattern opposite to the lay of the outer strands. Cables can be manufactured with both the wires and the strands wound in either a right or left hand lay.

Resistance to bending fatigue is an extremely important property, and one which has kept otherwise well executed designs from being successful. The temptation to conserve space by running cables over pulleys which have too short a radius of curvature is great, but can have catastrophic affects on cable fatigue life. In general, increasing the number of wires in a cable of given nominal diameter (by reducing the individual wire diameters) will increase the resistance to bending fatigue. Unfortunately, abrasion resistance will be reduced by an approximately equal amount. The fact that in this design, all the cable/pulley transmissions and reducers will be run in an oil bath should reduce cable abrasion.

Cable strength is also affected by pulley radius. Sava Industries, the manufacturer of the stainless steel cable used in this design, provided the information in Table 6.1.

Table 6.1: How Pulley Diameter Affects Cable Strength

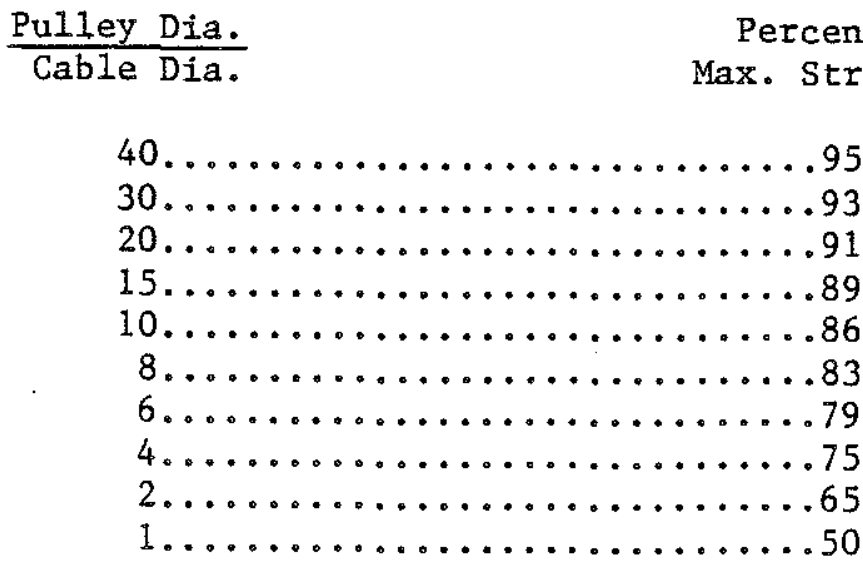

Provided by SAVA INDUSTRIES, INC. 
In light of the strength and fatigne issues, bends tighter than 15 times the cable diameter have been generally avoided. This was considered a reasonable compromise, especially since the cables would be operating in the extremely "pleasant" environment of an oil bath.

How the cable is wrapped on the pulley (assuming the pulley is without grooves, which all the pulleys in this design are) determines how much axial pulley surface the cable will occupy. Cable should be wrapped on the pulley in a lay which is opposite the lay of the cable. For example, a right hand lay cable should be wrapped on a pulley with a left hand lay; if it is not, the cable will tend to spread out along the pulley surface (see Figure 6.6). In the case of "figure eight" circuits, following this rule on both pulleys is not possible. Experience has shown that as long as wrapping on the smaller diameter pulley (all pulley circuits in this design have dissimilar diameter pulleys) follows the rule above, wrapping will take up the least amount of space.

Cables in tension tend to squash, as portrayed in Figure 6.7. Tests showed that within the operating limits of the cable, the width of the cable increased by no more than $7 \%$ (Townsend, ' 88 ). Adequate space on the pulley surface must be allowed for this effect.

Finally, cable coatings must be considered. Cable may be coated with a number of plastics, some of the more common ones being teflon and nylon. Experiments with coated cable showed that under load the coating compress and therefore the effective pulley radius changes. This is unacceptable because it introduces torque and velocity variations. In addition, the steel cable tends to cut through the coating when wrapped at high tension on pulleys. Only uncoated, $7 \times 19$ stainless steel cable is used in the transmissions and reducers of the manipulator.

\subsection{Reducers}

Cable/pulley reducers are based on running cable circuits around dissimilar diameter pulleys. The reduction ratio is determined by adding the diameter of the large pulley to the diameter of the cable (which would be known as the pitch diameter in gears) and dividing this quantity by the sum of the small pulley diameter and the cable diameter. If this ratio is represented by $\mathrm{N}$, and the desired number of rotations of the large pulley 

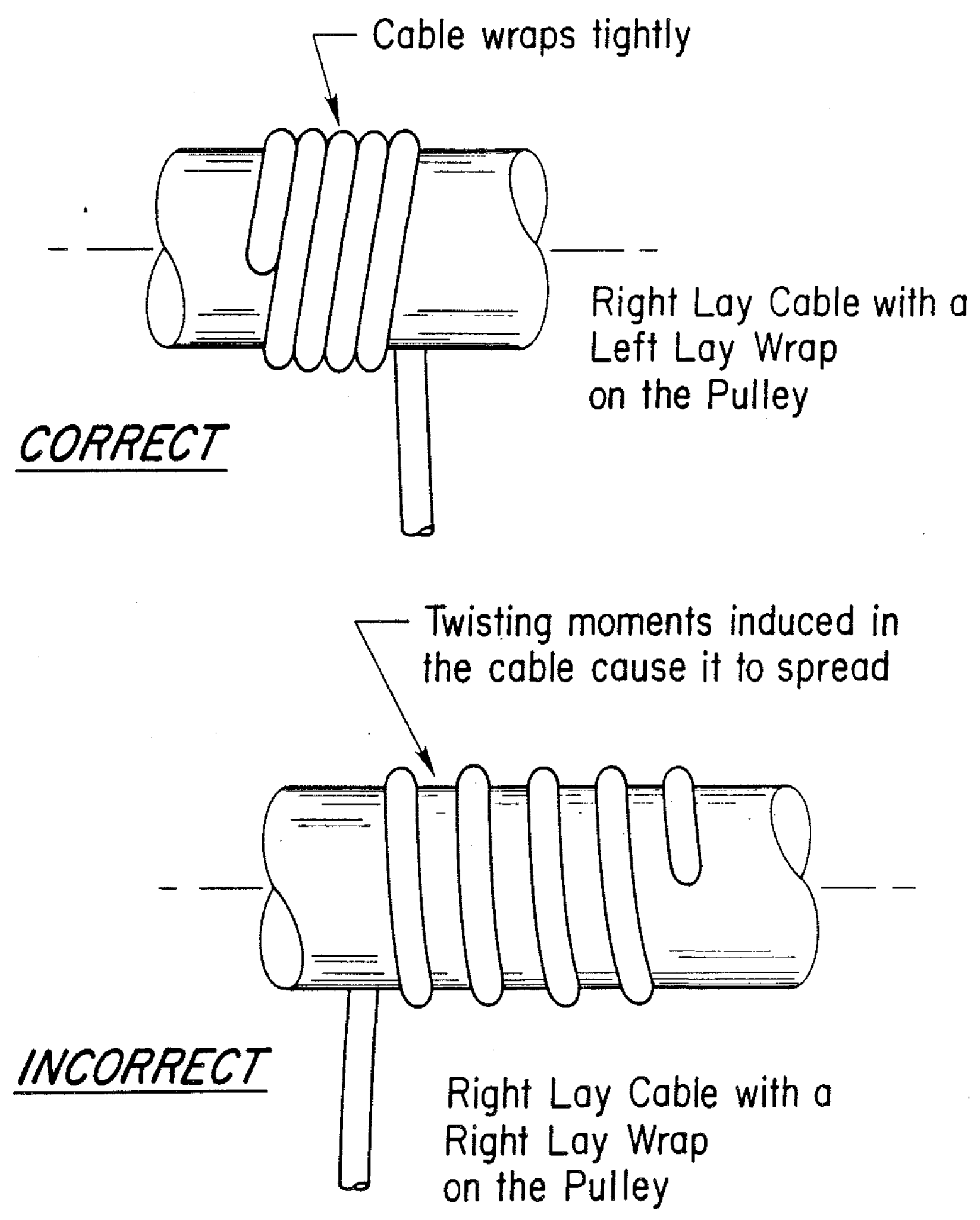

Figure 6.6: Cable Wrapping 


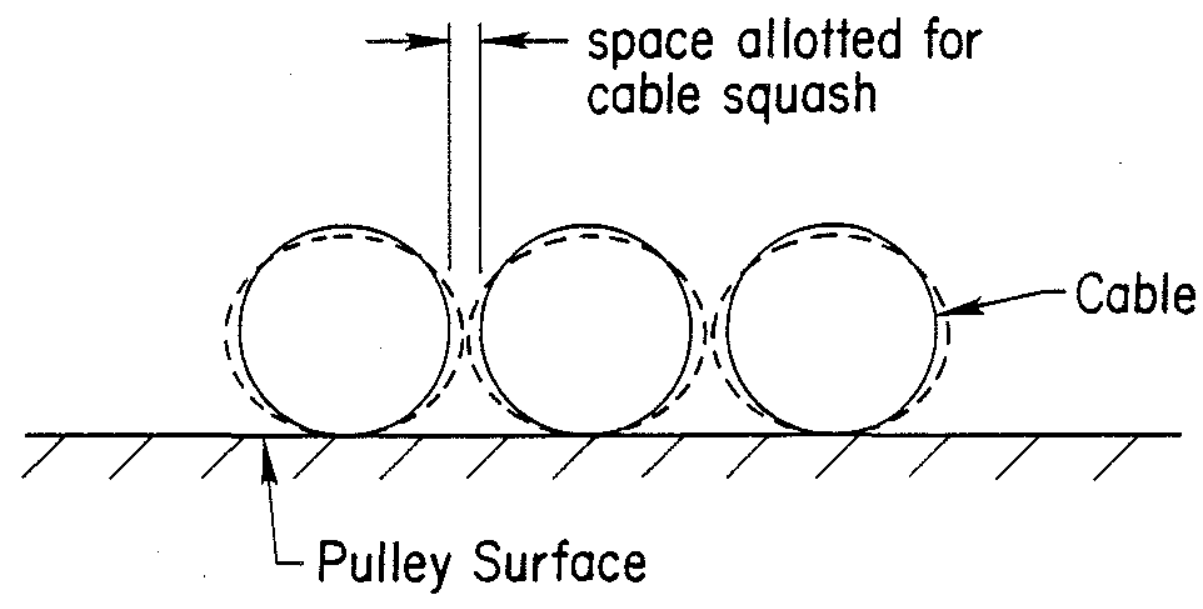

Figure 6.7: Cross-Section of Cables on a Pulley, Showing Cable Squash 
is represented by $\tau$, then the small pulley must be able to accept $N \tau$ wraps of cable. The axial length on the pulley surface, L, occupied by this amount of cable is given by

$$
L=(N \tau+1)(1+s) d
$$

where $d$ is the cable diameter and $s$ is a safety factor, usually less than 0.1 to account for cable squash under tension. The 1 added to the first quantity is based on the fact that one or more wraps will occupy at least two cable widths of pulley surface. The formula above assumes a loop type of cable circuit, as depicted in Figure 6.4. With this type of circuit, virtually all of both pulleys are covered by cable at all times. Figure eight circuits require twice as much axial pulley area because area used to wrap the top half of the circuit can not be used to wrap the bottom half of the circuit. This is done to avoid rubbing between the two halves of the circuit at the cross of the "eighto"

Both pulleys of any reduction must be the same width (axial pulley length) because the pitch angle on both pulleys must be equal. This means that if the cable on the small pulley wraps tightly, the cable on the large pulley will have $\mathrm{N}$ cable diameters between wraps. Figure 6.8 shows the relationship between cable wrapping on the small pulley and cable wrapping on the large pulley of a $3: 1$ reducer. The figure depicts half of a standard loop cable circuit.

Choosing the proper motor-reducer-transmission system is a difficult task, which has often been made to appear simple by reducing the number of variables influencing the decision. Optimizing a system about one or two figures of merit such as impedance match or power rate may be a good idea if the machine is designed for a very specific set of tasks, and issues such as size, aspect ratio, or environmental constraints are unimportant or missing entirely. In the case of manipulators designed to operate from remote platforms in unstructured environments, the number of variables which impact the selection of an actuator package makes an analytical optimization very challenging. None was executed for this design.

In selecting the reducer, the most fundamental question was what the reduction ratio should be. Three reducers are necessary, one for each of the axes. The motors for all three axes were to be identical (although 


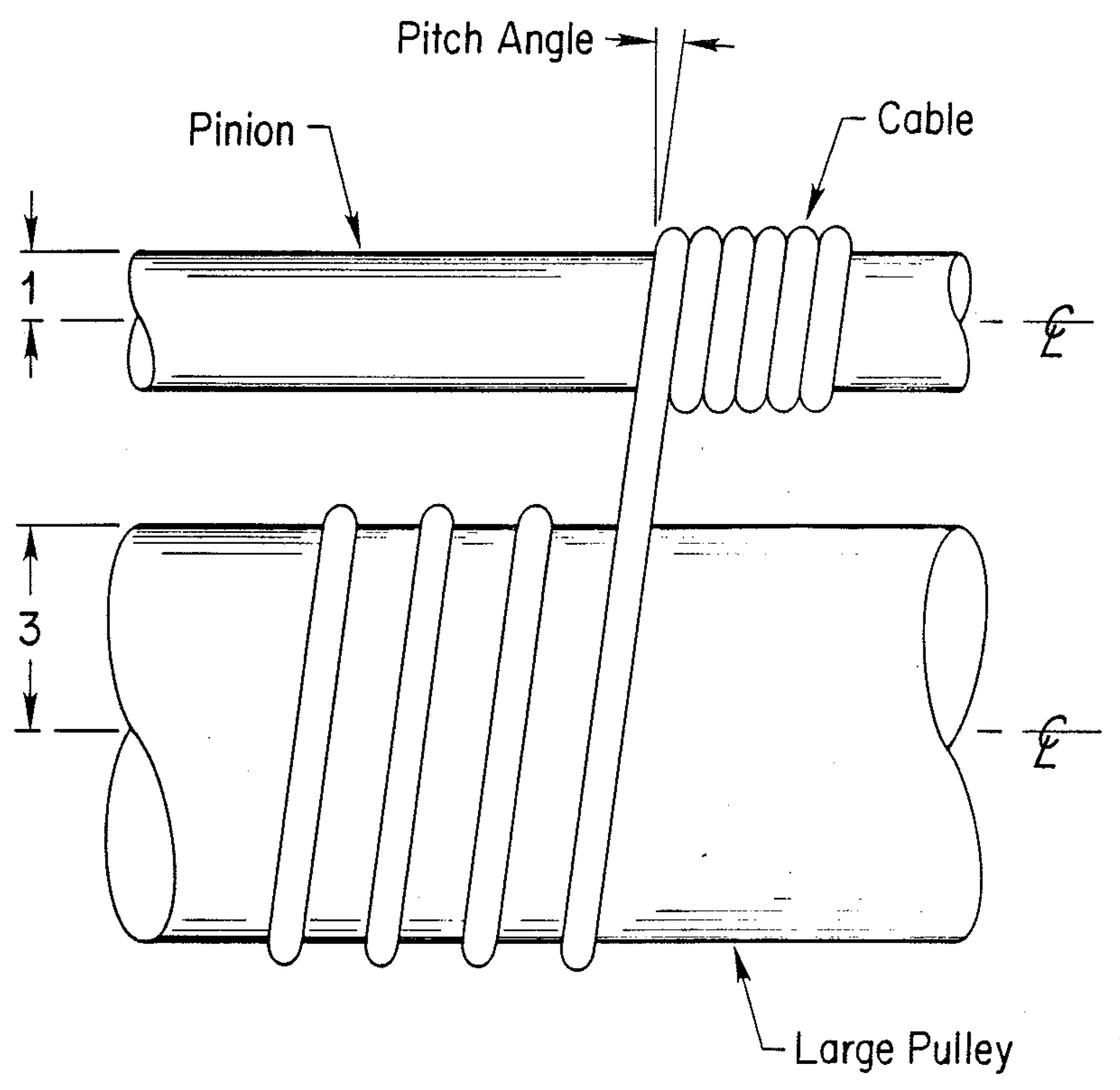

Figure 6.8: Cable Wrapping (half the loop of a 3:1 Reducer is shown). Pitch angle remains the same on both pulleys. 
their exact specifications were determined in conjunction with the reducer/transmission design), making them a common departure point for development of the reducers to complement them. Reduction ratios of $30: 1$ at both shoulder joints and 13:1 at the elbow joint were selected. These numbers, while somewhat arbitrary in exact magnitude, were based largely on the need for backdriveability, limited complexity, fairly small size, and high positional resolution with only the motor sensors.

Low reductions, or even direct drive, can meet all the criteria presented above, except that mounting the large and heavy motors necessary for this type of actuation package is impractical on links more distal than link one. Cable reductions significantly higher than $30: 1$ require large amounts of space and/or a large number of parts, and begin to lose backdriveability and efficiency. Perhaps the largest component of efficiency is lost due to viscous drag losses of the motor and pulleys moving in an oil bath. This loss mechanism operates as a square of the velocity, making the high speeds necessary in a high reduction reducer impractical.

Upon selection of the reduction ratio, the designer must determine how it is to be executed, i.e. how many reduction stages are desirable. Size and aspect ratio, stiffness, efficiency, and complexity, in that order, were identified to be the important parameters. Developing a cost function incorporating the many variables involved would have been one possible way of addressing this optimization problem. This approach was not taken because, in addition to potentially being very time consuming, it often relies on making marginal assumptions, and invariably must leave out certain variables which are difficult to quantify yet may be very important to the overall decision. In the following paragraphs, the issues affecting each of the parameters will be discussed and finally the decision which was reached will be evaluated.

Size (perhaps better defined as volume occuppied) and aspect ratio are closely coupled. Both are influenced by pulley diameter, cable size, mimimum bend radius of the cable, and mechanical issues such as cable terminations, bearings and their mounts, structural properties, easily manufactured shapes, access panels, and seals. The objertives vere to minimize the occuppied volumes and make those volumes ones which could conveniently be enclosed by rectangular housings. Rectangular housings having height to width aspect ratios approaching unity, and width/height 
to length aspect ratios less than four were desired (see Fifure 6.9). Shapes of this type would have similar bending stiffnesses in all directions and would avoid large differences in directionally dependent added mass and drag effects. Rectangular shapes are also easy to manufacture and seal.

The number of stages necessary in a reducer to obtain a given reduction ratio is determined by the difference in pulley diameters. The maximum diameter of the small pulleys is determined by the type of cable being used, according to the rules enumerated in Section 6.2. The diameter of the large pulleys dictates the height of the reducer. Assuming output torque is known, the strength of the cable necessary to support the load is calculated by dividing the output pulley radius by the load torque. A safety factor of at least four should be used. Cable strength, for a given type of cable, is based on cross-sectional area. Cross-sectional area increases as the square of the cable radius, and linearly as a function of the number of cables used in parallel. Using relatively smaller diameter parallel cables instead of a single cable of greater diameter. allows a smaller pinion pulley to be used (based on the minimum bend radius criteria), but requires a greater pulley width to accomodate the larger number of cables. Cables in parallel alway occupy more width than a single cable capable of carrying the same load because the larger diameter cable has a higher diameter to cross-sectional area ratio than the combined set of parallel cables. The fact that smaller diameter cables can be wrapped over smaller pinion pulleys means that the reduction ratio accomplished in one stage is greater. Depending on factors such as available cable sizes, minimum reasonable pinion diameter, space necessary to allow for cable terminations, and clearance between pulleys, this can mean that fewer stages will be necessary to achieve a desired ratio. Fewer stages means shorter reducer length, assuming a linear pulley arrangement. Giving a formulaic rule describing the tradeoff between reducer width and length is difficult for the reasons mentioned, but generally speaking, reducer length is inversely proportional to width, for a given output pulley diameter.

Increases, in reducer height allow several major advantages. Greater reducer height corresponds to greater output pulley diameters, which correlates with significant improvements in joint stiffness. Joint 


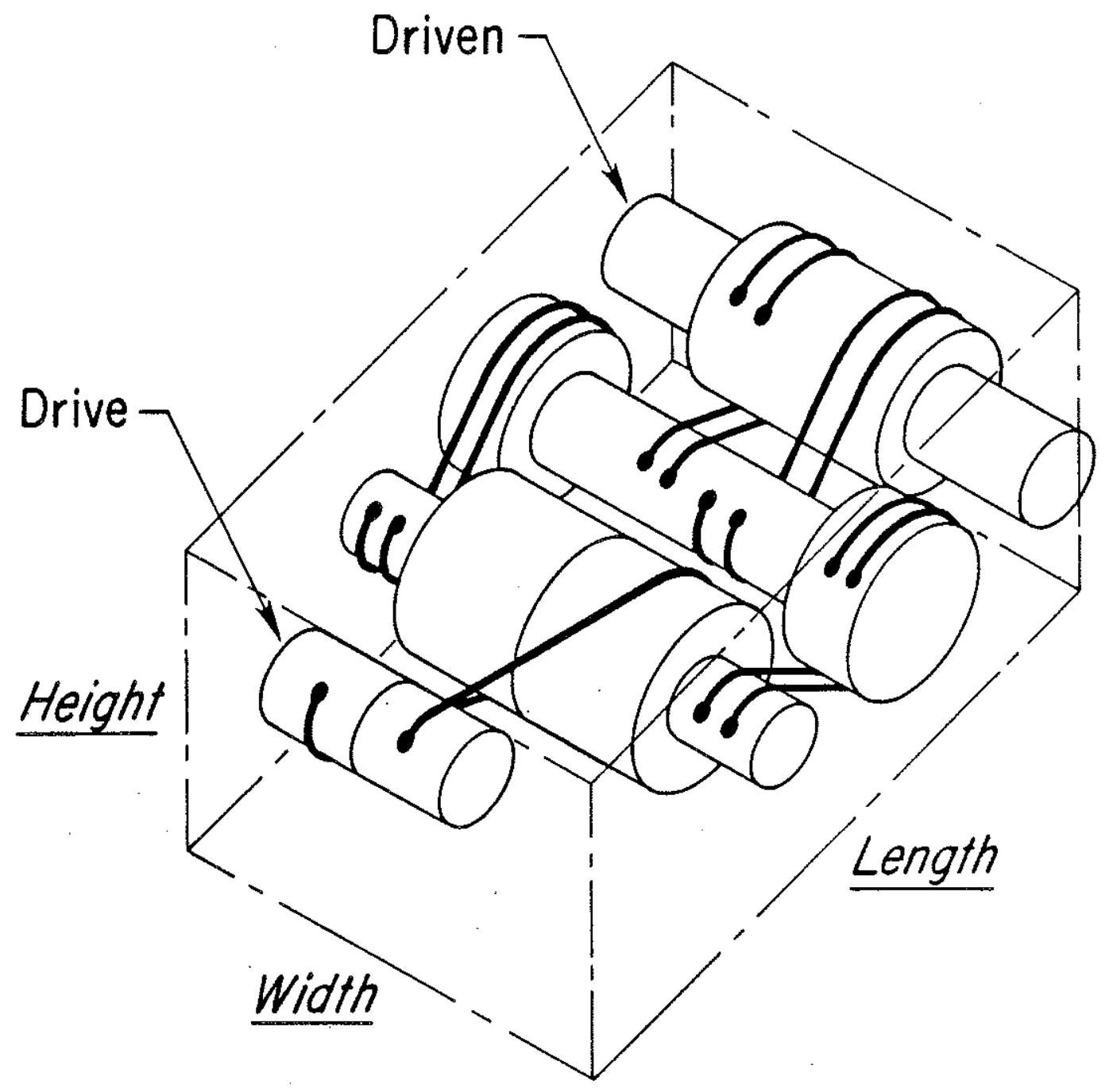

Figure 6.9: The Basic Volume Occupied by a 3-Stage Reducer 
stiffness, based on a single, pretensioned reduction stage, is described as follows:

$$
\mathrm{K}=2 \mathrm{EAR} \mathrm{R}^{2} / 1
$$

where $E$ is the effective Young's modulus of the cable, $A$ is the cable cross-sectional area (can be that of several cables in parallel) and $R$ is the radius of the output pulley. The symbol 1 represents the free length of cable between the pinion and output pulley, which for the sake of this discussion will be assumed constant for all reducers having pulleys located immediately next to each other. This relation clearly shows the stiffness benefits derived from larger pulleys. For example, compare two possible output pulleys, one having twice as great a diameter as the other. Two approaches are reasonable. The same diameter cable can be used for both applications, obtaining a four-fold increase in stiffness from the small pulley to the large. Or, the cable stress can be kept constant and the cable cross-sectional area reduced by a factor of two. For the latter option, the stiffness of the system with the large pulley will be only twice as great as the system with the small pulley, but a smaller pinion pulley can be used, due to the smaller cable diameter. This in turn may mean that fewer stages will be necessary, thus making the reducer fairly short. If an increase in width is permissable, several cables can be used in parallel on the larger pulley, thus keeping stiffness as high as if a single larger cable were used.

Stiffness considerations indirectly affect the choice of the number of stages to be used in the way they have impact on the choice of output pulley diameter, as discussed above. The desire for high stiffness also affects how many stages should be used in a more direct way. Effective joint stiffness, $K_{j}$, for a multistage, pretensioned reducer is governed by the relation

$$
K_{j}=R^{2} K_{o} K_{p} N^{2} /\left(K_{o}+K_{p} N^{2}\right)
$$

where $K_{p}$ represents the equivalent cable stiffness of all successively lower stages, $K_{0}$ represents the cable stiffness of the output stage. and $N$ represent the linear speed reduction BETWEEN stages one and two (this should not be confused with the rotary reduction at each stage). $R$ is the output pulley diameter. This relation shows that the difference between 
the pinion of the output stage and the large pulley of the next stage (which is attached to it), should be as large as possible. (The equation applies for all successive stages, but for simplicity, only the first two stages have been discussed here.) This is accomplished by having fewer number of stages for a given overall reduction ratio.

Efficiency considerations support the supposition that the number of stages should be minimized. A thermodynamic control volume analysis of a cable/pulley circuit, (Townsend and Salisbury, '87) found that these mechanisms cannot approach perfect efficiency. Friction losses in the form of cable/pulley slippage must exist. Overall efficiency, $n$, for a multiple stage reducer having equal cable stress in each stage, can be no greater than

$$
n=[1-(\Delta T / E A)]^{n}
$$

where $E$ is the effective Young's modulus of the cable (assumed the same for all cables in the circuit), $A$ is the cross-sectional area of the cable, $\Delta \mathrm{T}$ is the difference in cable tension between the high and low tension sections of cable in any one of the circuits. As stated, $\Delta T / A$ is constant for all stages. The symbol $\mathrm{n}$ represents the number of stages in the reducer. This function indicates that multi-stage reducers should be avoided if possibie. As shown in the example above, this is not always feasible.

The last parameter of importance is complexity. As the number of stages grows, so does mechanical complexity. The increase was generally reasoned to be fairly linear. Each additional stage requires more bearings, shafts, and pieces of cable. More parts mean more cost and more difficult and time-consuming maintenance.

After considering the factors above, and developing several options, a three stage reducer was designed for the two shoulder joints, and a two stage reducer was designed for the elbow joint. The shoulder reducers, one of which is shown in Figure 6.10, are identical. The photograph shows the reducer for joint two. At the top of the picture, inside the housing, is the drive pinion. The output torque tube for joint two is at the bottom of the housing. Four parallel cable circuits are used on the output stage, two on the intermediate stage, and only one on the drive stage. The elbow reducer is coupled with a transmission, which 


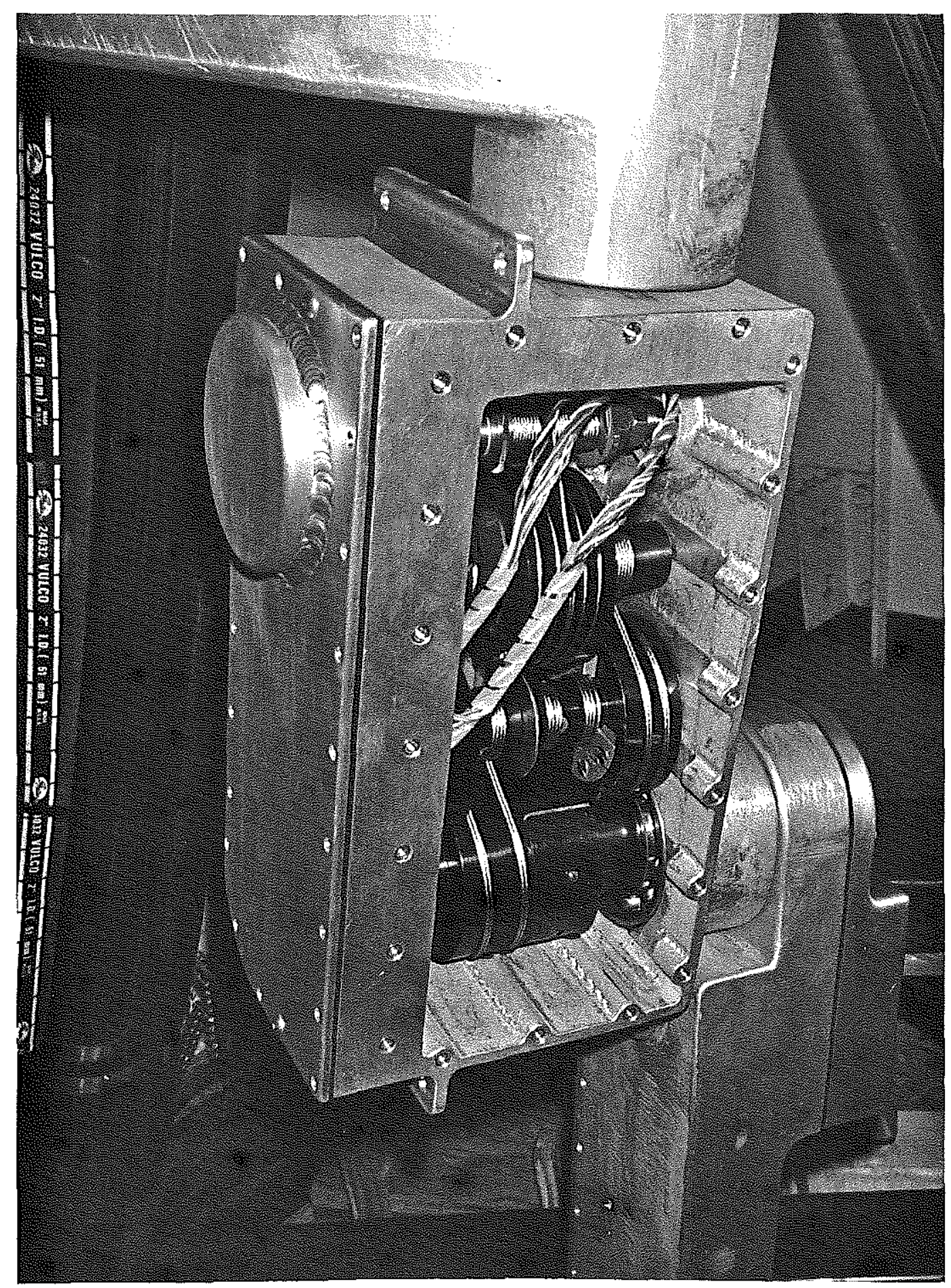

Figure 6.10: Transmission/Reduction Driving Link Two 


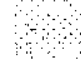

a 
will be discussed in the following section. Two parallel cable circuits are used on the elbow reducer's output stage, and a single circuit is used on the drive stage. Tensioning of all cable circuits in each reducer is done at the drive pinion.

Cable stress is approximately equal in the cables of a given reducer. In the case of parallel cable circuits, a tension equalization scheme similar to the one shown in Figure 6.11 is used. A single piece of cable is used for each half of the cable circuit. It wraps back and forth between two pulleys to provide the effect of several cable in parallel. For example, one of the cables on the output stage of the shoulder reducer starts on the pinion, runs over to the output pulley, loops back to the pinion, loops again and returns to the output pulley, and finally returns to the pinion and is terminated there.

\subsection{Transmissions}

of the three joint drives, only the one for joint three requires a transmission. Gravity issues played an important part in the design of link two. Proper weight placement in this link had direct impact on the manipulator's payload capacity. The easiest way to reduce the gravity moment on joint two was to place the motor for joint three as close as possible to joint two, within link two. Placement of this motor near joint two, and thus distant from joint three, may seem to introduce long, compliant sections of cable which reduce the joint stiffness. This deficiency can be largely overcome by the judicious placement of the reducer. Torsional joint stiffness, $k_{j}$, is governed by the equation

$$
K_{j}=2 \operatorname{EAN}^{2} R^{2} /[x(1-N)+N I]
$$

where $\mathrm{E}$ is the effective Young's modulus, $\mathrm{A}$ is the cross-sectional area of the input stage cables, $N$ is the reduction in linear cable velocity between the input and output stages, 1 is the distance between the motor and the joint, and $x$ is the distance from the motor to position of $N$, as diagramed in Figure 6.12. This equation is predicated on the assumption that the stress in the input and output stage cables is the same. This is roughly true in the actual system, being limited only by the availability 

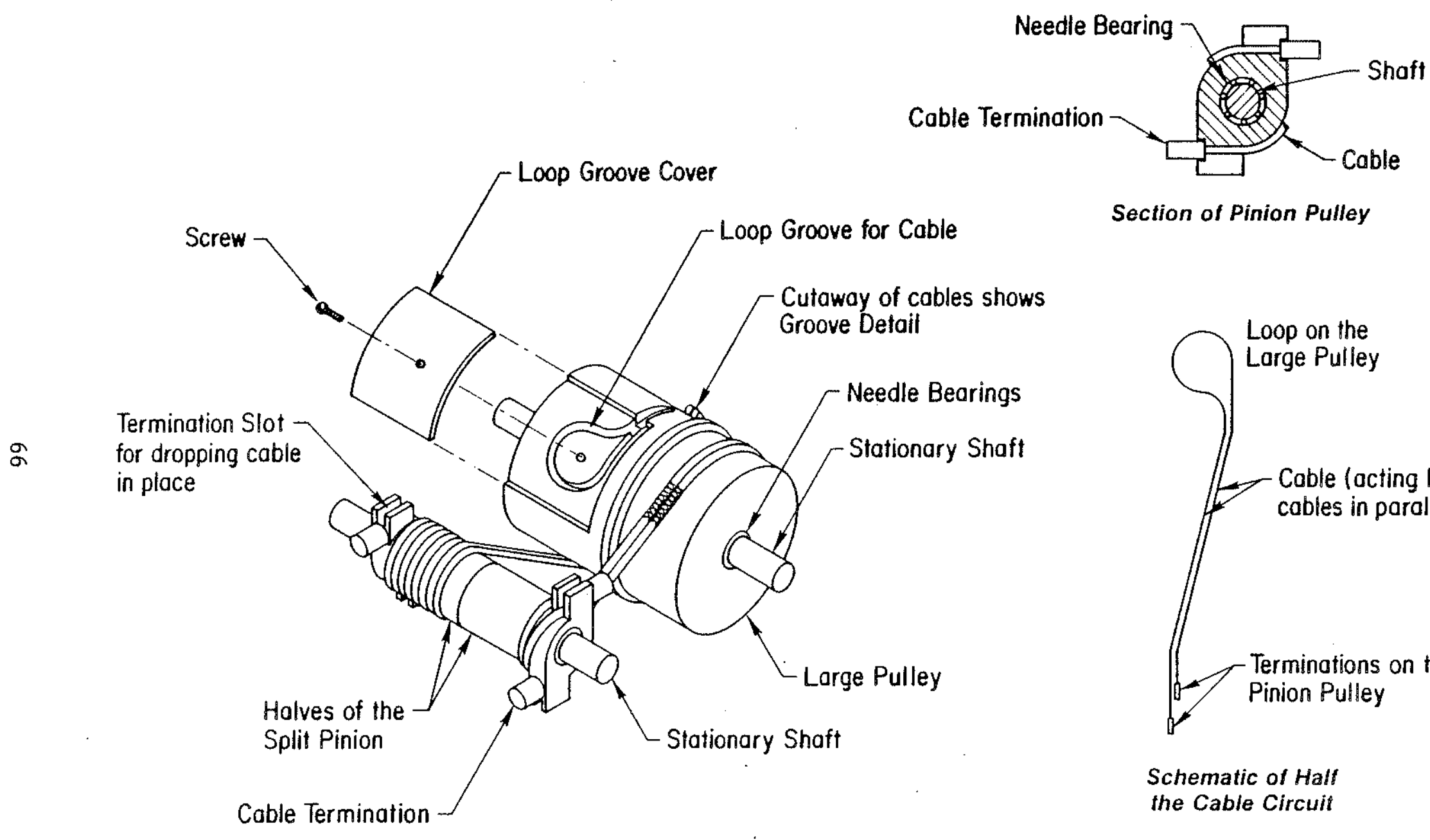

Section of Pinion Pulley

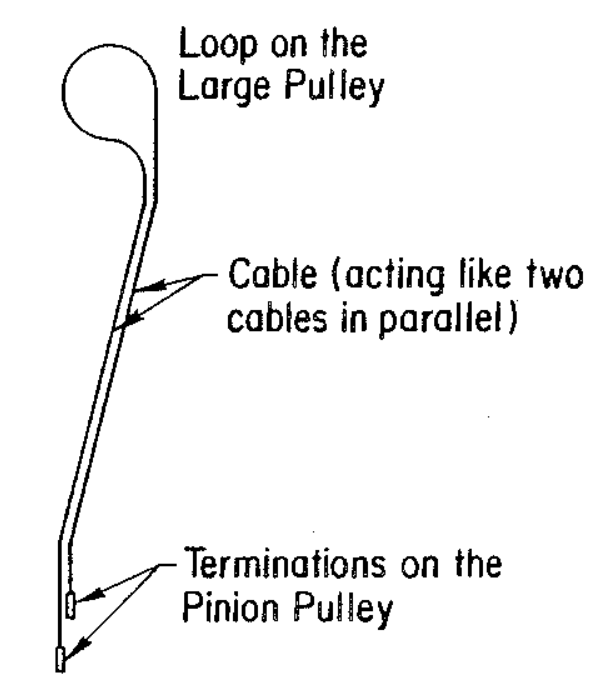

Schematic of Halt the Cable Circuit

Figure 6.11: Typical Reducer Stage Having a Couple of Cables Acting Like a Set of Two Cables in Parallel 

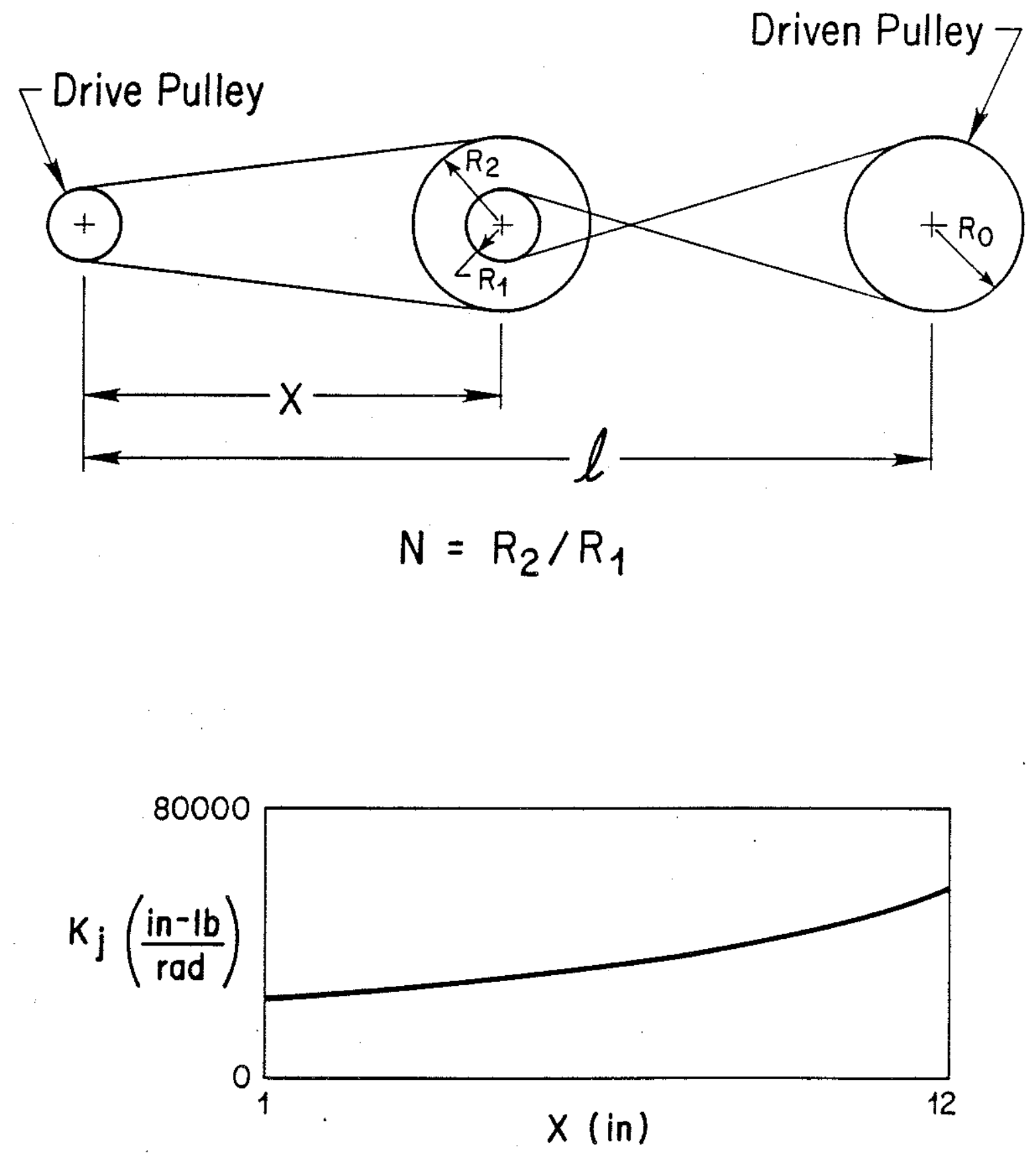

Figure 6.12: Stiffness as a Function of Reducer Position 
of discrete cable sizes. Therefore the cross-sectional area of cables in the output stage is $\mathrm{N}$ times the cross-sectional area of cables in the input stage. The equation reflects this fact. To maximize stiffness, the reducer should be placed as close to the joint as possible.

The gravity torque loading avoided by placing the motor near joint two was considered more important than the minor stiffness losses induced by the long transmission cables. As shown in Section 6.3, joint stiffness is strongly dominated by the stiffness of the final reduction stage.

\subsection{Modeling}

Bond graph methods were used to model both the elbow and shoulder transmission/reductions. The models, shown in Figure 6.13, assume the motors are pure torque sources and that the environment has not been contacted. The cables were modeled as springs. This assumption is valid only when the system is pretensioned. Each cable circuit was represented by a single stiffness which is the result of the two halves of the cable circuit effectively operating in parallel (see Section 6.2.1). All the elements in the bond graph were assumed linear. Theory predicts that this characterization is generally valid, with the possible exception of the damping characteristics. Damping internal to the transmission (due to bearing friction, windage losses, and cable friction) has been assumed negligible. Only viscous drag on the output links has been considered, and even then it was linearized about an operating point of 1 radian per second. Actual torsional drag, $\tau_{D}$, has been assumed to be of the form

$$
\tau_{D}=\left(C_{D} / 2\right)\left(p(\omega r)^{2} A r\right)
$$

where $C_{D}$ is the coefficient of drag, $\rho$ is the density of sea water, $\omega$ is the angular velocity of the link, $r$ is the distance from the joint axis to the imaginary point at which the drag force is applied, and $A$ is the projected cross-sectional area of the appropriate link. This equation is based on the formula for drag force of a square cross-section beam moving translationally. The basic drag force equation

$$
D=\left(C_{D} / 2\right)\left(O V^{2} A\right)
$$



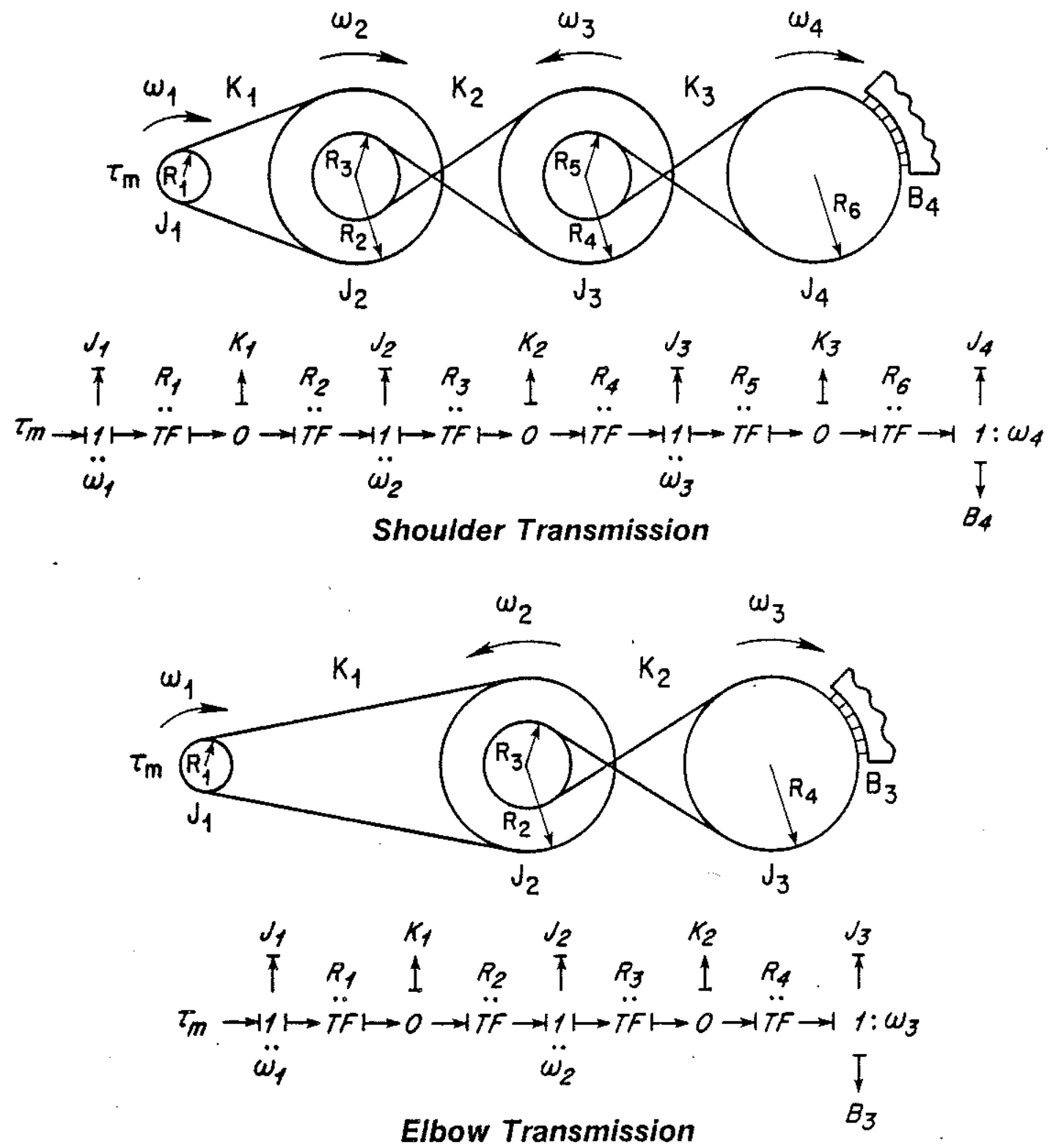

Figure 6.13: Transmission Schematics \& Bond Graphs 
where $V$ is translational velocity, was multiplied by an imaginary radius 0.75 times the length of the link and translational velocity was assumed to be the angular velocity times the imaginary radius. Linearizing the torsional drag equation resulted in

$$
\tau_{D}=C_{D} \rho \omega r^{3} A \omega_{p}
$$

where $\omega_{p}$ is the operating point angular velocity.

\subsubsection{Elbow Transmission}

The linearized equations of motion can be given in the following form:

$$
\left[\begin{array}{c}
\dot{\omega}_{I} \\
\dot{\omega}_{2} \\
\dot{\omega}_{3} \\
\dot{\mathrm{F}}_{\mathrm{K} 1} \\
\dot{\mathrm{F}}_{\mathrm{K} 2}
\end{array}\right]=\left[\begin{array}{ccccc}
0 & 0 & 0 & -\mathrm{R}_{1} / \mathrm{J}_{1} & 0 \\
0 & 0 & 0 & \mathrm{R}_{2} / \mathrm{J}_{2} & -\mathrm{R}_{3} / \mathrm{J}_{2} \\
0 & 0 & -\mathrm{B}_{3} / \mathrm{J}_{3} & 0 & \mathrm{R}_{4} / \mathrm{J}_{3} \\
\mathrm{~K}_{1} \mathrm{R}_{1} & -\mathrm{K}_{1} \mathrm{R}_{2} & 0 & 0 & 0 \\
0 & \mathrm{~K}_{2} \mathrm{R}_{3} & -\mathrm{K}_{2} \mathrm{R}_{4} & 0 & 0
\end{array}\right]\left[\begin{array}{c}
\omega_{1} \\
\omega_{2} \\
\omega_{3} \\
\mathrm{~F}_{\mathrm{K} 1} \\
\mathrm{~F}_{\mathrm{K} 2}
\end{array}\right]+\left[\begin{array}{c}
1 / J_{1} \\
0 \\
0 \\
0 \\
0
\end{array}\right]\left[\begin{array}{c}
\tau_{\mathrm{m}} \\
\end{array}\right]
$$

The state variables are $\omega_{n}$ and $F_{k n}$, representing pulley angular velocities and twice the cable differential tensions, respectively. Differential tension is the absolute value of the difference in tension between the current tension in the cables of half a cable circuit and the pretension in the cables of that half of the circuit. Actual tension in any single segment of cable is determined by dividing the differential tension by the number of cables in parallel in a given cable/pulley circuit. The state variable tensions are twice the differential tensions because half the state variable tensions are exerted by each of the two halves of the pretensioned cable circuit. As mentioned in Section 6.2.1 the two pretensioned halves of the cable circuit were modeled as a single spring, which has a stiffness equal to twice the stiffness of either of the two identical halves of the cable circuit. 
The values and meaning of the parameters are given below:

$$
\begin{array}{ll}
\mathrm{R}_{1}=.00889 \mathrm{~m} & \text { pinion radius } \\
\mathrm{R}_{2}=.04318 \mathrm{~m} & \text { pulley diameter } \\
\mathrm{R}_{3}=.01397 \mathrm{~m} & \text { pulley diameter } \\
\mathrm{R}_{4}=.04318 \mathrm{~m} & \text { output pulley diameter } \\
\mathrm{B}_{3}=.0321 \mathrm{kgm} / \mathrm{s} & \text { viscous damping } \\
\mathrm{J}_{1}=9.15 \times 10^{-5} \mathrm{kgm}^{2} & \text { inertia } \\
\mathrm{J}_{2}=3.38 \times 10^{-4} \mathrm{kgm}^{2} & \text { inertia } \\
\mathrm{J}_{3}=2.78 \times 10^{-2} \mathrm{kgm}^{2} & \text { inertia } \\
\mathrm{K}_{1}=400,000 \mathrm{~N} / \mathrm{m} & \text { cables } \\
\mathrm{K}_{2}=2,100,000 \mathrm{~N} / \mathrm{m} & \text { cables }
\end{array}
$$

The first resonant mode of was predicted to be at $73 \mathrm{~Hz}$. One other higher pole pair was found to be at $306 \mathrm{~Hz}$. A fifth eigenvalue was calculated to be at $0.1 \mathrm{kz}$ and was attributed to damping effects on the link inertia.

In order to avoid exciting the transmission's lowest natural frequency, effective bandwidth of the elbow transmission should be at least three times less than the lowest natural frequency (Asada and Slotine, '86). This would mean the frequency of control inputs to the elbow motor should be less than $24 \mathrm{~Hz}$.

\subsubsection{Shoulder Transmission}

The linearized equations of motion are listed below. The state variables are $\omega_{n}$, which represent the four angular velocities of the pulleys, and $F_{k n}$, which represent the differential tensions in the cables.

$$
\left[\begin{array}{c}
\dot{\omega}_{1} \\
\dot{\omega}_{2} \\
\dot{\omega}_{3} \\
\dot{\omega}_{4} \\
\dot{\mathrm{F}}_{\mathrm{K} 1} \\
\dot{\mathrm{F}}_{\mathrm{K} 2} \\
\dot{\mathrm{F}}_{\mathrm{K} 3}
\end{array}\right]=\left[\begin{array}{ccccccc}
0 & 0 & 0 & 0 & -\mathrm{R}_{1} / \mathrm{J}_{1} & 0 & 0 \\
0 & 0 & 0 & 0 & \mathrm{R}_{2} / \mathrm{J}_{2} & -\mathrm{R}_{3} / \mathrm{J}_{2} & 0 \\
0 & 0 & 0 & 0 & 0 & \mathrm{R}_{4} / \mathrm{J}_{3} & -\mathrm{R}_{5} / \mathrm{J}_{3} \\
0 & 0 & 0 & -\mathrm{B}_{3} / \mathrm{J}_{4} & 0 & 0 & \mathrm{R}_{6} / \mathrm{J}_{4} \\
\mathrm{~K}_{1} \mathrm{R}_{1} & -\mathrm{R}_{1} \mathrm{R}_{2} & 0 & 0 & 0 & 0 & 0 \\
0 & \mathrm{R}_{2} \mathrm{R}_{3} & -\mathrm{R}_{2} \mathrm{R}_{4} & 0 & 0 & 0 & 0 \\
0 & 0 & \mathrm{R}_{3} \mathrm{R}_{5} & -\mathrm{K}_{3} \mathrm{R}_{6} & 0 & 0 & 0
\end{array}\right]\left[\begin{array}{c}
\omega_{1} \\
\omega_{2} \\
\omega_{3} \\
\omega_{4} \\
\mathrm{~F}_{\mathrm{K} 1} \\
\mathrm{~F}_{\mathrm{K} 2} \\
\mathrm{~F}_{\mathrm{K} 3}
\end{array}\right]+\left[\begin{array}{c}
1 / \mathrm{J}_{1} \\
0 \\
0 \\
0 \\
0 \\
0 \\
0
\end{array}\right]\left[\tau_{\mathrm{mII}}\right]
$$


The parameters are described below. The viscous damping and output stiffness vary slightly between transmissions one and two, but their differences are negligible and have been ignore here. Both the shoulder transmission are therefore represented by the values below.

$$
\begin{array}{ll}
\mathrm{R}_{1}=.00889 \mathrm{~m} & \text { pinion radius } \\
\mathrm{R}_{2}=.03937 \mathrm{~m} & \text { pulley radius } \\
\mathrm{R}_{3}=.01397 \mathrm{~m} & \text { pulley radius } \\
\mathrm{R}_{4}=.03937 \mathrm{~m} & \text { pulley radius } \\
\mathrm{R}_{5}=.01397 \mathrm{~m} & \text { pulley radius } \\
\mathrm{R}_{6}=.03937 \mathrm{~m} & \text { pulley radius } \\
\mathrm{B}_{4}=4.768 \mathrm{kgm} / \mathrm{s} & \text { viscous damping } \\
\mathrm{J}_{1}=9.74 \times 10^{-5} \mathrm{~kg} / \mathrm{m}^{2} & \text { inertia } \\
\mathrm{J}_{2}=3.274 \times 10^{-4} \mathrm{~kg} / \mathrm{m}^{2} & \text { inertia } \\
\mathrm{J}_{3}=4.852 \times 10^{-4} \mathrm{~kg} / \mathrm{m}^{2} & \text { inertia } \\
\mathrm{J}_{4}=1.2178 \times 10^{-4} \mathrm{~kg} / \mathrm{m}^{2} & \text { inertia } \\
\mathrm{K}_{1}=330,000 \mathrm{~N} / \mathrm{m} & \text { cables } \\
\mathrm{K}_{2}=1,422,140 \mathrm{~N} / \mathrm{m} & \text { cables } \\
\mathrm{K}_{3}=6,027,702 \mathrm{~N} / \mathrm{m} & \text { cables }
\end{array}
$$

The lowest resonant mode was calculated to be $32 \mathrm{~Hz}$. The other two pole pairs had natural frequencies of $220 \mathrm{~Hz}$ and $442 \mathrm{~Hz}$ respectively, while a final pole, attributed to damping on the link inertia, was located at $0.5 \mathrm{~Hz}$.

The bandwidth of the shoulder transmissions should be kept below $11 \mathrm{~Hz}$. 


\subsection{STRUCTURE}

In this thesis, the structure of the manipulator is defined by those parts which give the machine its shape. These components are the housings, joint torque tubes, joint bearings, and joint stops.

Although in general, static and dynamic stiffness are the two issues of greatest concern when a manipulator structure is being determined, in this case they played reduced role in the system synthesis. The JASON design team recommended that the manipulator structure meet the following requirements:

- exterior surfaces should have at least a .125 inch wall thickness to resist puncture damage done on board the ship, at vehicle recovery $\rightarrow-$ when the JASON has the risk of striking the ship, and when the system is being shipped from site to site.

- the manipulator should be able to sustain high impact loads in the fully extended position, in the event that JASON strikes the environment with the manipulator outstretched.

- mechanical stops should be provided at each joint which prevent the manipulator from damaging itself and which allow the motors to be initialized.

\subsection{Housings and Associated Components}

All the housings were constructed of aluminum. The base, Iink one, and link two were fabricated using a green-sand casting method with A356 aluminum as the material. 6061-T6 aluminum was specified for link three and all covers. The joint torque tubes were machined from 7075-T6 aluminum bar stock and anodized. These parts were anodized for two reasons: 1) 7075 - T6 is very susceptible to corrosion, and 2) to make the surface of the male taper at the end of the tube hard. Tapered fits are easiest to disassemble when the surfaces of the male and female taper are of different hardness.

Schedule constraints prevented a complete finite element analysis from being accomplished. The shoulder housings have been deliberately designed with what was believed to be a high safety factor. Metal could 
always be removed later, following further analysis. The cast construction of the housings does not lend itself to weight optimization. A356 aluminum has a comparatively low yield strength (30,000 psi). In addition, since all but link three were sand cast, every effort was made to reduce the complexity of the housings in order to reduce pattern cost.

The fact that the housings have to enclose the mechanism, occupy as little volume as possible (to reduce drag and added mass effects), and provide for offset joints with only one dynamic seal per joint made making the links, particularly link two, uniform and symmetric in cross-section virtually impossible. Placement of access panels and construction methods further complicated this dilemma. The impact of the resultant asymmetric shape of link two is greater in terms of drag and added mass behavior than it is in terms of deflection.

Joint bearings, because of the large diameters necessary to accommodate the joint torque tubes and the potentially high impact loads, are the heaviest single elements in the manipulator with the exception of the motors. Axial joint play is avoided by preloading these bearings with wavy washers.

\subsection{Joint Stops}

Each joint has mechanical stops built in which limit range of motion. These stops are necessary because the mechanism and possibly the structure would be damaged if the joints exceeded their specifled range of motion. In addition, each time the motors are powered up, they must be initialized. This action requires that each motor be slowly moved until it encounters a stop. The angular position at the stop becomes the reference position.

The stops each consist of two hardened $17-4 \mathrm{PH}$ stainless steel parts, one connected to the housing and one connected to the joint torque tube. The contact surfaces of both types of parts are covered with an elastomer to distribute impact loading, and also to absorb energy. Joint motion is impeded when the two parts of a given stop contact.

Properly sizing the stops proved to be surprisingly difficult. The amount of energy transferred to a stop when a joint reaches the end of its range of motion can be roughly described by the equation 


$$
1 / 2\left(I \omega^{2}\right)=1 / 2\left(K \Delta \Omega^{2}\right)
$$

where $I$ is inertia of the moving link, including "added mass" inertia, $\omega$ is angular velocity of the link, $k$ is torsional stiffness of the joint and stop, and $\Delta \Omega$ is angular displacement induced in the joint and stop after contact between the two stop pieces has been made. Assuming all variables are known except $\Delta \Omega, \Delta \Omega$ can be determined, and then using the following formula, the resultant torque may be calculated.

$$
\mathrm{T}=\mathrm{K} \Omega
$$

Stress in the stops and their fasteners can be determined using this information.

Because the manipulator is capable of moving large loads at high speeds, and because of "added mass" inertia effects when accelerating, installing stops sufficient to tolerate the full range of possible loads was deemed impractical. Stops capable of handling worst case load would have had to have been attached to the exterior of the manipulator. These would have provided entanglement points, increased drag and added mass, and violated the requirement of smooth exterior surfaces. They also would probably have been unsightly! All the stops were designed to be able to sustain loads caused by their respective joints moving at angular velocities of 1 radian per second, carrying no payload. Although the manipulator can attain speeds higher than this, speeds greater than 1 radian per second would be impractical from an operator standpoint. The safety factor for all cases is at least two. 
The completed manipulator and its test stand are shown in Figure 8.1. Martin Bowen, the vehicle pilot is shown to give an idea of scale.

\subsection{Testing}

Results described in this section were obtained with a great deal of aid from Hagen Schempf. All testing done to date was accomplished without filling the manipulator with oil. The oil was left out of the system to avoid difficulty in observing the workings of the mechanism and to facilitate ease of assembly and disassembly. Prior to testing, the manipulator was carefully assembled and cable lengths were determined. Tests to obtain information on joint stiffness, hysteresis, and dynamic range were conducted.

\subsubsection{General Observations}

- Assembly issues: With the exception of cable installation, the manipulator proved very easy to assemble. The tapered joints proved easy to assemble and disassemble; disassembly being accomplished with a specially designed taper puller. The counterbores designed to seat the motor stators positioned the stators accurately and the motor rotor fit well on the tapered motor drive shafts. In fitting the stators, however, care had to be taken to ensure that the resin bonding the stator laminates together was removed from the exterior of the stators (the only resin on the outside of the stator was extra--that which had squeezed out from between the laminates). Failure to remove the resin resulted in improper seating of the stators.

Installation of the cables in each of the transmissions proved to be a time-consuming task. The time required to install the cables in the two shoulder transmissions is roughly two hours. Less than half an hour is required for the elbow transmission. Two people are required to perform final pretensioning on all the circuits. Cable 


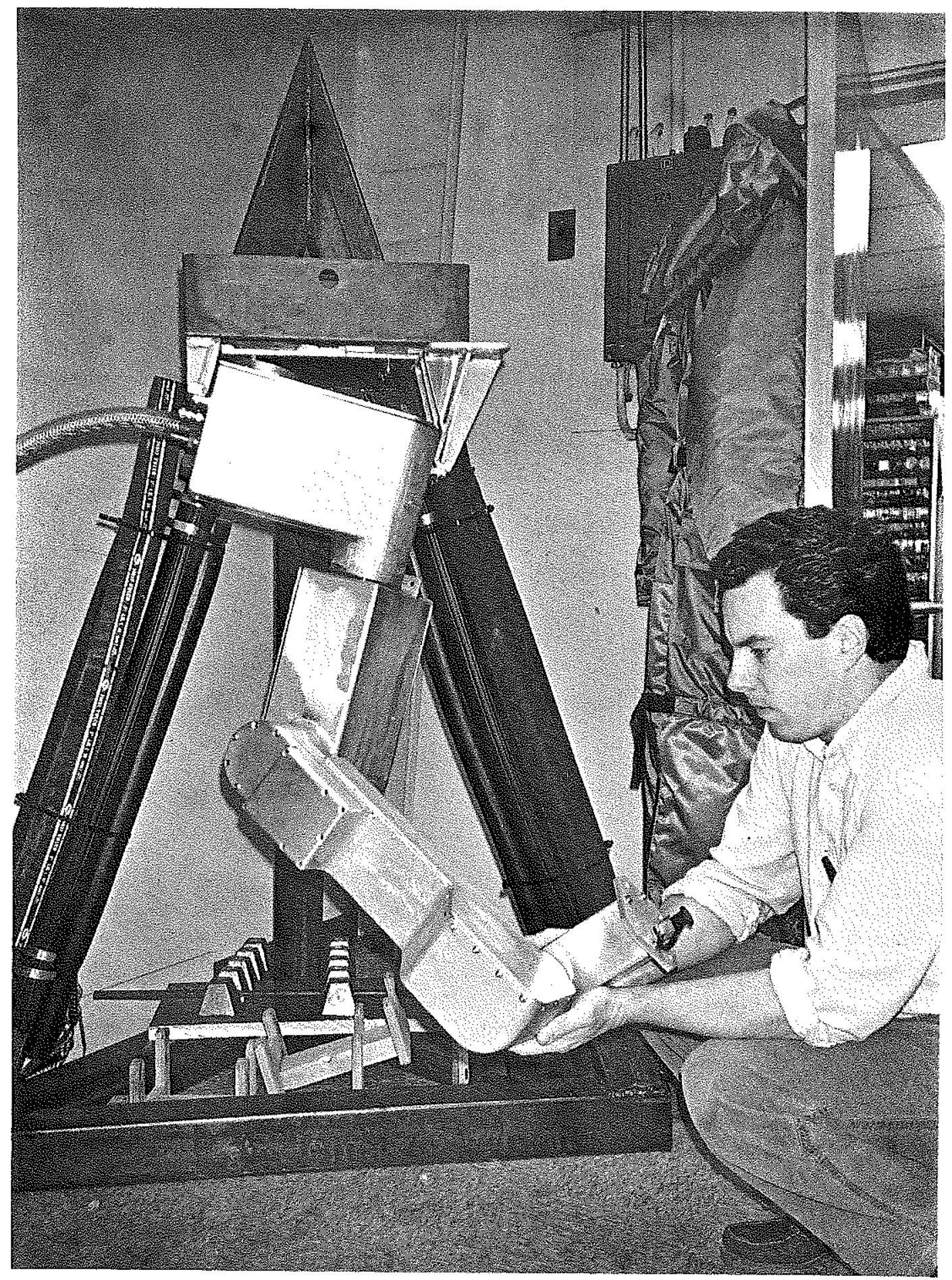

Figure 8.1: Manipulator, Test Stand, and Operator 
3

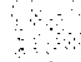


installation times will undoubtedly decline as the technicians become more familiar with the system.

Dynamic seal installation had not yet been tried at the time of this writing, but based on experiences with similar seals on JASON's thruster motors, installation will probably be fairly straightforward, but removal may require the use of a wheel puller.

- Cable running: Low volume rubbing noise could be heard when the joints of the manipulator were moved. This was the result of slight rubbing between the cables as they wrapped on and off the pinion pulleys (the small pulleys) in the transmissions. Rubbing of this kind will probably cause abrasion of the exterior surfaces of the cable, ultimately resulting in failure. The magnitude of this problem seemed low. Otherwise, when the cable circuits were pretensioned, cable wrapping was very predictable and well-behaved. The cables demonstrated no tendency to run off the pulleys, even though no pulley flanges were present on any of the pulleys. When the cable circuits were not pretensioned, and a load was applied, cable wrapping became unpredictable and greater rubbing occurred between cables.

\subsubsection{Locking the Motors and Deflecting the Output Links}

The output stiffnesses of the two types of transmission/reductions were measured by loading each of the two types of joints and observing deflections. The transmissions for joints two and three were tested by applying a gravity load to the endpoints of links two and three respectively. Deflection was measured with a dial indicator capable of resolving better than 0.001 inch. For these tests, each of the transmission/reductions was disconnected from any lower numbered links and clamped directly to a rigid table.

Data collected from two sets of tests conducted on joint two is shown in Figures 8.2 and 8.3. A negative load is defined as a force in the downward direction, while a postive load is a force in the upward direction. The sets of arrows on the plots indicate the way in which the links were loaded and unloaded. The linear nature of the arrows does not necessarily indicate linear relationships between forces and deflection in between the recorded points. The deflection vs. force curves shown do 


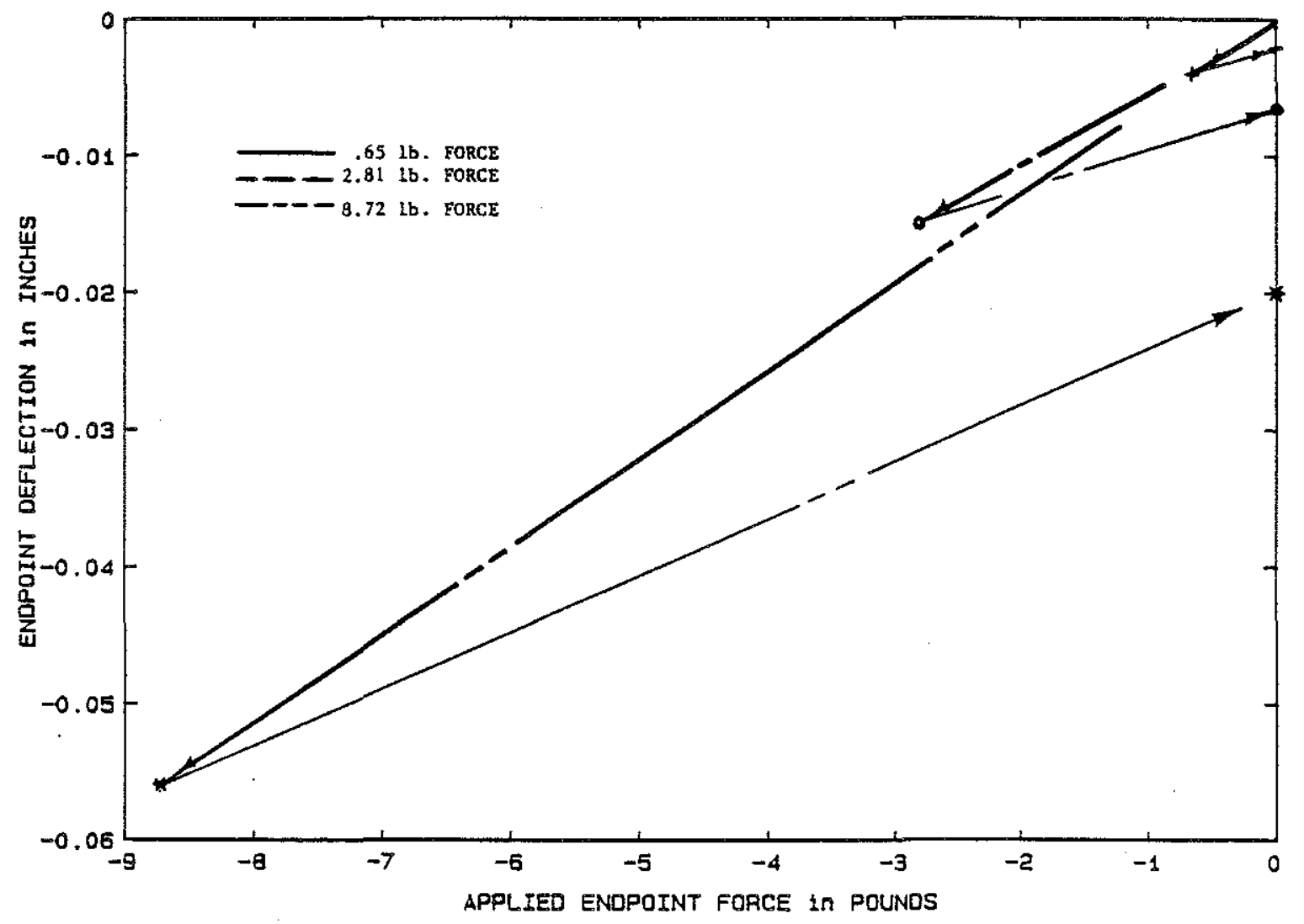

Figure 8.2: Link 2 Endpoint Deflection vs. Applied Endpoint Load. Test 1: Load applied in the negative direction. 


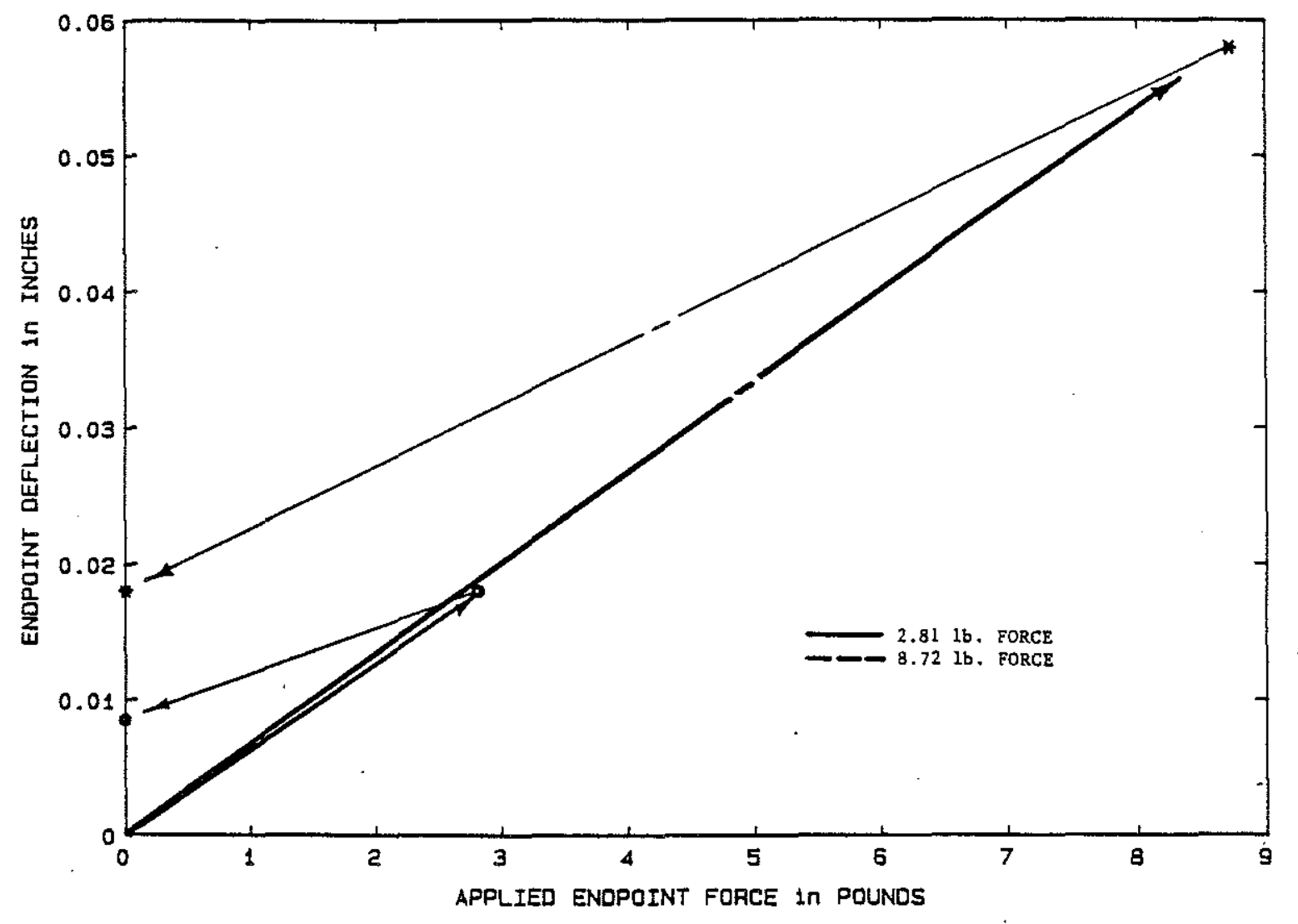

Figure 8.3: Link 2 Endpoint Deflection vs. Applied Endpoint Load. Test 2: Load applied in the positive direction. 
exhibit hysteretic behavior, caused most probahly by friction and stiction in the bearings, and by friction/stiction between the pulleys and the cables. This behavior is evidenced by the fact that each time the force applied causes a deflection, when the force is removed, the deflection does not become zero. This apparent friction/stiction induced deadband varies with force applied. The upshot of this observation is that the pure deadband in the systems, i.e. the region in which an applied force causes no movement of the transmission, is very small. If it were not, when the $0.65 \mathrm{lb}$. force were applied and removed, the final deflection would be the same as the deflection when the force were applied. In other words, the restoring force generated by the energy storing behavior of the cables would be inadequate to move the output link against the deadband force.

The effective output stiffness of the joint can best be determined by dividing the applied force by the initial deflection it produces (represented by the heavier arrowed lines on the plots). This is appropriate because the hysteresis would be overcome by the weight of the link. (Remember that all the loads applied were gravity loads, meaning that they would be superimposed on the load exerted on the joint by the inherent weight of the link. Link two, for example, was found to have an effective endpoint weight of $12 \mathrm{lb}$., more than enough to overcome the hysteretic effects.). Dividing applied force by the change in deflection between loading and unloading is not a valid measure of stiffness, because this change in deflection is affected by hysteresis.

\subsubsection{Locking the Output Links and Rotating the Motors}

The tests focused on the output side of the manipulator joints, enumerated above, were complemented with tests aimed at characterizing the system from the input side. The experimental apparatus used for these experiments is shown in Figure 8.4. A JR3 force sensor, on consignment from JR3, Inc., was placed under the endpoint of link two. The force sensor is extremely stiff, and under the loads experienced in these experiments, would deflect less than 0.001 inch. The manipulator, as a whole, was mounted to the test stand. Data from the force sensor was logged automatically by the computer. Position data was read off a rotary 


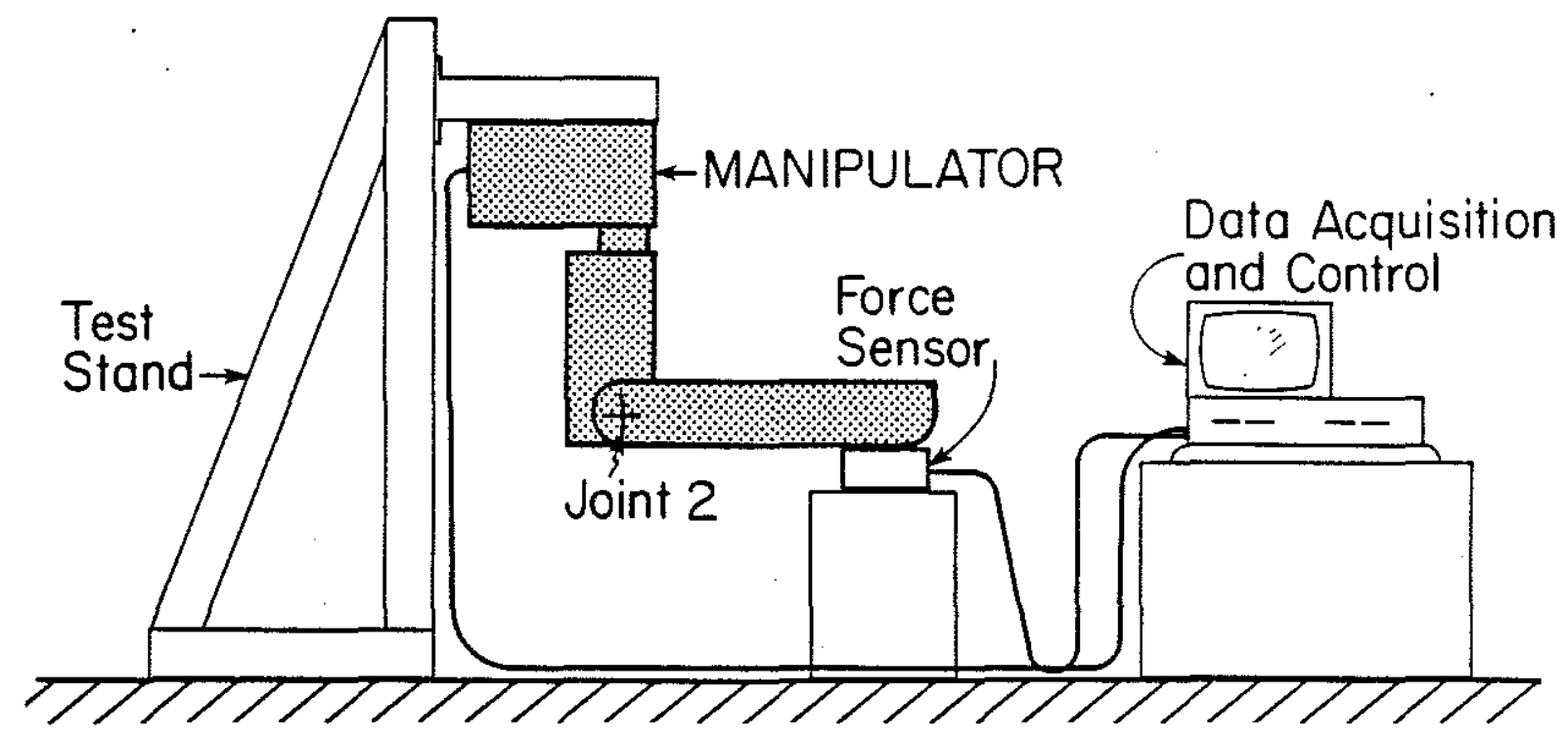

Figure 8.4: Experimental Set-up for Dynamic Range Test . 
dial indicator attached to the motor, and entered into the computer manually.

To learn about the behavior of the transmission/reduction, the motor was deflected in one degree increments as shown in Figure 8.5 and resultant force at the end of link two was monitored. Deflection of the motor was caused by attaching a wrench to the motor shaft (the end of it has a hex on it for this purpose) and turning the motor against the restoring force of the transmission cables. The resultant curve displayed several of the characteristics of the curves generated in the output stiffness tests. The weight of link two has been subtracted from the data shown in the figure. Only loads in excess of the steady state link two weight were displayed.

Throughout most of its range, i.e. for motor deflections in excess of 3 degrees, the curve is fairly linear. The slightly nonlinear behavior of the system is probably due at least in part to deflection of the entire manipulator and stand. This in turn caused changes in the effective lever arm applying force to the force sensor. The most interesting behavior, however, is in the range in which motor deflection is less than 3 degrees. Here the nonlinear hysteresis behavior described above is evident. The pure deadband is approximately $0.51 \mathrm{~b} .(2.22 \mathrm{~N})$.

\subsection{Stiffness Model}

The plot shown in Figure 8.6 is a hypothetical stiffness curve for joint two, showing the behavior noted in Section 8.1 .3 as well as in Section 8.1.2. The dashed region of the curve between the origin and $A$ represents the data collected by rotating the motor and monitoring the force sensor output. The linear section of the curve between $A$ and $B$ corresponds to the section of the plot in Figure 8.5 in which endpoint force is greater than three pounds. In Figure 8.6, however, this reginn of the curve is represented by a straight line, because the effects of the manipulator structure and stand deflection have been removed. The region between $\mathrm{B}$ and $\mathrm{C}$ reflects the roughly $0.5 \mathrm{lb}$. pure deadband found. The region from $C$ to $D$ is based on the data plotted in Figures 8.2 and 8.3. Points $E, F$, and $G$ in the third quadrant correspond to points $B, C$, and $D$ respectively, and were based on similar empirical results. The range of the curve reflects the tests done in Section 8.1.2. Higher applied loads 


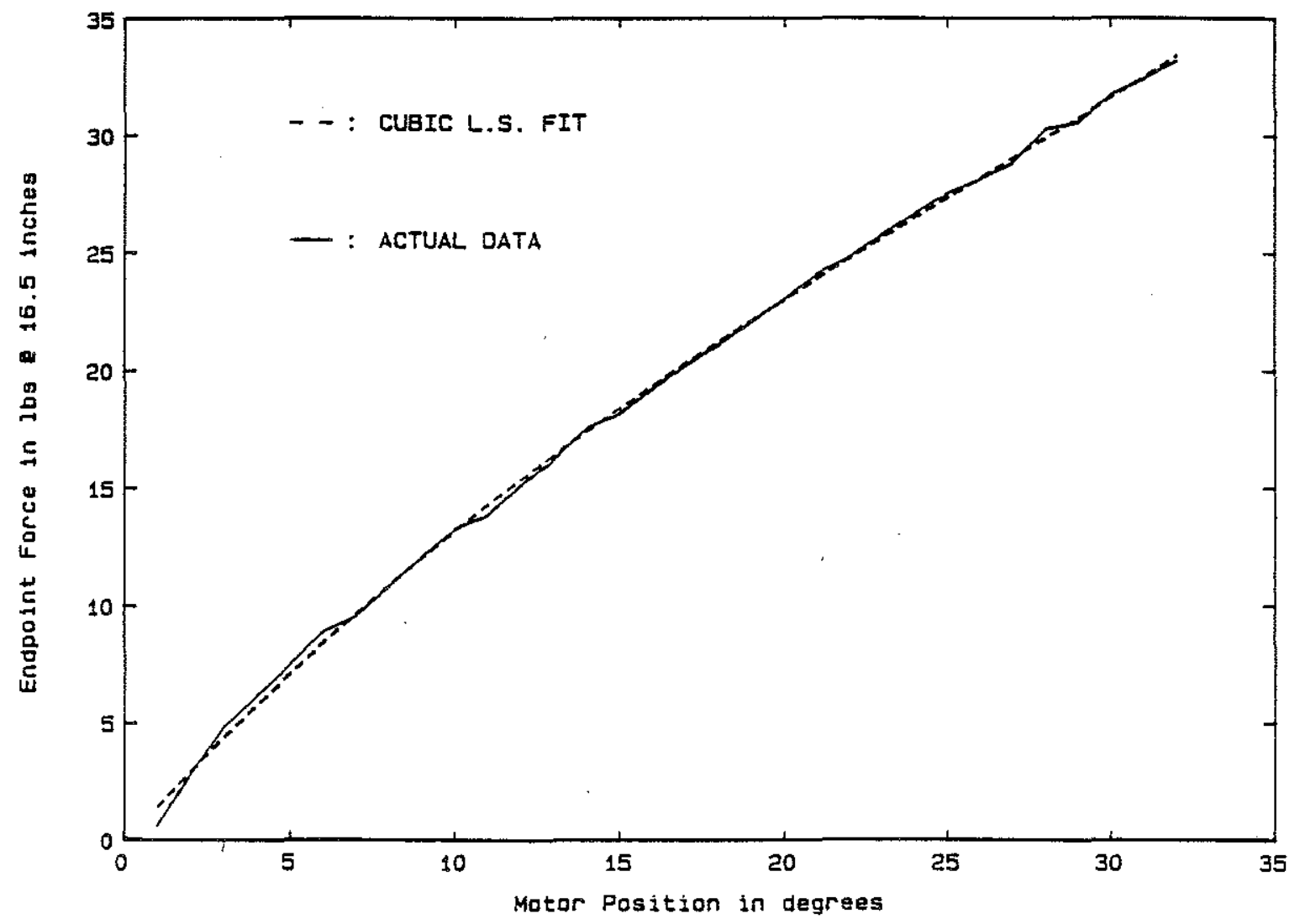

Figure 8.5: Endpoint Force vs. Motor Position.

Endpoint force on Link 2 was measured with JR3 Force Sensor, position data was measured with a rotary dial indicator. 


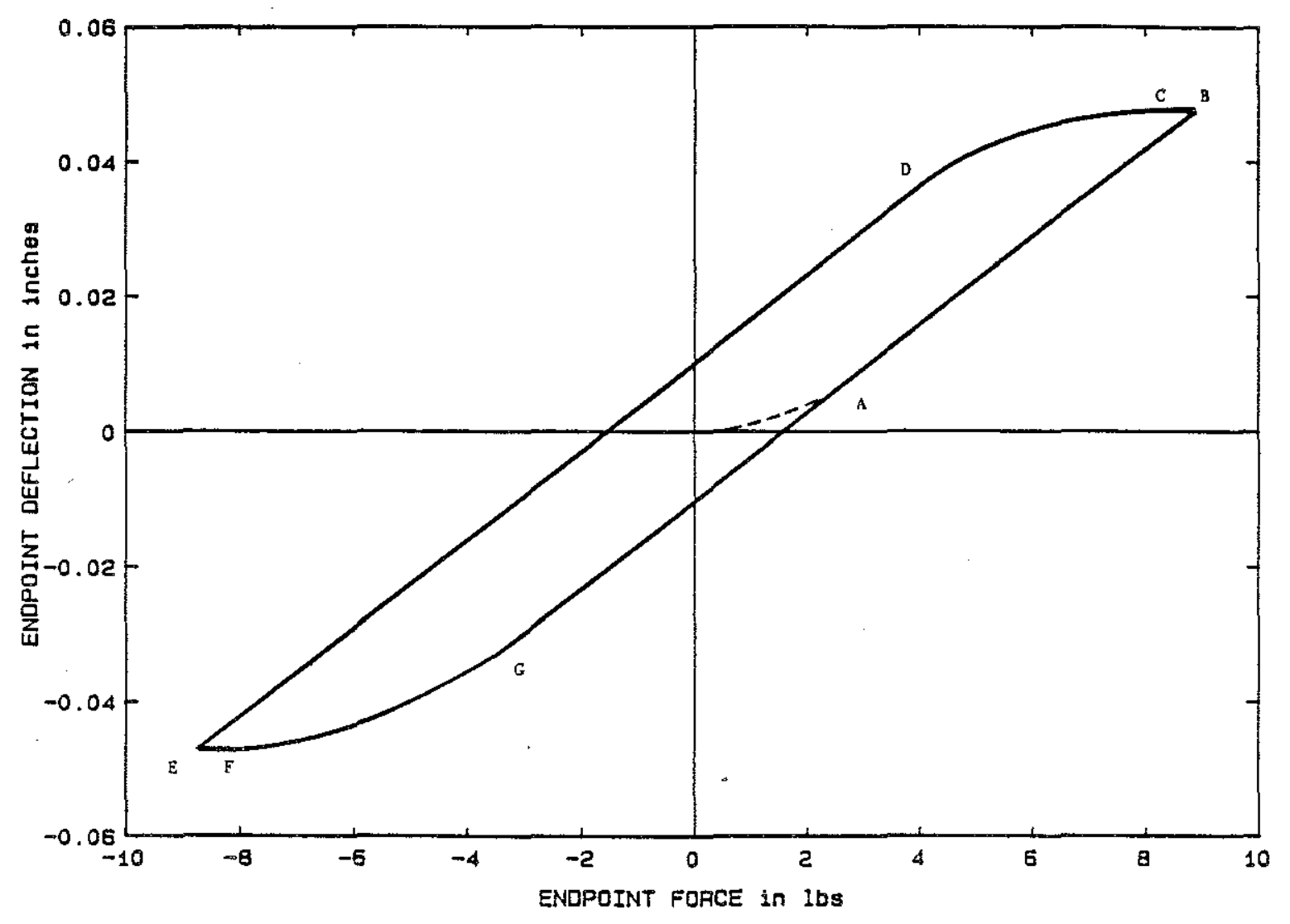

Figure 8.6: Hypothetical Stiffness Curve for the Shoulder Transmission/Reduction - based on empirical evidence. 
would produce greater deflections, but the general shape of the curve should remain the same. This type of curve will be important in determining exact endpoint position. Stiffness curves for joints one and three would probably similar to this one.

\subsection{Design Evaluation}

One way to evaluate a design is to compare the performance of the finished product with the design goals. Table 8.1 presents the intended performance specifications as of July 1987 (the end of the initial design phase), and the actual measured performance as of May 1988.

The majority of the design specifications were met or exceeded. Each one is addressed individually below.

1. A range of motion greater than the one obtained would be unnecessary. This manipulator's total work volume is virtually all of a sphere not obstructed by the structure of JASON.

2. The maximum joint speeds with no payload have not been determined experimentally, but knowledge of the motors' torques supports the "as designed" speeds. These speeds should prove more than adequate, since high speeds should very seldom be required in light of the high drag forces which are imparted to. JASON and the rapid changes in weight distribution which result.

3. Position resolution is based on the motors ability to resolved 2304 steps per revolution, multiplied by the reduction ratio--30 for the two shoulder joints and 13 for the elbow. The absolute position of the endpoint must be determined by compensating for system compliance in software. While the position resolution is potentially very high, finding input devices capable of commanding position with greater than 12 bit accuracy (4096) is difficult, and probably not worthwile for most applications.

4. The stiffness figures shown will hopefully disprove the fact that cabled manipulators can not be made to be stiff. The actual stiffness estimates are based on the output joint tests. High stiffnesses provide the system with high operational bandwidths. 
Table 8.1: Manipulator Specifications

1. Range of Motion:

axis 1

axis 2

axis 3

As Designed

Actual

2. Maximum Joint Speed:

axis 1

axis 2

axts 3

$\begin{array}{ll}225^{\circ} & 240^{\circ} \\ 225^{\circ} & 240^{\circ} \\ 360^{\circ} & 380^{\circ}\end{array}$

$120 \% \mathrm{~s}$

$120 \% \mathrm{~s}$

N.D.

$180^{\circ} / \mathrm{st}$

3. Position Resolution:

axis 1

axis 2

axis 3

69,000 steps/rev. $\quad 69,000 \mathrm{~s} / \mathrm{r}$ *

$69,000 \mathrm{steps} / \mathrm{rev} . \quad 69,000 \mathrm{~s} / \mathrm{r}$ *

30,000 steps/rev. $\quad 30,000 \mathrm{~s} / \mathrm{r} *$

4. Stiffness:

axis 1

axis 2

axis 3

$1855 \mathrm{Nm}$

$4700 \mathrm{Nm}$

$1855 \mathrm{Nm}$

$4700 \mathrm{Nm}$

$1415 \cdot \mathrm{Nm}$

$1000 \mathrm{Nm}$

5. Bandwidth:

axis 1

axis 2

axis 3

$11 \mathrm{~Hz}$

$11 \mathrm{~Hz}$

$24 \mathrm{~Hz}$

$16 \mathrm{~Hz}+$

$16 \mathrm{~Hz}+$

$20 \mathrm{~Hz}+$

6. Load Capacity at 30 " extension:

$89 \mathrm{~N}$

$80 \mathrm{~N}$

7. Dynamic Range:

53

$50+$

8. Backlash:

none

none

9. Backdriveabilfty:

very high

very high

10. Fatigue Life:

100,000 cycles

300,000 cycles

11. Overall Efficiency:

$45-60 \%$

N.D.

12. Weight:

$302 \mathrm{~N}$

$319 \mathrm{~N}$

13. Depth Capability:

ful1 ocean

$\star *$

N.D.: No Data

*: with software compensation

**: motors tested to $6000 \mathrm{~m}$ 
5. Bandwidths would be much higher, if not for the affects of "added mass" and the oil inside the link. Even so, bandwidth should be more than adequate for underwater tasks. Bandwidths were based on dividing the lowest structural resonant modes by 3 . Given the fact that the shoulder stiffnesses were much higher than predicted, the bandwidth of the shoulder transmissions should also be higher than predicted; the elbow bandwidth may be somewhat lower. Structural modes were the lowest restrictions on bandwidth. Time delays and sampling frequency should not have an impact on lowering the joint bandwidths.

6. The load capacity is defined as the endpoint payload the manipulator can lift when links two and three are stretched out horizontally. 30 inches is mentioned because this was the intended maximum reach of the manipulator with an end-effector installed.

7. Dynamic range is defined here as the maximum torque that can be applied by a joint of the manipulator divided by the minimum torque which that joint can apply and resolve. The manipulator dynamic range is determined by selecting the lowest dynamic range of the three joints, which was at joint one. Joint one is capable of applying $47.6 \mathrm{Nm}$ of torque. It was found to be able to apply and resolve torques at least as low as $0.96 \mathrm{Nm}$. The resultant dynamic range is thus roughiy 50 . The other two joints have much higher dynamic ranges--both in the neighborhood of 100. This calculation of dynamic range has not included limitations in torque resolution of the motor, most of which the manufacturer has agree to compensate for, but it has included to predicted affects of joint seals. Dynamic range may be better once the manipulator has been filled with a lubricating oil, although stiffness may be somewhat lower.

8. Backlash was not present, in the sense that neither the output nor the input of any transmission/reduction could be moved without a restoring force being felt. No discontinuous deadbands existed in the system.

9. The fact that backdriveability was very high means that this manipulator was, as its name implies, a system in which a wide range 
of joint stiffnesses could he commanded without the addition of sensors other than those in the motor, making it ideal for impedance control schemes.

10. One of the most important specifications which has not been tested is fatigue life. Determination of fatigue life is pivotal in allowing an overall evaluation of the design to be made. Fatigue life as listed in the charts was based on the expected life of the anticipated weakest part of the design--the cables in the shoulder transmissions. If fatigue life is 300,000 cycles of the motor shaft (a cycle here is defined by any change in direction), as predicted, months of operation will pass before the cables will have to be replaced. Cable fatigue life must be determined by testing prior to using the manipulator operationally. Inability to predict fatigue life will potentially result in the cables falling unexpectedly. This could cause damage to the transmission systems, as well as operational inconvenience.

11. Overall system efficiency estimates were based on motor efficiencies of $50-60 \%$ and transmission/reduction efficiencies of $90-95 \%$. The low motor efficiency was due largely to the fact the motors were designed for high torque at relatively low speeds. These features, coupled with the small relative size of the motor, keep efficiency relatively low.

12. The weight of the manipulator was slightly greater than initially anticipated, due to in-process design changes. Weight could be reduced substantially by machining away excess material.

13. The manipulator was designed to operate to at least $6000 \mathrm{~m}$ in sea water. Key elements of the system, such as motors, connertors, and seals have been tested to pressure equivalent to that at $6000 \mathrm{~m}$. No depth limitations are expected.

Perhaps the real test of this system's usefulness will come once closed loop control has been implemented. This system should function as an excellent test bed for force control schemes and should also serve as a useful tool in determining to what lengths manipulator designers should go 
to produce high-fidelity systems. Reliahility and manufacturing cost will probably be two key factors in determining whether the features inherent in actively compliant manipulators of this kind make them attractive as alternates to more traditional designs. 


\subsection{RECOMMENDATIONS FOR FUTURE WORK}

This section is divided into two parts, the first dealing with recommended improvements for the existing manipulator, and the second discussing long term conceptual suggestions.

\subsection{Improvements to the Existing Design}

The following improvements could be made to the existing manipulator without significantly altering the general layout or function of the system.

1. New pulleys could be made which have grooves on the surfaces. This would make the pulleys more like the ones often used in winch applications. Grooves would prevent the cables from rubbing against each other when coming on and off the pulleys. In addition, grooved pulleys would allow a cable's circular cross-section to be maintained while wrapped on a pulley, keeping cable stress fairly low compared to stress in a cable wrapped on a plain (ungrooved) pulley (such as the ones in this design). Both these features positively affect cable fatigue life.

2. Joint friction could be further reduced by using John Crane Type 21 seals with a silicon carbide wiper and ring. For the diameter given in this design, the seal breakaway torque would theoretically be reduced from $0.3 \mathrm{ft}-1 \mathrm{~b}$ to $0.02 \mathrm{ft}-\mathrm{lb}$. The improved seals would be three times more expensive, however.

3. Finite element analysis could be conducted on the manipulator housings and pulleys. Better understanding of the stresses in these parts would probably allow manipulator weight and effective joint inertia to be cut. (The cable/pulley manipulator at the A.I. Laboratory at M.I.T. is an excellent example of weight optimized design.)

4. Torque ripple compensation could be implemented in software. This would entail installing a lookup table in the memory of each 
Seiberco controller. This compensation would be motor/controller specific and would not work if motors and controllers were mixed.

5. The tension locking mechanism on the link two drive shaft should be redesigned to be more reliable and secure. A clamping nut, aircraft lock nut, or reversal of the pitch of the threads on the shaft would be possible solutions. Using Loctite compounds to hold the nut is definitely not appropriate. They may tend to wick under the sleeve on the drive shaft, and thus make tensioning the link transmission difficult or impossible.

\subsection{Long Term Conceptual Improvements}

The suggestions below are intended only as "food for thought," which in light of the ideas discussed elsewhere in this thesis, seem reasonable.

While this manipulator meets or exceeds most of its design performance requirements, complexity could be reduced and stiffness increased through a single modification. Although stiffness is certainly not low, it can be further increased, as discussed in section 6.3, by increasing the diameter of the output pulley, for a given reduction ratio. If the size of the large diameter pulleys in the shoulder transmissions, for example, were all scaled up properly, the number of stages could be reduced from three to two. With the reduction in the number of stages, a corresponding set of pulleys, shafts, bearings, and cables are also dispensed with; significantly reducing the complexity of the overall transmission.

Another alternative to the cable/pulley transmissions of the two shoulder axes is the use of direct drive motors. While direct drive motors remain inappropriate for distal links moving against gravity because of their high weight, they may be the proper choice for the base axes which often do not get moved against gravity. Direct drive motors have the advantage of being fairly simple (from an end-users standpoint). They were not used in this design because common motor type at all joints was a desired characteristic, direct drive motors developed to date have had low torque-to-weight ratios, and have generally been of low overall efficiency. Present trends in direct drive motor performance indicate, 
however, that these shortcomings are being remedied. The large relative magnitude torque ripple inherent in most current direct drive motors can be compensated for in software.

Constructing this manipulator of aluminum was done largely to reduce the time and cost spent manufacturing the it. Even though the aluminum alloys used have good resistance to corrosion, in the future, a titanium alloy (such as $\mathrm{Ti}-6 \mathrm{Al}-4 \mathrm{~V}$ ) might be a more appropriate material. As well as having outstanding corrosion resistance in sea water, titanium alloys have much higher surface hardness than 6061 or A356 aluminum, and thus would be less susceptible to scratches and dinges. They also have higher yield strength and higher stiffness. On the negative side, titanium alloys conduct heat at a rate 10 to 20 times less than Aluminum alloys. This could be a problem in keeping motors housed in titanium housings cool. Cooling the motors is critical in obtaining the maximum possible torque. Titanium alloys are also more difficult to machine and weld.

Active cable pretensioning was a idea which was entertained during the early phases of the design. It was rejected in favor of a system in which the pretension is set prior to operation of the manipulator. Active pretensioning requires at least one additional actuator in the system which sets the pretension in the transmission/reduction cables. Practically speaking, one more actuator would be required for each joint. Perhaps the greatest advantage of active pretensioning is that the transmission cables could remain at low stress levels when the manipulator is not handling payloads, thus dramatically increasing fatigue life. In addition, friction due to high preloads could be reduced somewhat.

The future of this manipulator type seems promising. If fatigue life of the cables can be demonstrated to be long and predictable, this manipulator should prove to be a useful tool in extending man's relepresence in the deep ocean. 
REFERENCES

1. Angle, T. L., "Analysing Taper Fits," Machine Design, February 24, 1983.

2. Asada H., Slotine J.-J., Robot Analysis and Control, John Wiley and Sons, Inc., Cambridge, MA, 1986.

3. Asada H., Youcef-Toumi K., Direct Drive Robots, MIT Press, Cambridge, MA, 1987.

4. Carlisle, B. H., "AC Drives Move into DC Territory," Machine Design, May $9,1985$.

5. Delonga, D., Internal DSL memo, 1988.

6. Dexter, S. C., Handbook of Oceanographic Engineering Materials, Robert E. Krieger Publishing Co., Malabar, FL, 1979.

7. Horton, H. L., ed., Machinery's Handbook, 15 th Edition, The Industrial Press, New York, NY, 1957.

8. Karlen, J. P., Thompson, J. M., Farrell, J. D., "Design and Control of Modular Kinematically-Redundant Manipulators," Second AIAA/NASA/USAF Symposium on Automation, Robotics, and Advanced Computing for the National Space Program, Arlington, VA, 1987.

9. Kenjo, T., Nagamori, S., Permanent-Magnet and Brushless DC Motors, Clarendon Press, Oxford, UK, 1985.

10. LaQue, F. L., Marine Corrosion, John Wiley and Sons, New York, NY, 1975.

11. Maloof, R. H., Forrester N. C., Albrecht, C. E., "A Brushless Electric Propulsion System for the Research Submersible Alvin", Proc. of Oceans '86, Washington, DC, 1986.

12. Mason T. M., Salisbury J. K., Jr., Robot Hands and the Mechanics of Manipulation, MIT Press, Cambridge, MA, $19 \overline{85 .}$

13. "Materials Selector", Materials Engineering, Penton Publishing, Cleveland, OH, 1988.

14. Mazurkiewicz, J., "Brushless Motors Coming on Strong," Electronic Products, September 3, 1984.

15. Meshkat, S., "Servo System Design," Motion, 2nd Quarter, 1985.

16. Mitchell, L. D., Shigley, J. E., Mechanical Engineering Design, Fourth Edition, McGraw-Hi1l, Inc., New York, NY, 1983.

17. Ogata, K., Modern Control Engineering, Prentice-Hall, Inc., Englewood Clif $\overline{f s, ~ N Y}, \overline{1970 .}$ 
18. Roth, B.,' "Performance Evaluation of Manipulators from a Kinematic Viewpoint," NBS Special Publication: Performance Evaluation of Programmable Robots and Manipulators, Washington, DC, 1975.

19. Salisbury, J. K., Townsend, W., Eberman, B., DiPietro, D., "Preliminary Design of a Whole-Arm Manipulation System (WAMS)," Proc. of the 1988 IEEE International Conference on Robotics and Automation, Philadelphia, PA, 1988.

20. Seitz, W. E., "Intelligent Position Control Employs Motor with Internal Feedback," Powerconversion and Intelligent Motion, June, 1986.

21. Townsend, W. T., "The Effect of Transmission Design on the Performance of Force-Controlled Manipulators," Ph.D. thesis, M.I.T. Department of Mechanical Engineering, M.I.T. Artificial Intelligence Laboratory, 1988.

22. Townsend, W. T., Salisbury, J. K., "The Effect of Coulomb Friction and Stiction on Force Control," Proc. of the 1987 IEEE International Conference on Robotics and Automation, Raleigh, NC, 1987.

23. Townsend, W. T., Salisbury, J. K., "The Efficiency Limit of Belt and Cable Drives," ASME Journal of Mechanisms, Transmissions, and Automation in Design, 1987.

24. Waldron, J. K., "Arm, Design of," Encyclopedia of Robotics, John Wiley and Sons, Inc., New York, NY, 1988.

25. Wire Rope Users Manual, Second Ed., American Iron and Steel Institute, washington, D.C., 1981

26. Yoerger, D. R., et al, "Design and Control of JASON," Intervention '88, Bergen, Norway, 1988. 
Appendix 


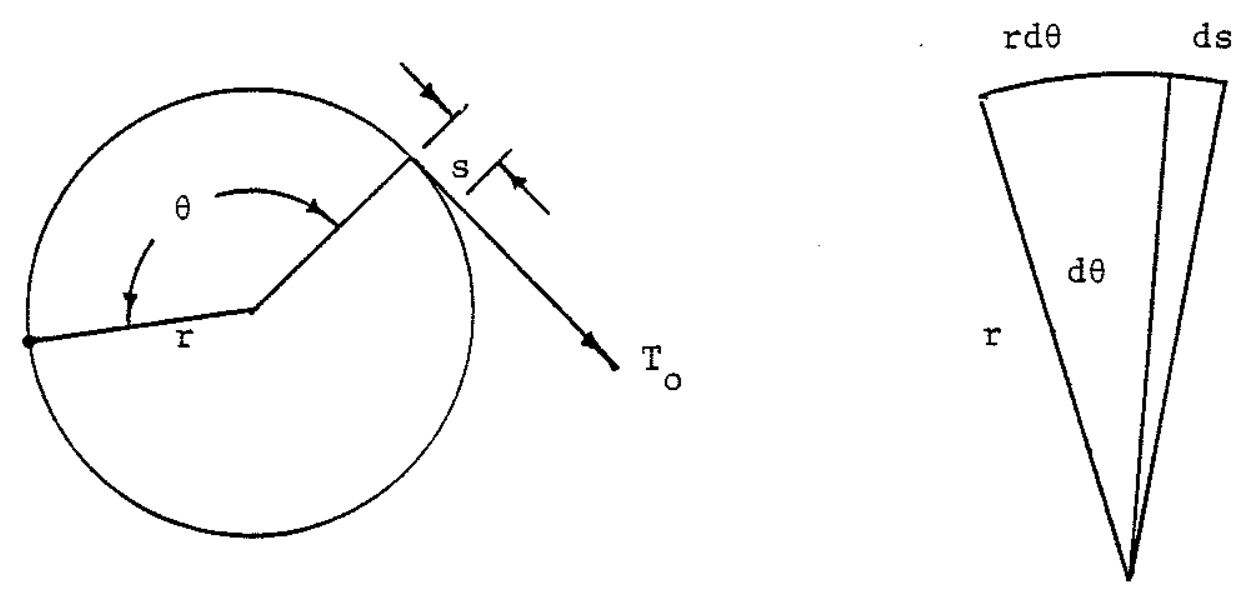

Given the diagram above, $\theta$ is the arc of cable wrapped on a given pulley and $E$ and $A$ are the Young's modulus and the cross-sectional area of the cable, respectively. $T_{0}$ is the tension in the free length of the cable. The tension in the section of cable wrapped around the pulley is described by the equation

$$
T=T_{0} e^{-f \theta}
$$

where $f$ is the coefficient of friction between the cable and pulley. $\theta=$ 0 at the point at which the cable separates from the pulley.

The quantity $s$ represents the stretch in the cable when a load $T_{0}$ is applied to the cable. To determine $s$, an incremental section of cable, rd $\theta$, will be examined. In this short region, tension, $T$, will be assumed constant. The amount of stretch in this increment of cable is ds. Stress 
in this piece of cable will be assumed uni-axial, and thus Hooke's Law will be applied, where strain is defined as:

$$
\varepsilon=\mathrm{ds} /(\operatorname{rd} \theta)
$$

Hooke's Law then takes the form:

$$
\begin{aligned}
& \text { EA(ds } /(\operatorname{rd} \theta)=\mathrm{T} \\
& \text { EAds }=\operatorname{Trd} \theta
\end{aligned}
$$

In order to determine an approximate solution for the stretch of the cable over the whole pulley, ds is integrated over the region.

$$
\begin{aligned}
& { }_{0} f^{s}={ }_{0}^{\theta} \operatorname{Trd} \theta /(E A) \\
& \int_{0}^{s}={ }_{0} \int^{\theta} \mathrm{T}_{0} e^{-f \theta_{0}} \mathrm{rd \theta} /(E A) \\
& s=\left[\left(r \mathrm{~T}_{0}\right) /(E A f)\right]\left[1-e^{-f \theta}\right]
\end{aligned}
$$

This solution for cable stretch was used to calculate joint stiffness and joint bandwidth. 